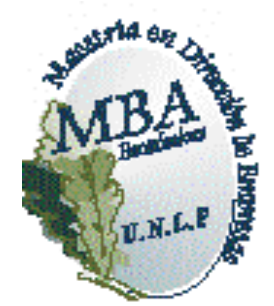

Universidad Nacional de La Plata Facultad de Ciencias Económicas MBA - Maestría en Dirección de Empresas

\title{
Satisfacción del Cliente del Servicio de Defensa del Consumidor de la Municipalidad de La Plata
}

\section{Trabajo final para optar al título de Magister}

Autor: Alfredo Raúl Irigoyen 


\section{Índice}

1. Planteo del Problema

2. Objetivos de la Investigación 2

3. Evaluación del Problema

4. Alcance de la Investigación 3

5. Marco Teórico de Referencia

5.1 Antecedentes de la Investigación. 4

5.1.1 Experiencia internacional y nacional 5

5.2 Bases Teóricas 7

5.2.1 Marco Jurídico de las Municipalidades y de la protección de los derechos de los consumidores 7

5.2.2 Excelencia en las organizaciones: 11

5.2.3 Calidad 13

5.2.4 Calidad Total: 16

5.2.5 Expectativas del cliente respecto de la organización 21

6. Metodología de la Investigación 24

6.1. Universo y Muestra 24

6.1.1 Universo 24

6.1.2 Muestra 24

6.2. Tipo de Investigación 25

6.3. Técnicas de Recolección de Datos 26

Encuestas 26

6.4 Técnicas de Análisis 27

\section{Resultados de la Investigación}

7.1 Análisis descriptivo de la muestra 29

7.2 Dimensión I: Elementos Tangibles: Apariencia de la instalaciones físicas, equipos, personal y materiales de comunicación 31

7.2.1 Equipos 31

7.2.2 Instalaciones físicas 34

7.2.3 Apariencia física de los empleados 37

7.2.4 Apariencia visual de los elementos materiales de comunicación 40

7.3 Dimensión II: Confiabilidad: Habilidad para ejecutar el servicio prometido de forma confiable y cuidadosa 42

7.3.1 Los empleados del servicio municipal cumplen lo que prometen 42 
7.3.2 Interés que tienen los empleados del servicio municipal por solucionar los problemas

7.3.3 Eficacia del servicio de Defensa del Consumidor 48

7.3.4 Tiempo de cumplimiento del trabajo 51

7.3.5 Eficiencia del trabajo del servicio de Defensa del Consumidor 54

7.4 Dimensión III: Capacidad de Respuesta - Disposición de los empleados para ayudar al cliente y proporcionar el servicio.

7.4.1 Nivel de comunicación con los empleados 57

7.4.2 Velocidad del servicio 60

7.4.3 Nivel de disponibilidad de atención 63

7.4.4 Grado de disponibilidad inmediata frente a otras actividades 66

7.5 Dimensión IV: Seguridad - Conocimiento y atención mostrados por los empleados y sus habilidades para inspirar credibilidad y confianza. 69

7.5.1 Confianza que brinda el comportamiento de los empleados 69

7.5.2 Nivel de seguridad que se siente en las transacciones con el servicio de Defensa del Consumidor 72

7.5.3 Nivel de amabilidad que muestran los empleados del servicio 75

7.5.4 Grado de conocimiento que tienen los empleados para resolver las inquietudes de los usuarios 78

7.6 Dimensión V: Empatía - Atención individualizada que ofrece la organización a los clientes. 81

7.6.1 Nivel de individualización en la atención del servicio 81

7.6.2 Conveniencia de los horarios de trabajo 84

7.6.3 Nivel de personalización en la atención del servicio 87

7.6.4 Grado de preocupación que tienen los empleados por los intereses del cliente 90

7.6.5 Grado en que el servicio comprende las necesidades específicas del cliente 93

7.7 ¿Cuál es la dimensión más importante para el cliente de la Dirección de Defensa del Consumidor?

7.8 Calificación global de la percepcion de los usuarios de la Dirección Operativa de Licencias de Conducir. 96

7.9 Calificación global de la percepcion de los usuarios de la Dirección Operativa de Licencias de Conducir. 96

7.10 Calificación global de la percepcion de los usuarios de la Dirección Operativa de Licencias de Conducir. 
Anexo 2 MATRIZ DE RESULTADOS

Expectativa de los consumidores en la calidad del servicio 104

Percepción de los consumidores en la calidad del servicio 104

Brecha generada entre la expectativa y la percepción de los consumidores en la calidad del servicio 105

Resumen de brecha generada entre la expectativa y la percepción de los consumidores en la calidad del servicio . ¡Error! Marcador no definido.

Detalle de saldo de respuesta de brecha. ¡Error! Marcador no definido. 


\section{Planteo del Problema}

En la actualidad existe un interés creciente por la evaluación de la conducta del sector público en general, y en particular de los municipios, dado su cercanía con la comunidad en su rol de prestador de servicios públicos, de la construcción de las obras que demande el progreso local, de la ordenación del desarrollo de su territorio, de la promoción de la participación comunitaria, el mejoramiento social, cultural y la defensa de los derechos de sus habitantes.

La temática de la Calidad de los Servicios adquiere relevancia toda vez que la población tiene diferentes necesidades y/o requerimientos que deben ser satisfechos a través de la oportuna atención del Estado. Esta presencia estatal y su preocupación en los servicios públicos básicos, proporciona a la ciudadanía confianza en la utilización de los diferentes servicios cuando estos son requeridos, dando además un parámetro de solvencia y oportunidad, frente a la tecnología con la cual se va desarrollando la atención al cliente.

Una de las situaciones más comunes de la institución es que surgen problemas con las personas debido a la falta de comunicación, ya que muchas veces no se escucha al solicitante y por ende existen diversas barreras que impiden que se capte la información correcta, ya que el personal sólo se limita a brindar una opción de solución de la problemática a diversas dudas que posee el cliente, esto representa un serio problema, porque no se brinda un servicio de calidad al cliente y es necesario que el personal posea el conocimiento necesario para tratar con éstos y así ofrecer diferentes soluciones a las expectativas que surgen.

Las organizaciones públicas, como cualquier organización prestadora de servicios, necesita conocer el grado de aceptación de su oferta. Cabe, entonces, preguntarse si los servicios prestados por los municipios alcanzan los valores de calidad requeridos por los usuarios, o si por el contrario existe una diferencia entre la calidad del servicio prestado con el servicio requerido por los vecinos. 


\section{Objetivos de la Investigación}

- Evaluar el nivel de satisfacción de los clientes del servicio de Defensa del Consumidor de la Municipalidad de La Plata en relación a:

- La importancia de cada atributo del servicio: en relación a la atención al público, en relación a la infraestructura y equipamiento y en relación a los procesos para la realización de trámites.

- El grado de satisfacción del servicio en general.

- Identificar en qué medida la calidad del servicio que se presta en la Dirección de Defensa del Consumidor de la Municipalidad de La Plata cumple con las expectativas de los usuarios.

\section{Evaluación del Problema}

Mejorar la calidad en el servicio al cliente implica superar el trabajo con respecto a lo que antes se hacía, para satisfacer las necesidades del cliente, sin olvidarse que el éxito de la mayoría de las instituciones, actualmente, es conocerlos desde el mismo instante en que éstos se ponen en contacto con la institución.

Este nuevo paradigma es el que enfrentan los municipios con ciudadanos más informados de sus derechos y de los deberes de la organización municipal para con la comunidad, así como también con un marcado interés en la transparencia de las decisiones. Esta nueva realidad enfrenta a las organizaciones municipales con un cliente polifacético, que se encuentra en su comunidad, al interior de su organización y en los niveles superiores de Gobierno.

Estas nuevas condiciones demandan de las organizaciones municipales una mayor capacidad para predecir los resultados, una administración más rigurosa de la información de sus procesos, una capacitación más especializada de sus funcionarios, una mejora sustantiva de la administración de la información al 
interior de la organización y la adopción más formal y comprometida de un estilo de administración.

En este contexto los argumentos que justifican un análisis de calidad en el sector público son diversos. Entre ellos se encuentran, la magnitud de su actividad económica en el agregado de la economía, la ausencia de competencia en gran parte de los servicios públicos provistos, la necesidad de justificar resultados en un contexto presupuestario restrictivo, y por sobre todas las cosas, el impacto de los servicios públicos en el crecimiento económico y el bienestar de la población.

Evaluar la percepción de la calidad de los servicios públicos por parte de sus usuarios, es de vital importancia por varias razones entre las que se pueden mencionar:

- Mandato legal

- Compromiso político

- Reducción de costos

- Satisfacción del usuario

- Mejora de los servicios públicos

- Reducción de reclamos y conflictos

- Estabilidad

Se entiende que este trabajo ayudará a los gobiernos municipales a establecer con más precisión los parámetros para evaluar el nivel de satisfacción de los clientes que solicitan sus servicios. Esta información permitirá detectar y corregir errores en la calidad de los servicios y por lo tanto mejorarlos.

\section{Alcance de la Investigación}

Los resultados que se presentan son el producto de un proyecto de investigación del MBA cuyo título es "La competitividad empresarial y su impacto regional", acreditado en el marco del Programa de Incentivos de la Secretaría de Ciencia y Técnica de la UNLP, con un tronco común cuyo objeto 
de estudio es la Municipalidad de La Plata, y que posteriormente se subdivide en las áreas Defensa del Consumidor, Obras privadas, Defensa del consumidor, Juzgado de faltas y Recaudaciones y cobranzas. Comprendió el segundo semestre 2012.

\section{Marco Teórico de Referencia}

\subsection{Antecedentes de la Investigación.}

En la cultura organizacional actual, se busca por parte de las empresas generar un servicio que proporcione una ventaja competitiva, pero dicha ventaja sólo se consigue teniendo la capacidad suficiente para satisfacer las necesidades del cliente.

Frente a todo se encuentra un obstáculo al menos aparente, como es la dificultad de la intangibilidad de los servicios, y más aún de los servicios públicos; dificultad que empezó a resolverse gracias a la aportación de Parasuraman, Zeithmal y Berry $(1985,1988)$.

Estos autores crearon una metodología que definieron como "un instrumento resumido de escala múltiple, con un alto nivel de fiabilidad y validez que las empresas pueden utilizar para comprender mejor las expectativas y percepciones que tienen los clientes respecto de un servicio", identificando el término "Escala" con una clasificación de preguntas. Por lo tanto consistía en un cuestionario con preguntas estandarizadas desarrollado en los Estados Unidos con el apoyo del Marketing Science Institute llamado escala SERVQUAL.

A nivel mundial, las organizaciones buscan satisfacer a sus clientes para que éstos sigan consumiendo el servicio que la institución u organización provee. En el caso de instituciones públicas, en una perspectiva comercial buscan dar un buen servicio para que las autoridades que las provean generen una buena imagen en la retina de los clientes (ciudadanos), y de esta manera ser tomados en cuenta para próximos comicios. 
Cabe recalcar, que este modelo SERVQUAL se puede utilizar para medir la satisfacción del usuario de cualquier tipo de servicio, ya sea de una organización pública o privada.

EI modelo SERVQUAL define la calidad del servicio como la diferencia entre las percepciones reales por parte de los clientes del servicio y las expectativas que sobre éste se habían formado previamente. De ésta forma, un cliente valorará negativamente (positivamente) la calidad de un servicio en el que las percepciones que ha obtenido sean inferiores (superiores) a las expectativas que tenía. Por ello, las compañías de servicios en las que uno de sus objetivos es la diferenciación mediante un servicio de calidad, deben prestar especial interés al hecho de superar las expectativas de sus clientes.

\section{$\underline{5.1 .1 \text { Experiencia internacional y nacional }}$}

Según las experiencias exitosas estudiadas respecto de gobiernos que buscaban mejorar la calidad de los servicios públicos a través de la modernización de la gestión del Estado (Scott y Shieff-1993; Wisnieswski y Donnelly-1996; Gaster-1996; Donnelly y Shiu; Wisniewski-2001; Gutiérrez y Jorge-2008), se puede establecer que no hay una sola forma de asegurar mejores resultados en la calidad de los servicios municipales. Sin embargo, se pueden destacar algunas características presentes en todas las experiencias de éxito analizadas:

- Foco en el ciudadano. Bajo distintas metodologías, todas las experiencias estudiadas han derivado en un cambio de paradigma en la relación entre el ciudadano y el Estado, así como su posterior impacto en las prácticas, procesos y prestaciones.

- Estrategia global. Los proyectos de mejora se enmarcan en una estrategia de gobierno, como parte de una política pública, que busca una nueva y mejor relación con el ciudadano, dándole mayor peso político y social. 
- Vocación de servicio público. Los funcionarios comparten una profunda vocación de servicio público y han buscado implementar mejoras a partir del trabajo voluntario de cada uno de sus miembros. En estos casos los recursos económicos no siempre son lo más importante.

- Procesos participativos e identificación de factores clave. En los casos estudiados se observa el surgimiento de una preocupación colectiva en torno a un problema específico, que se aborda desde muchos frentes distintos. Ese espacio abierto, de alta participación, permite el surgimiento de iniciativas, en un principio marginales, las que un momento crítico cobran importancia. Lo relevante entonces, no es encontrar la fórmula única para replicar e implementar rápidamente, sino descubrir las variables que están en juego, los factores clave que permitan la obtención de resultados, su contexto social y cultural.

- Alineamiento corporativo en torno al objetivo. Uno de los elementos que ha resultado clave para que la implementación de programas de resultados concretos en el mediano plazo es el compromiso del nivel directivo superior con los sistemas de gestión.

- Marketing interno y motivación. En organizaciones grandes es difícil lograr alineamientos y compromisos en forma rápida y la promoción interna es tremendamente necesaria al momento de perseguir resultados.

- Formación permanente. Para mejorar los servicios es necesario que toda la organización participe en un proceso de formación permanente, liderado internamente a partir de la propia experiencia. Esto refuerza conocimientos, aborda nuevas temáticas de acuerdo con los nuevos desafíos que se van presentando y ayuda a comprender que no se mejoran los servicios una vez, se mejoran siempre, en forma permanente y sistemática, instaurando la lógica de la mejora continua.

- Mediciones. Una medición inicial marca el comienzo de un trabajo que nunca termina, y buscará oportunidades de mejora inimaginables a los ojos de hoy. No se puede avanzar en forma segura a un objetivo si se está ciego y sin guía. 
Nadie mejor que el usuario sabe orientar los esfuerzos para satisfacer sus expectativas de servicio, y las mediciones son el único medio que permite acercarse a ellas.

- Gestión del conocimiento. Una vez iniciado el camino a la excelencia y generadas las condiciones de funcionamiento que permiten la participación de todos, comienzan a surgir proyectos de mejora en distintos ámbitos de la organización. Generalmente sucede que comienzan a surgir planes que pueden compartirse entre los distintos equipos o unidades para ir estimulando tanto la creatividad como su replicabilidad en otros ámbitos.

Comienza a juntarse una gran cantidad de buenas prácticas que es necesario administrar, premiar y distribuir. Si esta información se encuentra en un solo sitio es posible acceder de mejor manera al conocimiento acumulado, la información del programa, documentos oficiales, archivos tipo, etc.

\subsection{Bases Teóricas}

5.2.1 Marco Jurídico de las Municipalidades y de la protección de los derechos de los consumidores

La Constitución Nacional establece en su art. 5, capítulo 1, primera parte: "Cada provincia dicta para sí una constitución bajo el sistema representativo republicano, de acuerdo con los principios, declaraciones y garantías de la Constitución Nacional, y que asegure su administración de justicia, su régimen municipal, y la educación primaria. Bajo esta forma el Gobierno Federal, garante a cada provincia el goce y ejercicio de sus instituciones."

El artículo 42 de la Constitución Nacional, establece: "Los consumidores y usuarios de bienes y servicios tienen derecho, en la relación de consumo, a la protección de su salud, seguridad e intereses económicos; a una información adecuada y veraz; a la libertad de elección y a condiciones de trato equitativo y digno. 
"Las autoridades proveerán a la protección de esos derechos, a la educación para el consumo, a la defensa de la competencia contra toda forma de distorsión de los mercados, al control de los monopolios naturales y legales, al de la calidad y eficiencia de los servicios públicos, y a la constitución de asociaciones de consumidores y de usuarios."

"La legislación establecerá procedimientos eficaces para la prevención y solución de conflictos, y los marcos regulatorios de los servicios públicos de competencia nacional, previendo la necesaria participación de las asociaciones de consumidores y usuarios y de las provincias interesadas, en los organismos de control."

Cada provincia, conforme a lo dispuesto por el artículo $5^{\circ}$ debe asegurar la autonomía municipal reglando su alcance y contenido en el orden institucional, político, administrativo, económico y financiero. (art.123; título 2, sección 4).

Por otra parte, el Decreto-Ley 6769/58-Ley Orgánica de las Municipalidades expresa en el art. 10: La Administración local de los Partidos que forman la Provincia estará a cargo de una Municipalidad compuesta de un Departamento Ejecutivo, desempeñado por un ciudadano con el título de Intendente, y un Departamento Deliberativo, desempeñado por ciudadanos con el título de Concejal, y en el Art 25\%: Las ordenanzas (dictadas exclusivamente por el Concejo Deliberante) deberán responder a los conceptos de ornato, sanidad, asistencia social, seguridad, moralidad, cultura, educación, protección, fomento, conservación y demás estimaciones encuadradas en su competencia constitucional que coordinen con las atribuciones provinciales y nacionales. Las mismas por el Art. 27: (Texto según Decreto-Ley 9117/78) dice que corresponde a la función deliberativa municipal reglamentar: 1. - La radicación, habilitación y funcionamiento de los establecimientos comerciales e industriales, en la medida que no se opongan a las normas que al respecto dicte la Provincia y que atribuyan competencia a organismos provinciales. 2. El trazado, apertura, rectificación, construcción y conservación de calles, caminos, puentes, túneles, plazas y paseos públicos y las delineaciones y niveles en las situaciones no comprendidas en la competencia provincial. 3. La conservación de monumentos, paisajes y valores locales de interés tradicional, turístico e histórico. 4. - La imposición de nombres a las calles y a 
los sitios públicos. 5. - Las obligaciones de los vecinos respecto de los servicios de la Municipalidad y de los escribanos con relación al pago de los tributos municipales en ocasión de los actos notariales de transmisión o gravamen de bienes. 6. - La instalación y el funcionamiento de abastos, mataderos, mercados y demás lugares de acopio y concentración de productos y de animales, en la medida que no se opongan a las normas que al respecto dicte la Provincia y que atribuyan competencia a organismos provinciales. 7 - La protección y cuidado de los animales. 8. - Las condiciones de higiene y salubridad que deben reunir los sitios públicos, los lugares de acceso público y los baldíos. 9. - La instalación y el funcionamiento de establecimientos sanitarios y asistenciales; de difusión cultural y de educación física; de servicios públicos y todo otro de interés general en el partido, en la medida que no se opongan a las normas que al respecto dicte la Provincia. 10. - La elaboración, transporte, expendio y consumo de materias o artículos alimentarios, exigiendo el cumplimiento de las condiciones higiénico-sanitarias, bromatológicas y de identificación comercial que establezcan las normas de aplicación, así como también el certificado de buena salud de las personas que intervengan en dichos procesos. 11. - La inspección y contraste de pesas y medidas. 12. - La inspección y reinspección veterinaria, así como el visado de certificados sanitarios de los animales faenados y sus derivados. 13. - El registro de expedición de documentación relativa a la existencia, transferencia y traslado de ganado. 14. La sanidad vegetal en las situaciones no comprendidas en la competencia nacional y provincial. 15. - La publicidad en sitios públicos o de acceso público. 16. - La habilitación y el funcionamiento de los espectáculos públicos: como asimismo la prevención y prohibición del acceso para el público, por cualquier medio, a espectáculos, imágenes y objetos que afecten la moral pública, las buenas costumbres y los sentimientos de humanidad, particularmente cuando creen riesgos para la seguridad psíquica y física de los concurrentes o de los participantes. 17. - La prevención y eliminación de las molestias que afecten la tranquilidad, el reposo y la comodidad de la población, en especial las de origen sonoro y lumínico, así como las trepidaciones, la contaminación ambiental y de los cursos de agua y el aseguramiento de la conservación de los recursos naturales. 18. - El tránsito de personas y de vehículos públicos y privados en las calles y caminos de jurisdicción municipal, atendiendo, en especial a los conceptos de educación, prevención, 
ordenamiento y seguridad, así como en particular, lo relativo a la circulación, estacionamiento, operaciones de cargas y descargas, señalización, remoción de obstáculos y condiciones de funcionamiento de los vehículos, por medio de normas concordantes con las establecidas por el Código de Tránsito de la Provincia. 19. - La ubicación, habilitación y funcionamiento de guardacoches, playas de maniobras y de estacionamiento. 20. - La expedición de licencias de conductor, en las condiciones establecidas por la legislación y reglamentación provincial. 21. - El patentamiento de vehículos que circulen por la vía pública, que no estén comprendidos en regímenes nacionales o provinciales. 22. - El transporte en general $\mathrm{y}$, en especial, los servicios públicos de transporte de pasajeros, en cuanto no sean materia de competencia nacional o provincial. 23. - Los servicios de vehículos de alquiler y sus tarifas. 24. - La construcción, ampliación, modificación, reparación y demolición de edificios públicos y privados, así como también sus partes accesorias. 25. - Lo referente a las propiedades ribereñas y condominio de muros y cercos. 26. - Los servicios fúnebres y casas de velatorios. 27. - El funcionamiento de comisiones o sociedades de fomento. 28. - Y toda otra materia vinculada a los conceptos y estimaciones contenidas en el artículo $25^{\circ}$.

Asimismo, el Art. $131^{\circ}$ expresa que la ejecución directa de los servicios de la Municipalidad corresponde al Departamento Ejecutivo, quien administrará los establecimientos por medio de empleados a sueldo, comisiones de vecinos $u$ organismos descentralizados. En los convenios, cooperativas o consorcios, será obligatoria su participación en los órganos directivos.

La Constitución de la Provincia de Buenos Aires establece en su artículo 38: Los consumidores y usuarios tienen derecho, en la relación de consumo, a la protección frente a los riesgos para la salud y su seguridad, a la promoción y defensa de sus intereses económicos y a una información adecuada y veraz. La Provincia proveerá a la educación para el consumo, al establecimiento de procedimientos eficaces para la prevención y resolución de conflictos y promoverá la constitución de asociaciones de usuarios y consumidores. 
La Ley № 24.240 Defensa del Consumidor, establece Normas de Protección y Defensa de los Consumidores. Autoridad de Aplicación. Procedimiento y Sanciones. Disposiciones Finales.

La Ley 13133, Código Provincial de Implementación de los Derechos de los Consumidores y Usuarios tiene por objeto:

Art. 1.-La presente Ley establece las bases legales para la defensa del consumidor y del usuario según los términos del artículo $38^{\circ}$ de la Constitución de la Provincia de Buenos Aires, y tiene por objeto establecer las reglas de las políticas públicas y los mecanismos administrativos y judiciales para la efectiva implementación en el ámbito provincial:

a) De los derechos de los consumidores y usuarios reconocidos en la Constitución Nacional y en la Constitución de la Provincia de Buenos Aires.

b) De las normas de protección consagradas en la Ley Nacional de Defensa del Consumidor y disposiciones complementarias, sin perjuicio de las competencias concurrentes de la Autoridad Nacional de Aplicación.

El Sistema Municipal de Defensa del Consumidor de la Municipalidad de La Plata tiene como objetivos el asesoramiento, la difusión de derechos, la prevención y resolución de conflictos, y la sanción de infracciones a la Ley Nacional 24.240 de Defensa del Consumidor y sus leyes complementarias destinadas a proteger los derechos de los consumidores y usuarios. Está conformado por la Oficina Municipal de Defensa del Consumidor y el Juzgado Municipal de Defensa del Consumidor que se encargan, respectivamente, de la etapa conciliatoria y de la etapa resolutiva del procedimiento administrativo establecido por la Ley 13.133 de la Provincia de Buenos Aires, denominada "Código Provincial de Implementación de los Derechos de los Consumidores y Usuarios".

\subsubsection{Excelencia en las organizaciones:}

Desde la aparición de la globalización, se han provocado profundos cambios en todo el mundo y en todas las organizaciones, generando particularmente un gran impacto en las estructuras políticas y administrativas del Estado, que le exigen modernizaciones y significativos progresos en materia de comunicación, 
transparencia, eficiencia y coordinación (ILPES 1995). Las exigencias anteriores están estrechamente relacionadas con los cambios estructurales y con el nuevo estilo de gestión pública que demandan estas nuevas estructuras. Por otra parte, el impacto de la globalización en las organizaciones privadas ha cambiado significativamente las estrategias de competencia, dando una atención preferencial al paradigma del cliente (Ivancevich et al. 1996). Esto también genera una nueva actitud del ciudadano, que observa a los gobiernos con renovada visión y demanda de ellos servicios eficientes y responsables, reducción del déficit y control del gasto público.

La mayoría de los modelos de excelencia desarrollados en el mundo han sido creados en el marco del desarrollo económico. Objetivos declarados para la implantación de modelos de excelencia suelen ser: mejorar la competitividad de las organizaciones; provocar efectividad de las organizaciones en la creación de valor para todos sus grupos de interés, especialmente para sus clientes y mercados; promover, desarrollar y difundir procesos y sistemas destinados al mejoramiento continuo de la calidad en los productos y en los servicios a fin de apoyar la modernización y competitividad de esas organizaciones; promover la comprensión de los factores y elementos que tiene una influencia decisiva en la obtención de niveles superiores de calidad. Si bien los modelos de excelencia nacen para ser implementados en organizaciones privadas o sin fines de lucro, rápidamente su aplicación se ha extendido exitosamente en instituciones del sector público.

Esta creciente realidad, exige de sus gobiernos locales, fundamentalmente las municipalidades, como órgano jurídico y político - nuevos roles y nuevos estilos de gestión, que respondan a las demandas de comunicación, transparencia, eficiencia y coordinación, exigidas también a los gobiernos provinciales y nacionales.

Los nuevos estilos de gestión de las organizaciones municipales, requieren el uso de herramientas modernas que apoyen categóricamente el mejoramiento y el cambio que estas organizaciones demandan para asumir sus nuevos roles.

El modelo de gestión tradicional del Sector Público se caracteriza por un alto nivel de burocratización, en el cual las conductas se rigen por medio de reglas 
y normas de las cuales no es posible apartarse. En esta línea, entonces, el control de gestión tiende a centrarse sobre los procedimientos, a fin de asegurar que la normativa sea respetada.

La gestión de una municipalidad en Argentina tiene asociada una serie de características que la hacen distintiva respecto de otros tipos de organizaciones. Dentro de las principales características se encuentran:

- El líder de la organización, el intendente o intendenta, así como su Concejo, son elegidos democráticamente por los ciudadanos de la comuna cada cuatro años.

- El actuar de la municipalidad está geográficamente determinado por los límites comunales.

- Cada comuna está inserta en una realidad única y singular.

\section{$\underline{5.2 .3 \text { Calidad }}$}

La más clásica definición la defiende el experto en TQM (Calidad Total), Philips B. Crosby: "Es la conformidad con los requerimientos."

Se define como calidad de diseño el grado con el que el producto cumple con las expectativas del cliente

La calidad es el conjunto de propiedades y características de un servicio, producto o proceso, que satisface las necesidades y expectativas establecidas por el usuario, el ciudadano o el cliente de los mismos.

El concepto anterior involucra explícitamente los siguientes términos:

Producto: Es el resultado de todo proceso. Este resultado puede ser para el caso municipal de información o la prestación de un servicio administrativo (extensión de certificaciones, licencias, etc.) o un servicio público (agua, drenajes, infraestructura, mercados, cementerios, rastros, etc.). Por lo tanto, cuando se habla de producto, no sólo se refiere a un bien tangible, sino también a servicios e información que son los procesos habituales en el ámbito de los servicios municipales. 
Cliente: Es quien recibe el producto. Pague directamente por el mismo o no. Sea miembro de la misma organización, o no. Por lo que existe el cliente interno, que es cuando el receptor es un miembro de la organización y cliente externo, en el caso de que el receptor no pertenezca a la organización que produce el producto. La denominación de cliente externo en la administración pública refuerza la visión del ciudadano como un usuario con derecho a exigir y que sus demandas sean atendidas. Dentro del ámbito municipal, se puede definir que el cliente interno lo constituyen los funcionarios y trabajadores de la municipalidad y el cliente externo son básicamente todos los vecinos del municipio, así como los transeúntes que son las personas que se encuentran accidentalmente en una jurisdicción municipal, teniendo su vecindad en otra, y que pudiera realizar alguna gestión en la municipalidad.

Características del producto: Propiedades del producto (información o servicios) con las que se espera satisfacer las necesidades del cliente, pueden ser de distinto tipo: técnicas, físicas y económicas, según la naturaleza del producto y de las necesidades que se desean satisfacer.

Necesidades del cliente: Necesidad es algo requerido por la persona que solicita la información o servicio y que le motiva a la acción para su satisfacción. Las características del producto o servicio son las que deben satisfacer las necesidades del cliente.

Satisfacción del Cliente

Philip Kotler (Marketing en el sector público. 2006, Págs. 40, 41), define la satisfacción del cliente como “... el nivel del estado de ánimo de una persona que resulta de comparar el rendimiento percibido de un producto o servicio con sus expectativas".

Expectativas: Lo que el cliente espera de la información, producto o servicio.

Como puede observarse, en las definiciones anteriores queda suficientemente claro que el cliente es el protagonista. El cliente se convierte en el objetivo de una organización que desea brindar información y servicios con calidad, en el 
centro de sus actividades y procesos, y la evaluación de su satisfacción se convierte en un elemento primordial que permite obtener la retroalimentación esencial para mejorar la calidad.

Servicios: En economía y en marketing (mercadotecnia) un servicio es un conjunto de actividades que buscan responder a una o más necesidades de un cliente. Se define un marco en donde las actividades se desarrollarán con la idea de fijar una expectativa en el resultado de éstas. Es el equivalente no material de un bien. La presentación de un servicio no resulta en posesión, y así es como un servicio se diferencia de proveer un bien físico.

Entre las características propias de un servicio que permiten diferenciarlo de un producto aparecen la intangibilidad (un servicio no puede verse, probarse, sentirse, oírse ni olerse antes de la compra), la heterogeneidad (dos servicios similares nunca serán idénticos o iguales), la inseparabilidad (la producción y el consumo son parcial o totalmente simultáneos), la perecibilidad (un servicio no se puede almacenar por la simultaneidad entre producción y consumo) y la ausencia de propiedad (los compradores de un servicio adquieren el derecho a recibir una prestación, uso, acceso o arriendo de algo, pero no la propiedad del mismo).

Servicios Públicos: Son las actividades de las entidades u órganos públicos o privados con personalidad jurídica creados por Constitución o por ley, para dar satisfacción en forma regular y continua a cierta categoría de necesidades de interés general, bien en forma directa, mediante concesionario o a través de cualquier otro medio legal con sujeción a un régimen de Derecho Público o Privado, según corresponda.

\section{Características:}

a) Todo servicio público debe suministrarse con un criterio técnico gerencial y con cuidadosa consideración a las funciones del proceso administrativo científico: planificación, coordinación, dirección, control y evaluación, tanto en su concepción orgánica como en el sentido material y operativo. 
b) Debe funcionar de manera permanente, es decir, de manera regular y continua para que pueda satisfacer necesidades de las comunidades por sobre los intereses de quienes los prestan.

c) La prestación del servicio público no debe perseguir principalmente fines de lucro; se antepone el interés de la comunidad a los fines del beneficio económico de personas, organismos o entidades públicas o privadas que los proporcionan.

\subsubsection{Calidad Total:}

La calidad total incluye todas las funciones y fases que intervienen en el desarrollo de un producto o servicio, no sólo en cuanto al producto en sí, sino a la gestión de la organización en su totalidad, poniendo en juego todos los recursos necesarios para la prevención de los errores, involucrando a todo el personal, sistematizando en todas sus vertientes las múltiples relaciones proveedor-cliente (interno y externo), mejorando el clima organizacional y las relaciones entre los miembros integrantes y reduciendo las pérdidas de tiempos, movimientos y recursos, provocados por una gestión deficiente. Tiene en cuenta la totalidad de las necesidades y expectativas de los clientes con la finalidad de satisfacerlas.

La calidad total abarca a toda la organización y a todas sus actividades que tiene como meta la satisfacción del cliente y al menor costo.

La calidad total se fundamenta en los siguientes principios:

$\checkmark$ La organización se debe orientar hacia el cliente, identificando y satisfaciendo sus necesidades.

$\checkmark$ La calidad la hacen las personas.

$\checkmark$ La calidad alcanza a toda actividad de la organización.

$\checkmark$ La mejora continua es el pilar básico de la calidad total.

$\checkmark$ La mejora de la calidad implica una actuación sobre la simplificación y agilización de los procesos. 
$\checkmark$ El espíritu de colaboración, una de cuyas expresiones es el trabajo en equipo, es el mejor mecanismo para avanzar.

$\checkmark$ La calidad total abarca a toda la organización y todas sus actividades.

$\checkmark$ Es preciso mantener receptividad a expresiones e innovaciones acaecidas en otras organizaciones, públicas o privadas, en la búsqueda de mejores prácticas.

$\checkmark$ Reducción de costos.

\subsubsection{Orientar la organización hacia el cliente:}

Satisfacer las necesidades del cliente es lo principal. La organización debe girar en torno a los procesos que son importantes para este fin y que aportan valor añadido. Es toda la organización, la que debe participar en alcanzar dicha satisfacción y no considerar que sólo sean responsables los departamentos encargados del producto o del servicio. Cada una de las partes de la organización debe trabajar en forma coordinada para satisfacer las necesidades del cliente.

La calidad es intrínseca al servicio y es el cliente quien la juzga a partir de sus percepciones. Del mismo modo, la organización debe estar atenta a todas las características y atributos del producto o servicio, pues son éstos los que le entregan valor agregado a los clientes, aumenta su satisfacción, determinan sus preferencias y los hacen fieles a la marca, producto o institución. Una organización con foco en el cliente busca satisfacer las necesidades actuales y anticipar las expectativas de los clientes y mercados potenciales. Con una gestión orientada hacia la clientela, la organización está alerta a los cambios que ocurren a su alrededor, principalmente en relación a nuevas demandas y necesidades. El logro de la satisfacción de los clientes y la conquista de su fidelidad son fundamentales para aumentar la competitividad de la organización que se vuelve un tema estratégico.

En toda referencia a "Cliente" debe entenderse de igual forma el concepto de "Usuarios y Usuarias" empleado en los servicios públicos. 


\subsubsection{Ampliar el concepto cliente:}

La organización tiene clientes internos y clientes externos. Tradicionalmente, solo se considera al cliente externo o sea, en el caso de las municipalidades, a los vecinos del municipio u otras personas que pudieran requerir información o un servicio, pero es muy importante también considerar a los funcionarios y trabajadores municipales como clientes internos. El cliente interno es aquel miembro de la municipalidad que recibe el resultado de un proceso anterior, llevado a cabo dentro de la misma; si el resultado es satisfactorio, él podrá realizar eficientemente el proceso que le corresponda, pero si el resultado recibido no es satisfactorio, éste incidirá negativamente en la actividad que debe realizar, llevando consigo: errores, omisiones o atrasos. Los clientes internos vienen a constituir un sistema de engranajes uniforme, del cual cada uno de sus partes debe dar productos de calidad, ya que de otro modo, se producirían fluctuaciones y fallas en la calidad de los resultados.

\subsubsection{La calidad total la hacen las personas:}

El papel de los recursos humanos de la organización en la calidad total es fundamental, y constituyen el principal activo de la organización, por lo que su satisfacción es un objetivo preeminente. El establecimiento de un clima organizacional que permita que las personas contribuyan efectivamente al rendimiento de la organización es clave, y representa crear las condiciones adecuadas hacia la calidad total.

Valorando su experiencia y capacidad creativa mediante la participación en la gestión de los procesos de la organización, el trabajo en equipo y, complementariamente, privilegiando su calidad de vida y clima laboral.

La comprensión de que el desempeño de la organización depende de la capacitación, motivación y bienestar de la fuerza laboral, crea un ambiente de trabajo propicio en participación y desarrollo de las personas. El desarrollo de éstas depende cada vez más de las oportunidades para aprender en un ambiente favorable donde desarrollar sus capacidades y potencialidades. 
La participación en todos los aspectos del trabajo es fundamental para desarrollar su potencial, lo que contribuirá a lograr los resultados de la organización.

\subsubsection{La mejora continua:}

Todo es susceptible de ser mejorado.

La mejora continua debe incorporarse al modo habitual de trabajar de la municipalidad, a su propia cultura organizacional, siendo asumida como un valor fundamental. Debe constituir un estilo de gestión, cuya principal característica es que no finaliza nunca. Se puede definir que mejora continua es obtener un grado de rendimiento mejor que el anterior.

El principio de mejora continua se basa en:

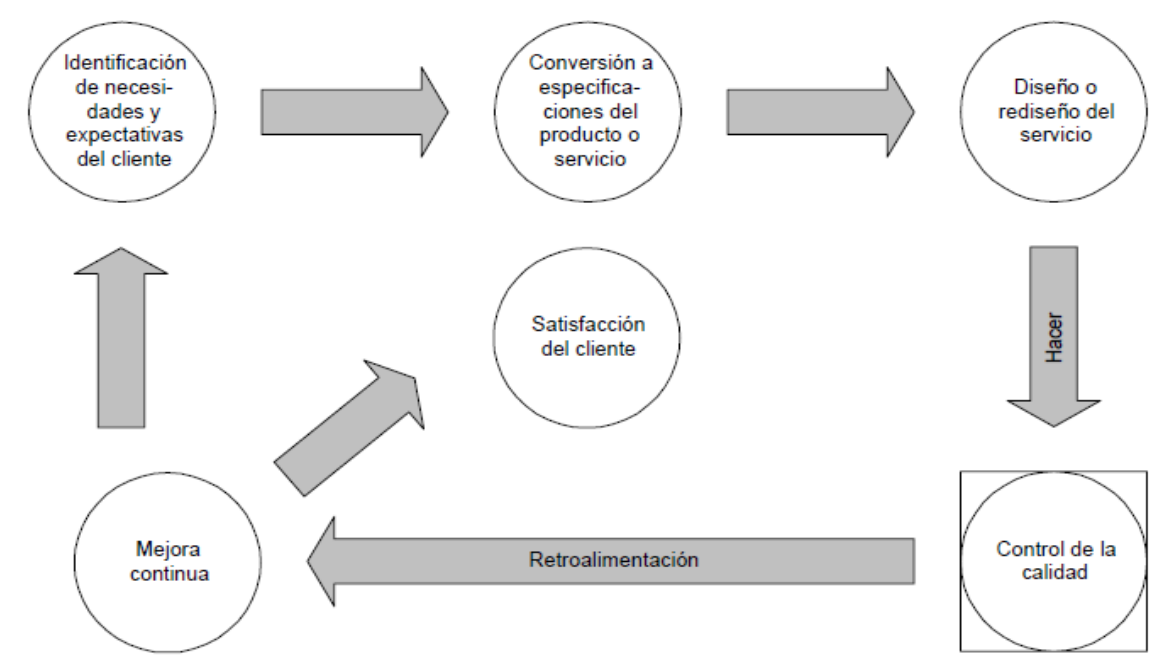

\subsubsection{Simplificación y agilización de procesos:}

Un proceso se define como un conjunto de actividades enlazadas entre sí que partiendo de uno o más insumos (entradas) se transforman generando un producto (servicio o información). Que la Municipalidad posea procesos simples y ágiles es otro de los elementos fundamentales para alcanzar la calidad total, ya que permite brindar una mejor y más rápida atención al cliente, así como optimizar los recursos existentes en la Municipalidad y reducir trámites, costos y tiempos para el usuario. 


\subsubsection{Trabajo en equipo:}

Todos los miembros de la Municipalidad deben tener bien definidas y asignadas sus funciones, las cuales deben estar orientadas a alcanzar los objetivos institucionales. Los beneficios que el trabajo en equipo puede ofrecer son incuestionables. Entre los factores que influyen en el buen desempeño de los equipos están:

- Un grupo de personas trabajando estructuradamente, pueden alcanzar sinergia, lo que significa que el resultado global obtenido por el grupo es superior a la suma de los resultados que tendrían los funcionarios y empleados municipales trabajando cada uno por su lado.

- Mediante los equipos se procura la motivación, el sentido de pertenencia y compromiso de cada uno de sus miembros con la Municipalidad.

\subsubsection{La calidad total abarca a toda la organización y todas sus actividades:}

La calidad total persigue facilitar productos satisfactorios al cliente, para lo cual habrá que orientar a toda la municipalidad y sus actividades para alcanzar:

$\checkmark$ La calidad en los insumos

$\checkmark$ La calidad en los procesos

$\checkmark$ La calidad en los recursos humanos

$\checkmark$ La calidad en los recursos técnicos

$\checkmark$ La calidad en la infraestructura

$\checkmark$ La calidad en la gestión

$\checkmark$ La calidad en los servicios, productos e información

\subsubsection{Receptividad a quejas e innovaciones:}

Los funcionarios y empleados municipales deben estar abiertos a recibir, analizar y evaluar quejas e innovaciones que manifiestan los vecinos y público en general, a fin de tomar las decisiones que les permita mejorar de manera continua. 


\subsubsection{Reducción de costos:}

La calidad tiene un costo el cual es provocado por la prevención y la evaluación, sin embargo el costo de la calidad es menor que el costo de la no calidad. Así, por ejemplo se pueden mencionar algunos costos provocados por la no calidad, los cuales son producidos por:

$\checkmark$ Duplicar procesos

$\checkmark$ Procesos largos y engorrosos

$\checkmark$ Falta de definición en los procesos

$\checkmark$ Repetir trabajos

$\checkmark$ Corregir errores

$\checkmark$ Soportar costos por reclamaciones ante trabajos y servicios mal realizados

$\checkmark$ Almacenar excedentes innecesarios

\section{$\underline{5.2 .5}$ Expectativas del cliente respecto de la organización}

Dentro de los factores básicos que determinan que el cliente está satisfecho por la información o servicio obtenido, se encuentran:

$\checkmark$ Confiabilidad

$\checkmark$ Simplicidad, sencillez y agilidad en los trámites de la gestión

$\checkmark$ Claridad en la comunicación oral y escrita

$\checkmark$ Capacidad de respuesta y agilidad

$\checkmark$ Seguridad

$\checkmark$ Idoneidad

$\checkmark$ Atención individualizada

$\checkmark$ Ambiente adecuado

$\checkmark$ Transparencia

$\checkmark$ Facilidad para formular sugerencias, quejas y reclamaciones

$\checkmark$ Flexibilidad en los horarios de atención al público

$\checkmark$ Existencia de oficinas próximas al domicilio o lugar de trabajo. 


\subsubsection{Confiabilidad:}

Tener la confianza que la municipalidad puede realizar el servicio prometido de manera precisa, continua y sin errores. O sea, prestar el servicio bien.

\subsubsection{Simplicidad, sencillez y agilidad en los trámites de la gestión:}

Que los trámites que le corresponde realizar sean pocos, simples y rápidos, eliminando requisitos o pasos innecesarios y reduciendo los tiempos de atención y gestión. Involucra también que los requisitos y pasos del procedimiento estén claramente establecidos.

\subsubsection{Claridad en la comunicación oral y escrita:}

Facilitar la comunicación con la población y los procedimientos que ésta tiene que llevar a cabo. Esto equivaldría a simplificar formularios y documentos, hacer más accesible el lenguaje administrativo y unificar procedimientos afines, entre otras acciones a tomar.

Dentro de este aspecto también es muy importante considerar que tanto los trabajadores como los funcionarios municipales asuman su rol como servidores públicos.

\subsubsection{Capacidad de respuesta y agilidad:}

Disposición de los funcionarios y trabajadores municipales a prestar el servicio a la población de forma rápida, atenta y personalizada.

\subsubsection{Seguridad:}

Capacidad de trasmitir credibilidad y confianza, mediante el conocimiento y atención mostrados por los funcionarios y empleados municipales. En este aspecto, es importante también que exista transparencia en el manejo de los recursos municipales, a fin que los vecinos se sientan seguros que sus impuestos y contribuciones están siendo bien invertidos. 


\subsubsection{Idoneidad:}

Preparación, competencia, amabilidad y buen trato personal de los funcionarios y empleados municipales, principalmente aquellos que atienden a los vecinos y público en general.

\subsubsection{Atención individualizada:}

Que el vecino o usuario sienta que el servicio que se le proporciona se personaliza y que es tratado como un ser humano, no como un número más o alguien más en la cola. Incluye la capacidad para entender al cliente y de comunicarse con él en forma clara y concisa.

\subsubsection{Ambiente adecuado:}

Los elementos físicos que están presentes en la prestación del servicio: instalaciones, equipos, áreas cómodas de espera, señalización, iluminación, ventilación, temperatura, servicios sanitarios, formularios, lapiceros y otros servicios que hagan más agradable la permanencia del vecino o usuario dentro de la municipalidad. De igual forma, el ambiente adecuado contribuye para que el trabajador se desempeñe de manera más eficiente, así como que el vecino o usuario se sienta mejor atendido.

\subsubsection{Transparencia:}

Facilitar información clara, precisa y continua, identificación del personal que presta el servicio y facilidad de acceso a archivos y registros públicos.

\subsubsection{Facilidad para formular sugerencias, quejas y reclamaciones:}

Tener un encargado o buzón de sugerencias, quejas o reclamos a disposición del cliente. Implica estar dispuesto a escuchar al cliente sobre los trámites que realiza y tomar las medidas correctivas que sean necesarias para mejorar la calidad del servicio. 


\subsubsection{Flexibilidad en los horarios de atención al público:}

Mientras más amplios sean los horarios, los vecinos y usuarios tendrán que hacer menor esfuerzo para realizar sus trámites. Es recomendable, que las autoridades municipales analicen la posibilidad de atender al público por lo menos la mañana del día sábado o extender por lo menos un día a la quincena el horario de la jornada laboral hasta las 18:00 horas, lo que facilitaría que los vecinos que trabajan puedan hacer sus gestiones municipales ese día, evitando pedir permisos innecesarios en sus respectivos trabajos.

\subsubsection{Existencia de oficinas próximas al domicilio o lugar de trabajo:}

Mientras más cerca se esté la oficina al vecino o usuario, éste tendrá que hacer menor esfuerzo para realizar sus trámites. Dependiendo cantidad de usuarios, las distancias, acceso, área geográfica y otras características propias del municipio, los funcionarios municipales podrán analizar la posibilidad de abrir otra oficina municipal en otro lugar fuera de la cabecera municipal o crear una oficina móvil que se desplace periódicamente hacia los lugares que presenten problemas a los vecinos para llegar hasta la cabecera municipal.

\section{Metodología de la Investigación}

\subsection{Universo y Muestra}

\subsubsection{Universo}

Para el servicio que se estudió -la Dirección de Defensa del Consumidor de la Municipalidad de La Plata-, el universo está constituido por los habitantes de la Municipalidad de La Plata (654.324 habitantes).

\subsubsection{Muestra}

La población bajo estudio para esta investigación está constituida por todos los habitantes del Partido de La Plata. De la misma se considera extraer una muestra aleatoria cuyo tamaño n se calcula mediante la expresión: 


$$
n=\frac{Z_{\alpha}^{2} \cdot N \cdot p \cdot q}{e^{2} \cdot(N-1)+Z_{\alpha}^{2} \cdot p \cdot q}
$$

La misma corresponde al cálculo del tamaño muestral cuando se desea estimar la proporción de éxitos $p$, con universo conocido.

Donde:

$\mathrm{N}=654.324$ habitantes (tamaño de la población)

$p=$ prevalencia esperada del parámetro a evaluar, que en caso de desconocerse, se aplica la opción más desfavorable $(p=0,5)$, que hace mayor el tamaño muestral

$q=$ complemento de la prevalencia esperada del parámetro a evaluar, es decir $1-p=0,5$

$Z=1,95996$ para $\alpha=5 \%$, o sea un nivel de confianza del $95 \%$

e $=6,21 \%$ error de muestreo

$\mathrm{N}=250$ personas a encuestar (tamaño de la muestra)

Dado que se trata de cinco áreas a estudiar, se ha distribuido el total equitativamente entre las mismas, lo cual implica un $20 \%$ del total para cada una de las siguientes áreas:

\begin{tabular}{lr}
\multicolumn{1}{c}{ Área } & Encuestas \\
\hline Licencias de conducir & 50 \\
\hline Dirección de Obras Particulares & 50 \\
\hline Defensa del consumidor & 50 \\
\hline Juzgado de faltas & 50 \\
\hline Agencia Platense de Recaudación & 50 \\
\hline \multicolumn{2}{c}{ Total }
\end{tabular}

\subsection{Tipo de Investigación}

Se trató de una investigación de tipo exploratoria y de naturaleza cuantitativa. 


\subsection{Técnicas de Recolección de Datos}

\section{Encuestas}

Las encuestas permitieron obtener información por parte de los ciudadanos con relación al servicio que se le brinda al cliente en la Dirección de Defensa del Consumidor de la Municipalidad de La Plata. Se realizaron preguntas del tipo "cerradas".

En cada una de ellas se le pidió a los encuestados que califiquen tanto su percepción del servicio, como las expectativas con las que llegaban a la Dirección de Defensa del Consumidor.

Se interrogó a las personas que voluntariamente quisieron participar sobre cinco dimensiones asignando calificaciones entre 1 y 5 , correspondiendo el 1 a la mejor calificación y 5 a la peor opción.

Las dimensiones fueron definidas de la siguiente manera:

1) Elementos tangibles: apariencia de las instalaciones físicas, equipos, personal y materiales de comunicación.

2) Confiabilidad: habilidad para ejecutar el servicio prometido de forma confiable y cuidadosa.

3) Capacidad de respuesta: disposición y voluntad de los empleados para ayudar al cliente y proporcionar el servicio

4) Seguridad: conocimiento y atención mostrados por los empleados y sus habilidades para inspirar credibilidad y confianza

5) Empatía: atención individualizada que ofrece la organización a los clientes.

Para llevar a cabo las encuestas, los encuestadores estuvieron presentes en las oficinas municipales para encuestar a los clientes que acudieron a dicha repartición municipal. 


\subsection{Técnicas de Análisis}

El análisis de la información se llevó a cabo luego de la confección de una base de datos. Los datos obtenidos en las encuestas fueron cargados a una matriz, donde cada campo representa cada pregunta de la encuesta. Las respuestas fueron codificadas numéricamente, para facilitar la carga. A su vez, se llevó a cabo un análisis univariado.

Luego se calculó el "Saldo de respuesta"1 de cada pregunta realizada, en función de la fórmula siguiente:

$$
\text { Saldo de Re spuesta }=\frac{\sum_{i=1}^{n} F_{i} \cdot i}{\sum_{i=1}^{n} F_{i}}
$$

Donde:

$\mathrm{Fi}=$ Es la cantidad de respuestas (frecuencias) de cada ítem para cada valor de las opciones de respuesta

$\mathrm{i}=$ Es el valor de cada uno de las opciones de respuesta

El cálculo consiste en multiplicar los componentes de las cantidades de respuestas (frecuencias) por el tipo de respuesta dado y luego sumar esos

\footnotetext{
1 El cálculo de ese promedio sigue idéntica metodología que la del Global Competitiveness Index del World Economic Forum para el procesamiento de la Executive Opinion Survey en que se pregunta sobre una serie de cuestiones y se solicita que se califique en un rango que va de 1 a 7 en que 1 es lo peor y 7 lo mejor y que luego se sintetiza a través de un promedio. Xavier Sala-i-Martin (Cabrera de Mar, Barcelona, España, 1963), es un economista de origen español y de nacionalidad estadounidense, articulista, catedrático de economía en la Universidad de Columbia y Asesor Jefe ("Chief Advisor") del World Economic Forum donde, además, es coautor del Global Competitiveness Report y el padre intelectual del Global Competitiveness Index que ordena a más de 140 países del mundo según su competitividad.
} 
productos. Posteriormente a ese número se lo divide por la sumatoria de la cantidad de respuestas.

Luego se calculó la frecuencia de la brecha de satisfacción sobre la calidad del servicio, como la diferencia entre las percepciones y las expectativas que tienen los clientes de la Dirección de Defensa del Consumidor.

La brecha de satisfacción del cliente es la resultante de la resta entre la calificación otorgada a la expectativa que un cliente tiene sobre un aspecto del servicio y la percepción respecto del servicio obtenido. Dado que las calificaciones, para ambos aspectos, eran números enteros del uno al cinco, se definieron las categorías según la tabla que sigue:

\begin{tabular}{|c|c|c|c|}
\hline Expectativa & Percepción & Brecha & Situación \\
\hline 5 & 1 & 4 & Satisfacción absoluta \\
\hline 5 & 2 & 3 & Mucho más que Satisfecho \\
\hline 4 & 1 & 3 & Mucho más que Satisfecho \\
\hline 5 & 3 & 2 & Bastante más que Satisfecho \\
\hline 4 & 2 & 2 & Bastante más que Satisfecho \\
\hline 3 & 1 & 2 & Bastante más que Satisfecho \\
\hline 5 & 4 & 1 & Algo más que Satisfecho \\
\hline 4 & 3 & 1 & Algo más que Satisfecho \\
\hline 3 & 2 & 1 & Algo más que Satisfecho \\
\hline 2 & 1 & 1 & Algo más que Satisfecho \\
\hline 5 & 5 & 0 & Satisfecho \\
\hline 4 & 4 & 0 & Satisfecho \\
\hline 3 & 3 & 0 & Satisfecho \\
\hline 2 & 2 & 0 & Satisfecho \\
\hline 1 & 1 & 0 & Satisfecho \\
\hline 4 & 5 & -1 & Algo Insatisfecho \\
\hline 3 & 4 & -1 & Algo Insatisfecho \\
\hline 2 & 3 & -1 & Algo Insatisfecho \\
\hline 1 & 2 & -1 & Algo Insatisfecho \\
\hline 3 & 5 & -2 & Bastante Insatisfecho \\
\hline 2 & 4 & -2 & Bastante Insatisfecho \\
\hline 1 & 3 & -2 & Bastante Insatisfecho \\
\hline 2 & 5 & -3 & Muy insatisfecho \\
\hline 1 & 4 & -3 & Muy insatisfecho \\
\hline 1 & 5 & -4 & Insatisfacción total \\
\hline
\end{tabular}


Finalmente, para determinar el orden de importancia de las dimensiones según los usuarios encuestados, se utilizó la fórmula de la importancia promedio ponderada (similar a la de "saldo de respuesta") definida como la suma de la productoria entre la frecuencia de la importancia asignada y la importancia, todo ello dividido por la sumatoria de la frecuencia.

\section{Resultados de la Investigación}

\subsection{Análisis descriptivo de la muestra}

- Se realizaron 50 encuestas.

- El $60 \%$ fueron mujeres y el $40 \%$ hombres.

\section{Género}

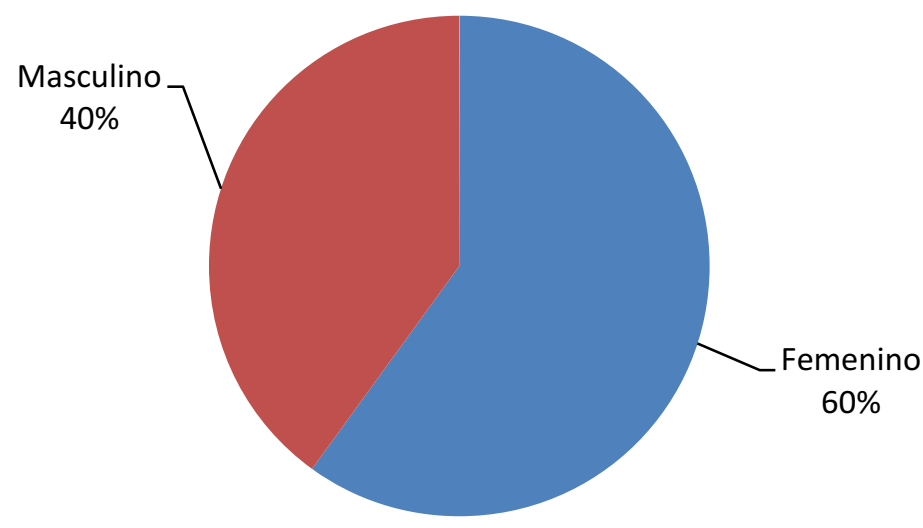

- El rango de edad de los encuestados fue el siguiente:

\begin{tabular}{|crr|}
\hline Edades & Frecuencia & Porcentaje \\
\hline Hasta 20 años & 0 & $0 \%$ \\
\hline Entre 20 y 30 años & 7 & $14 \%$ \\
\hline Entre 30 y 40 años & 9 & $18 \%$ \\
\hline Entre 40 y 50 años & 22 & $44 \%$ \\
\hline Entre 50 y 60 años & 10 & $20 \%$ \\
\hline Más de 60 años & 2 & $4 \%$ \\
\hline Totales & 50 & $100 \%$ \\
\hline
\end{tabular}




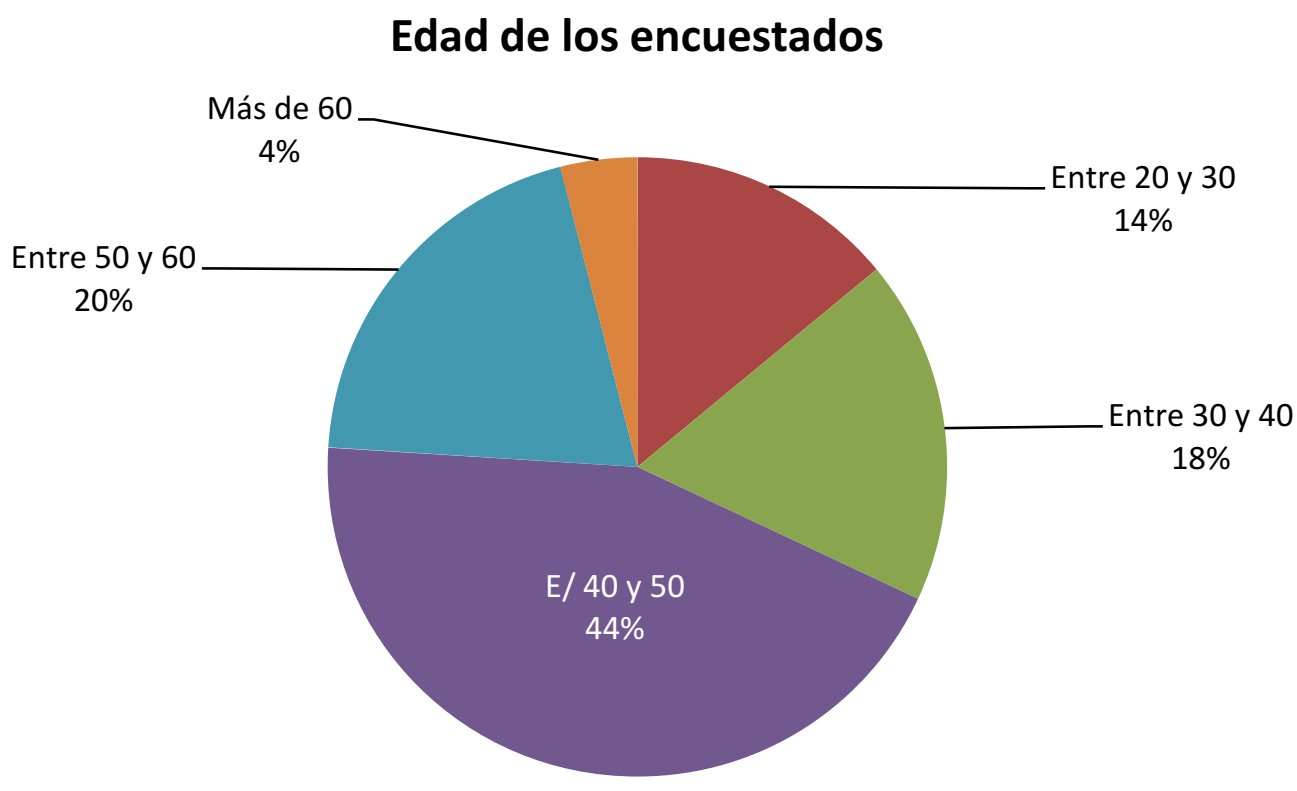

En primer lugar se va a analizar la frecuencia de utilización del servicio de Defensa del Consumidor. En ese sentido se encontró que el $56 \%$ de los usuarios, se presenta en las oficinas municipales cada varios años, mientras que el $22 \%$ lo hace solo una vez al año, el $16 \%$ una vez cada seis meses y un $6 \%$ de los encuestados utiliza el servicio mensualmente.

\section{Frecuencia en la utilización del servicio}

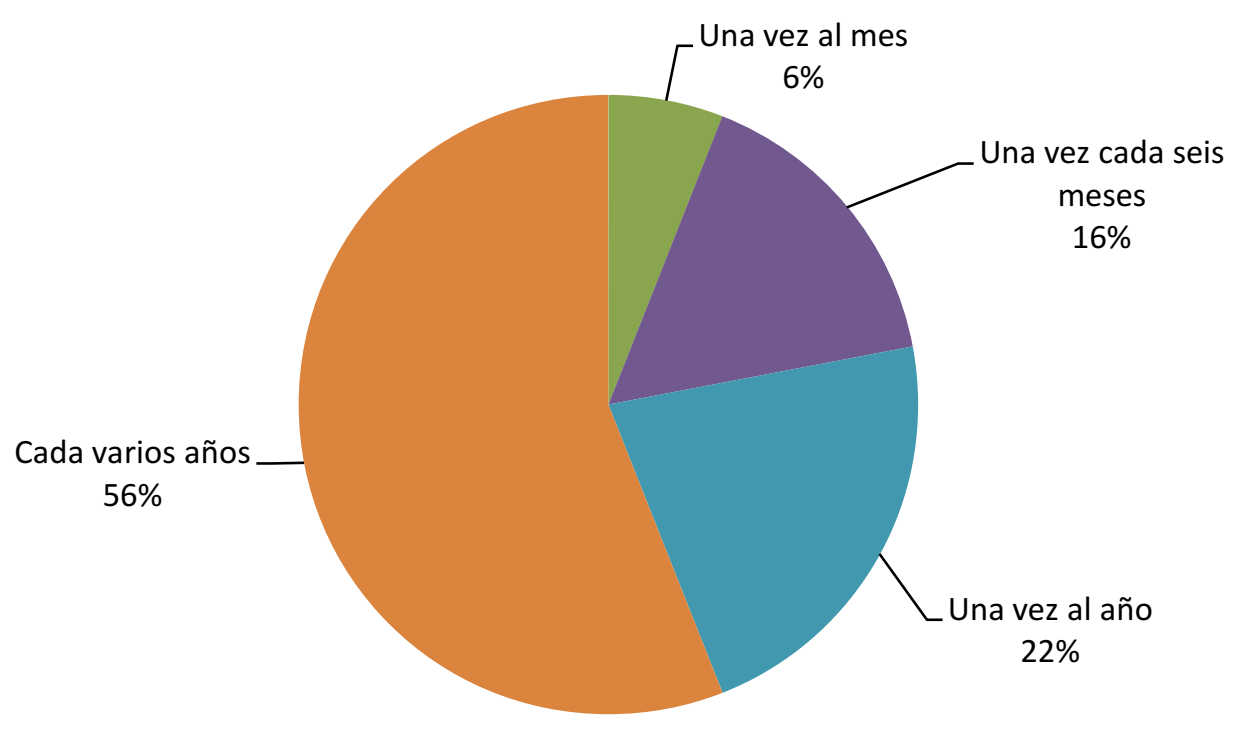

Luego, se consultó acerca de cómo calificaría la organización integral del servicio, en una escala de cinco opciones que iban entre "excelente" a "pésimo". Ningún encuestado calificó al servicio como "Pésimo" o "Malo", en 
tanto que el $26 \%$ consideró que la organización integral del servicio es "Regular". La gran mayoría, 70\%, lo calificó como "Bueno" y un 4\% "Excelente:

\begin{tabular}{|lrr|}
\hline $\begin{array}{c}\text { Calificación de la } \\
\text { organización del } \\
\text { servicio }\end{array}$ & Frecuencia & Calificación \\
\hline Excelente & 2 & $4,0 \%$ \\
\hline Bueno & 35 & $70,0 \%$ \\
\hline Regular & 13 & $26,0 \%$ \\
\hline Malo & 0 & $0,0 \%$ \\
\hline Pésimo & 0 & $0,0 \%$ \\
\hline Totales & 50 & $100,0 \%$ \\
\hline
\end{tabular}

7.2 Dimensión I: Elementos Tangibles: Apariencia de la instalaciones físicas, equipos, personal y materiales de comunicación

A continuación se exponen los resultados obtenidos en la Dirección de Defensa del Consumidor en los elementos equipos, instalaciones físicas, apariencia física de los empleados, y, apariencia visual de los elementos de comunicación.

\subsubsection{Equipos}

\subsubsection{Expectativa}

En principio se consultó a los encuestados acerca de las expectativas que traían respecto de los equipos que se utilizan en el servicio de Defensa del Consumidor, entre opciones que iban desde modernos a obsoletos, obteniendo los siguientes resultados: 


\section{Apariencia de los equipos}

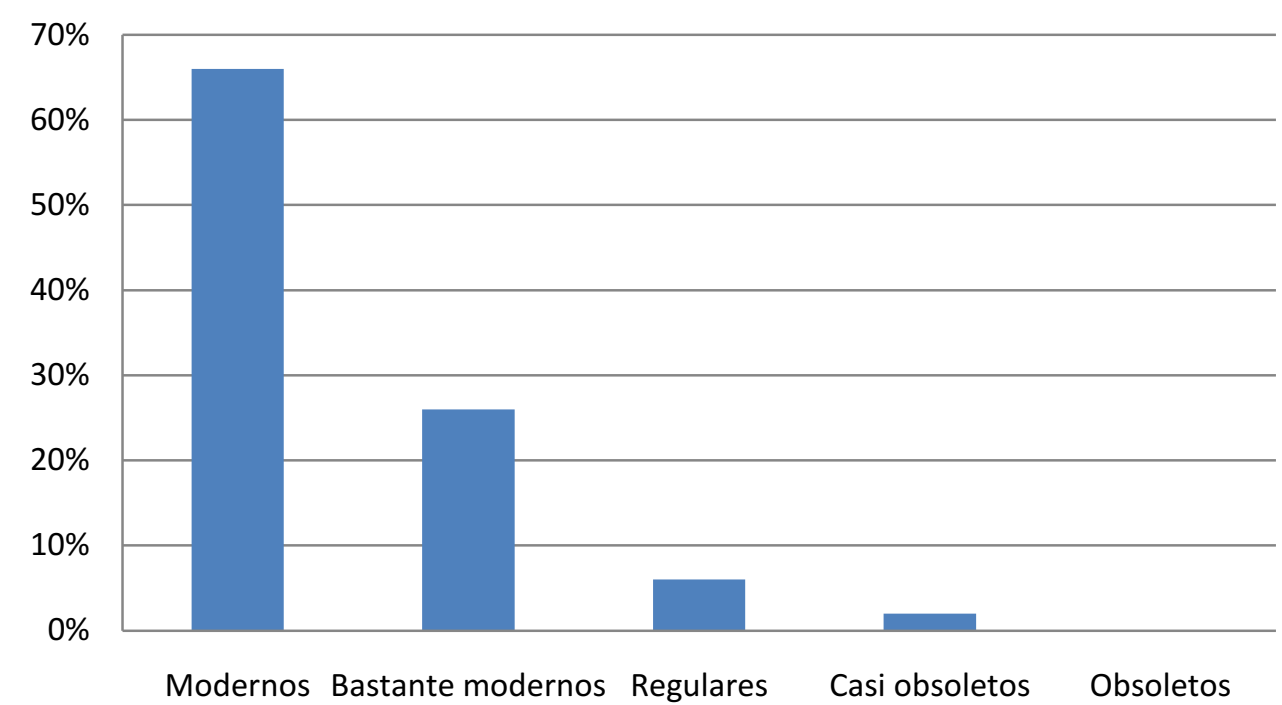

Saldo de Respuesta: 1,44 "Modernos" a "Bastantes modernos".

\subsubsection{Percepción}

La percepción de los encuestados sobre los equipos con los que cuenta el servicio de Defensa del Consumidor fue la siguiente:

\section{Apariencia de los equipos}

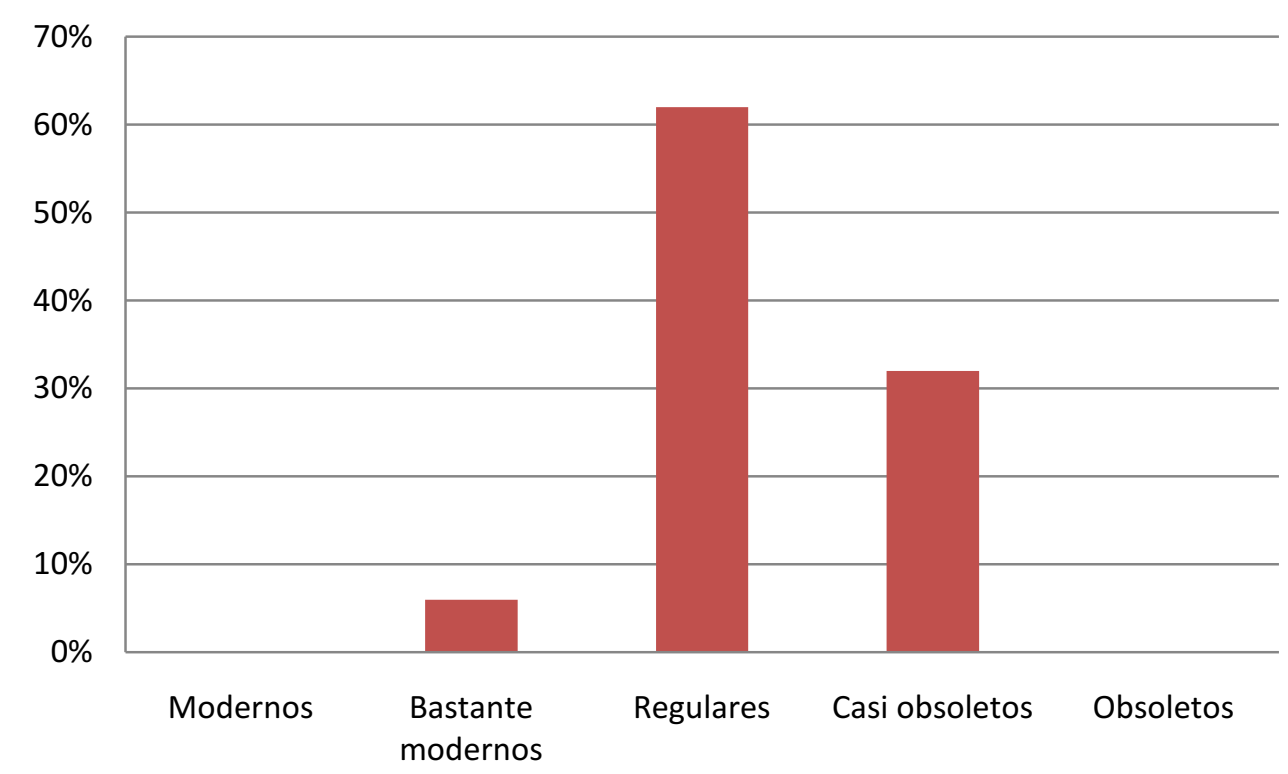


Teniendo en cuenta el orden de las alternativas de calificación, siendo la opción "Modernos" la primer alternativa (1) y "Obsoletos" la quinta (5), los usuarios del sistema de Defensa del Consumidor califican a los equipos de regulares a casi obsoletos, ubicando su percepción según el Saldo de Respuesta en 3,26 es decir Regulares.

\subsubsection{Brecha}

En el siguiente gráfico se puede observar la apreciación por parte de los clientes, de los equipos del servicio junto con las expectativas que traían los encuestados:

\section{Apariencia de los equipos}

Expectativa $\rightarrow$ Percepción

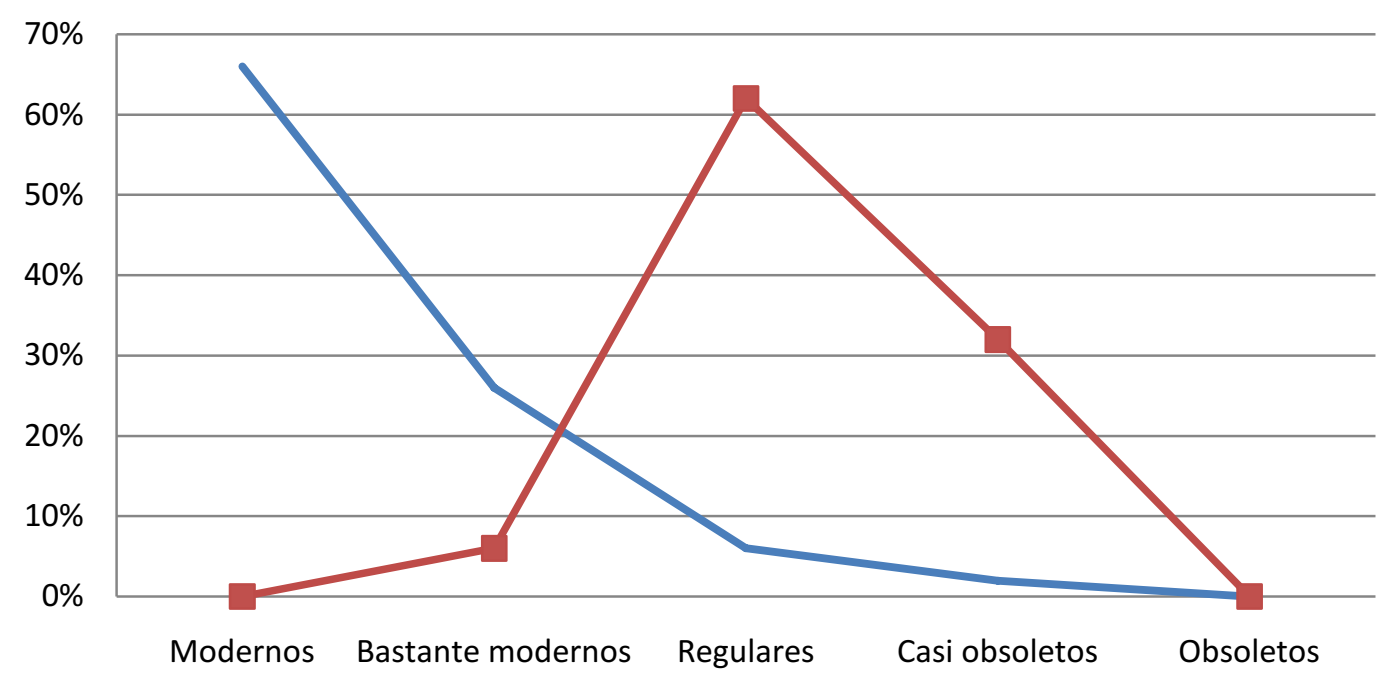

Como se observa en el gráfico precedente, es evidente que los clientes esperaban en su mayoría encontrar un nivel de equipos de modernos a bastante modernos.

En el esquema siguiente se muestra la brecha de satisfacción entre lo que esperan y las percepciones de los equipos del servicio una vez que hacen uso de la Dirección: 


\section{Brecha equipamiento}

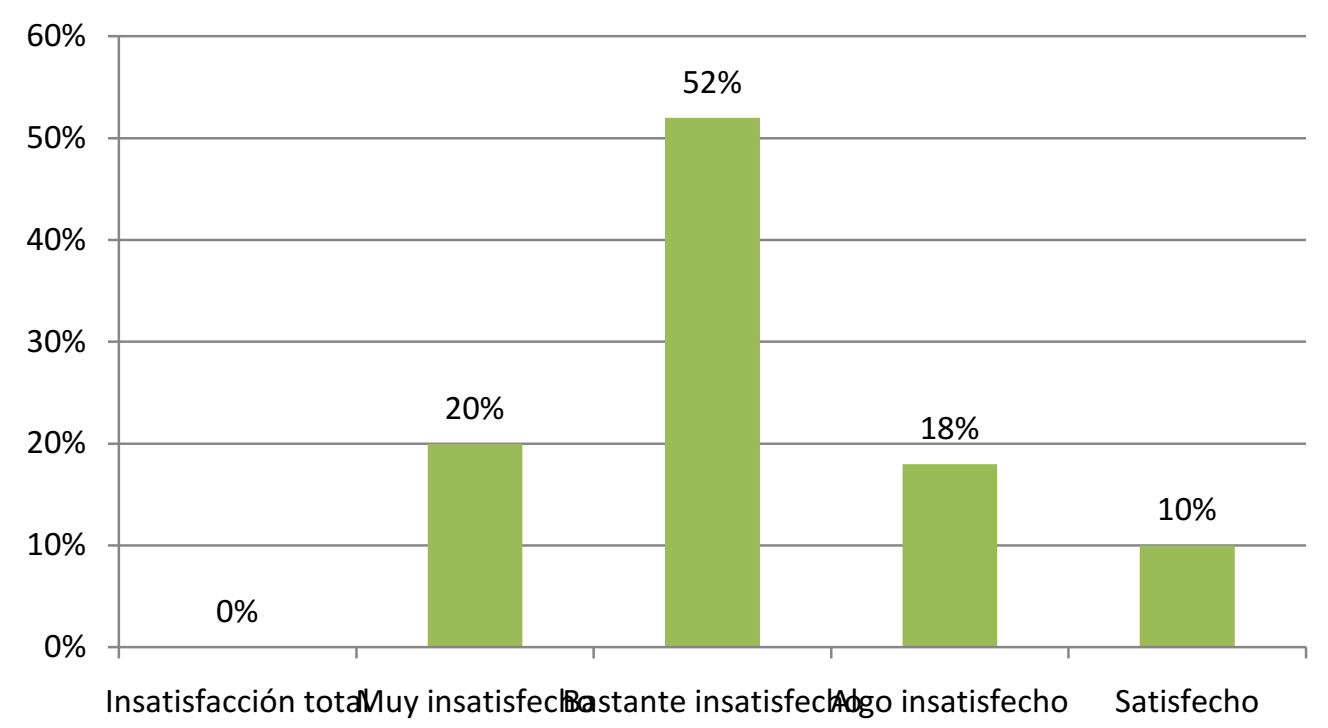

Saldo de Respuesta: $-1,82$ "Bastante insatisfecho" con tendencia a "Algo insatisfecho".

\subsubsection{Instalaciones físicas}

\subsubsection{Expectativa}

En cuanto a la expectación sobre las instalaciones físicas de la dependencia se observaron los siguientes resultados:

\section{Instalaciones físicas del servicio}

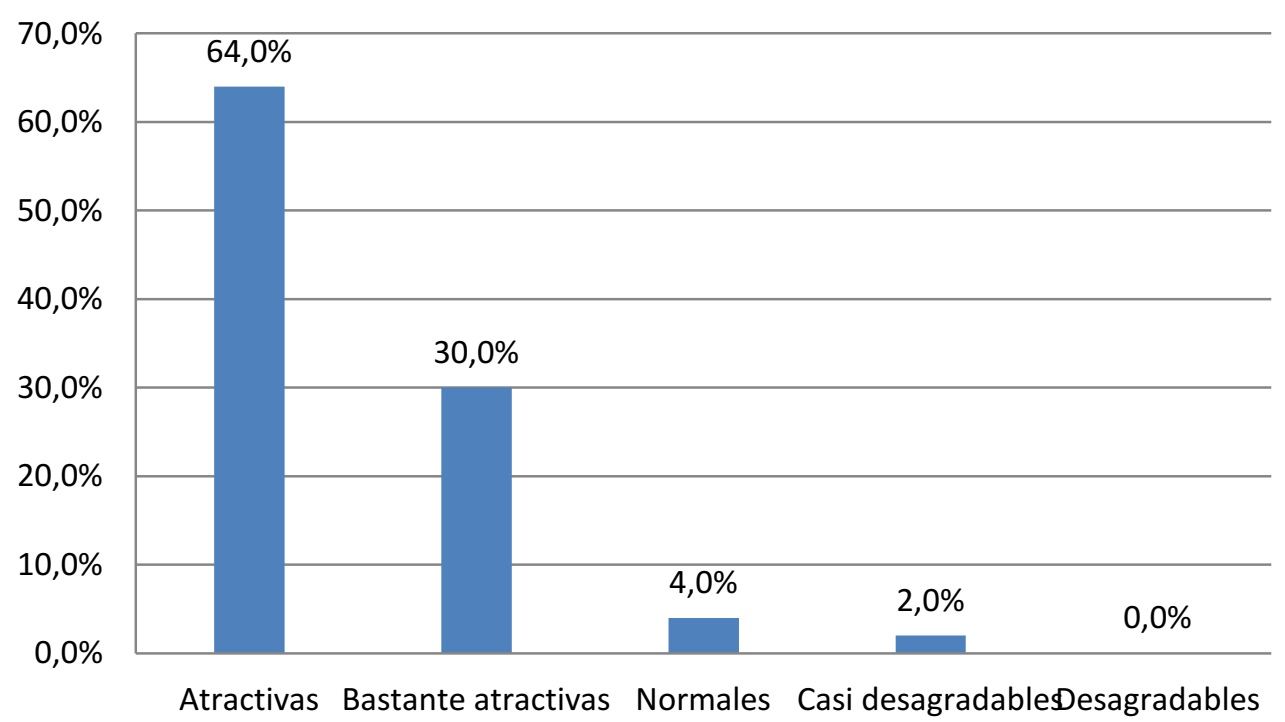


Saldo de Respuesta: 1,44 "Atractivas" a "Bastante atractivas".

\subsubsection{Percepción}

Se muestran a continuación los resultados de las percepciones sobre las instalaciones físicas:

\section{Instalaciones físicas del servicio}

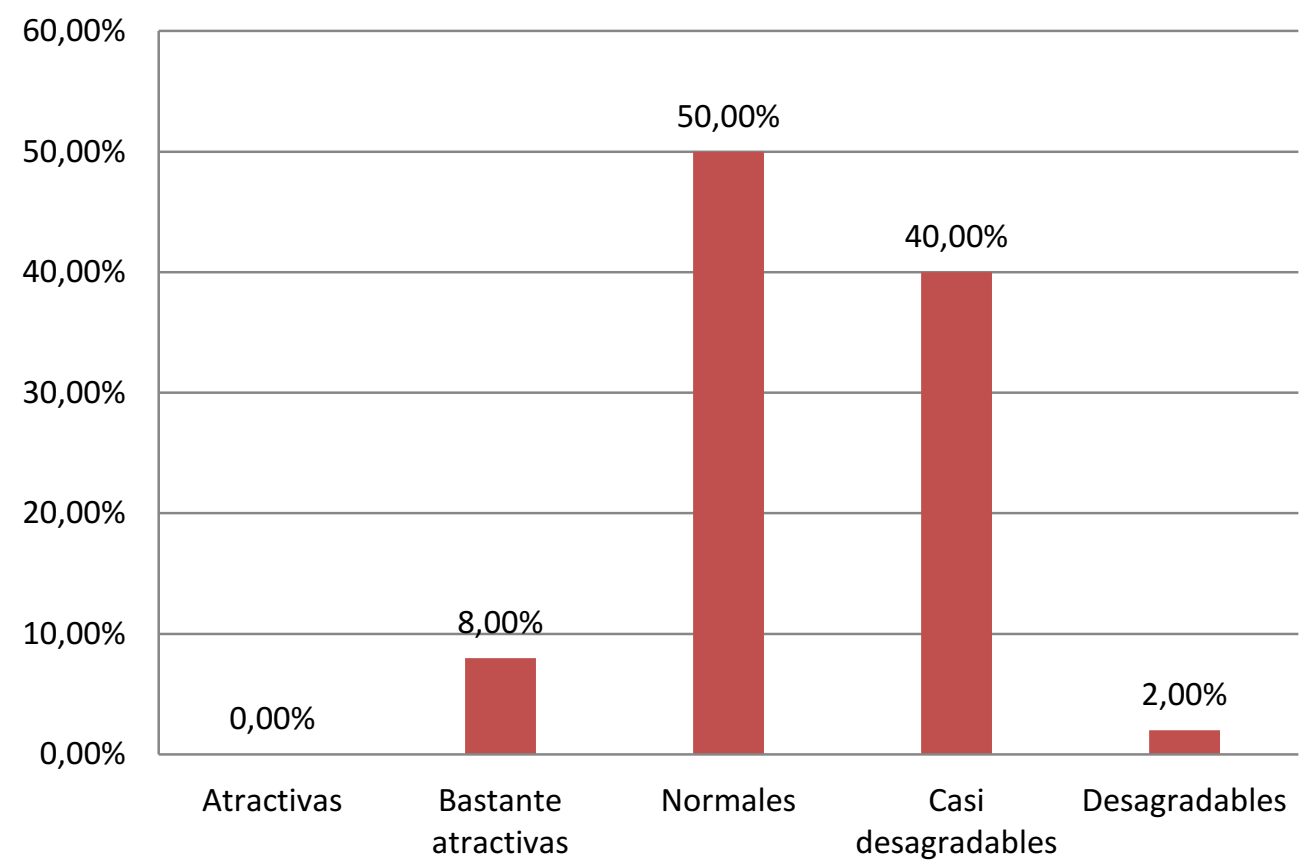

El Saldo de Respuesta de las percepciones sobre las instalaciones físicas es 3,36 , de normales con tendencia a casi desagradables. 


\subsubsection{Brecha}

\section{Instalaciones físicas del servicio}

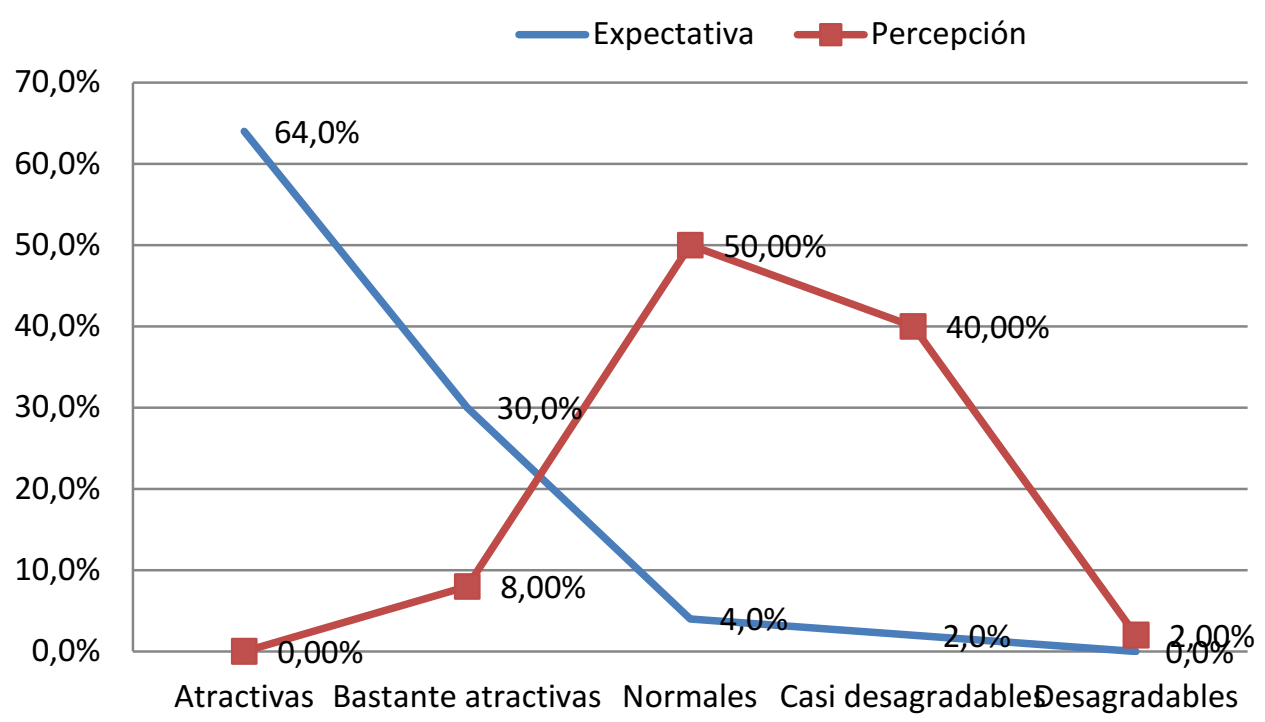

Es del caso señalar que la brecha de satisfacción de las instalaciones físicas se asemeja bastante a la obtenida en el caso de los equipos, como se muestra a continuación:

\section{Brecha instalaciones físicas}

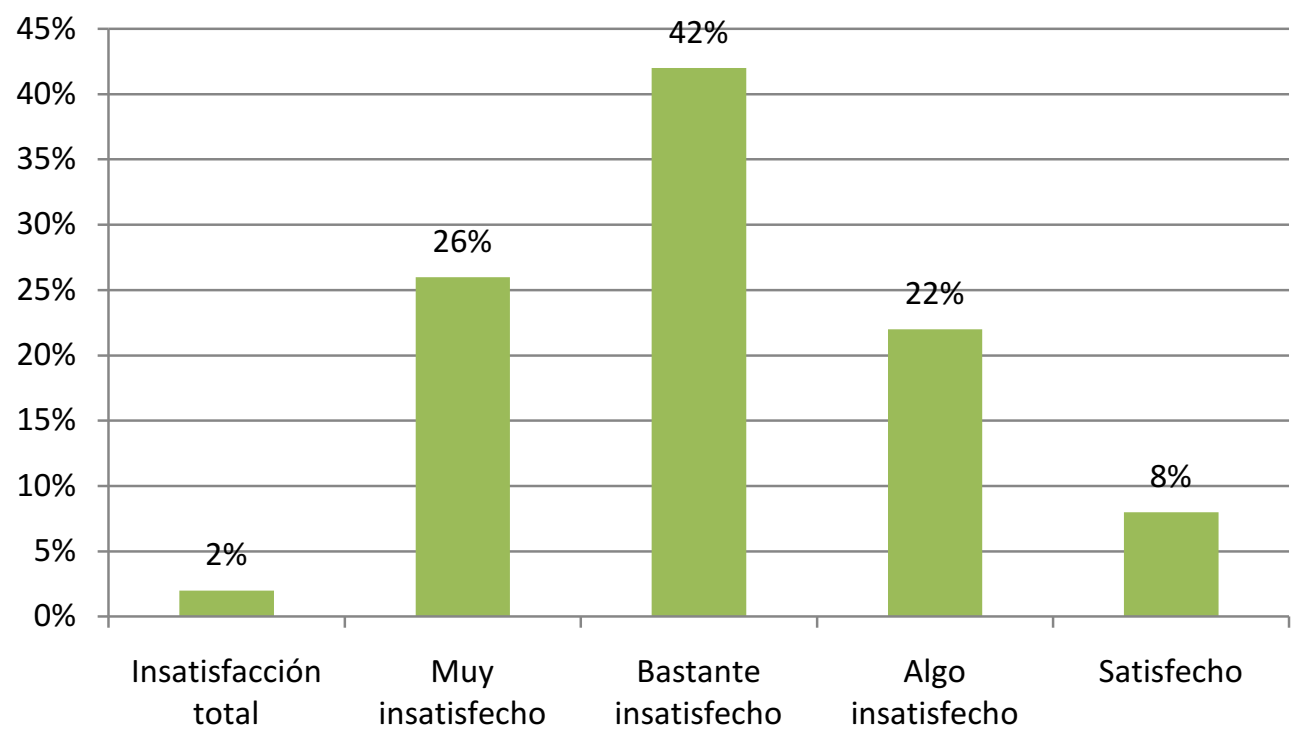

Saldo de Respuesta: -1,92 "Bastante insatisfechos". 


\subsubsection{Apariencia física de los empleados}

\subsubsection{Expectativa.}

En su gran mayoría los usuarios confiaban en que el aspecto físico de los empleados del servicio sería pulcro, como se muestra a continuación.

\section{Apariencia física de los empleados}

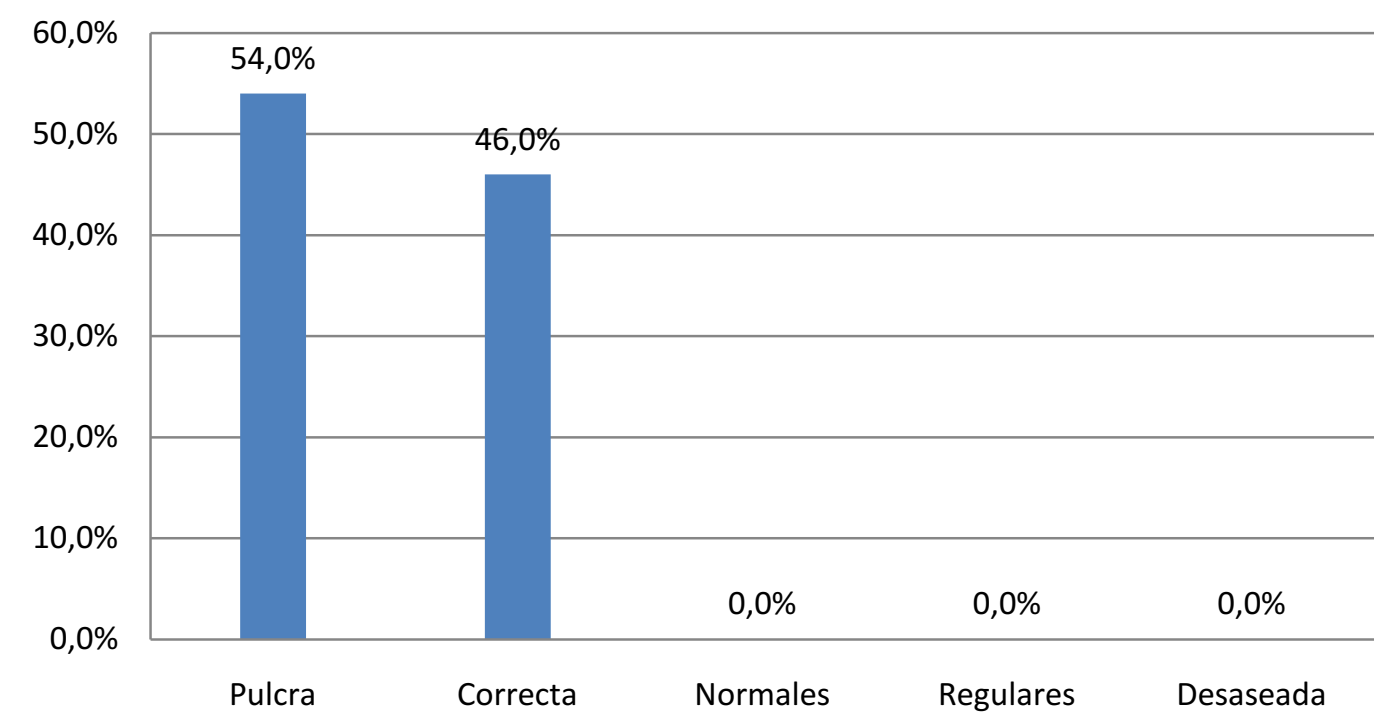

Saldo de Respuesta: 1,46 "Pulcra" a "Correcta". 


\subsubsection{Percepción}

\section{Apariencia física de los empleados}

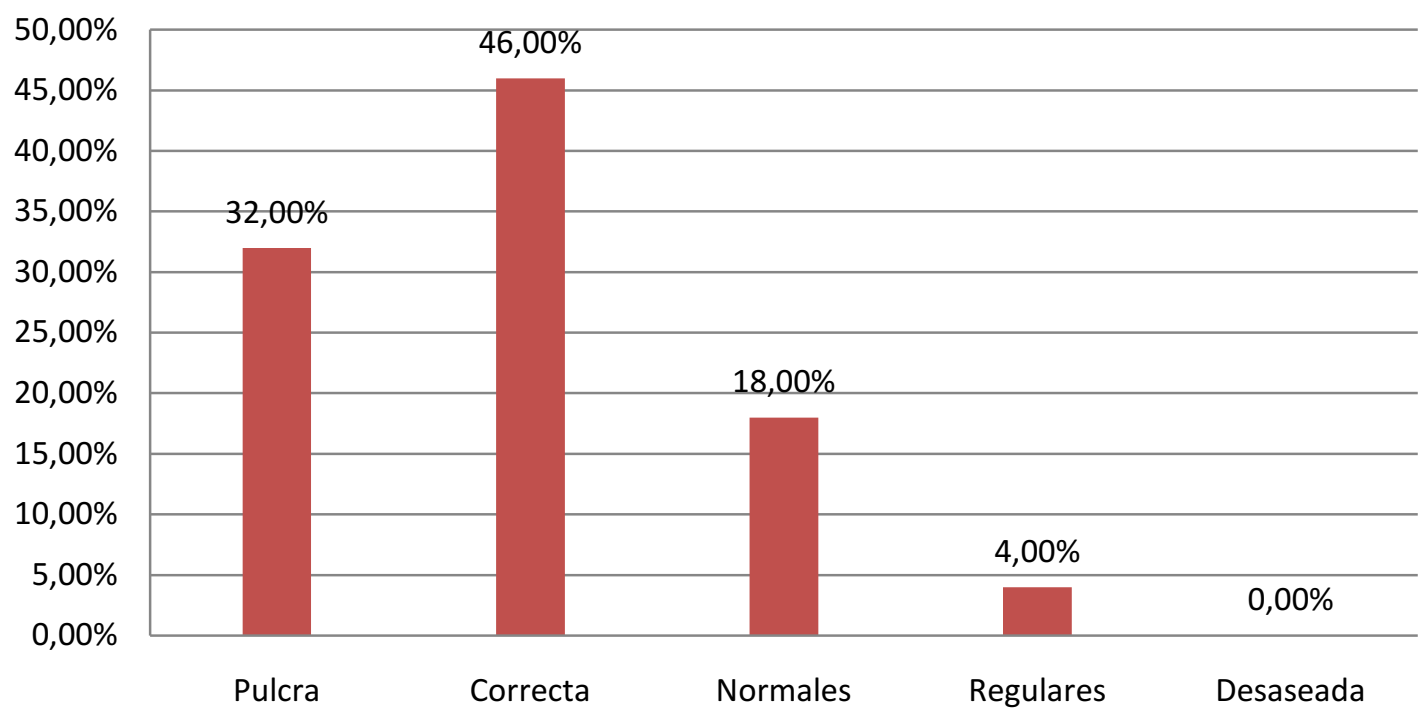

Se evalúa positivamente la pulcritud de los empleados, con un Saldo de Respuesta de 1,46.

\subsubsection{Brecha}

Comparando en un mismo gráfico la percepción y las expectativas que traían los usuarios respecto de la apariencia física de los empleados, se obtuvo 


\section{Apariencia física de los empleados}

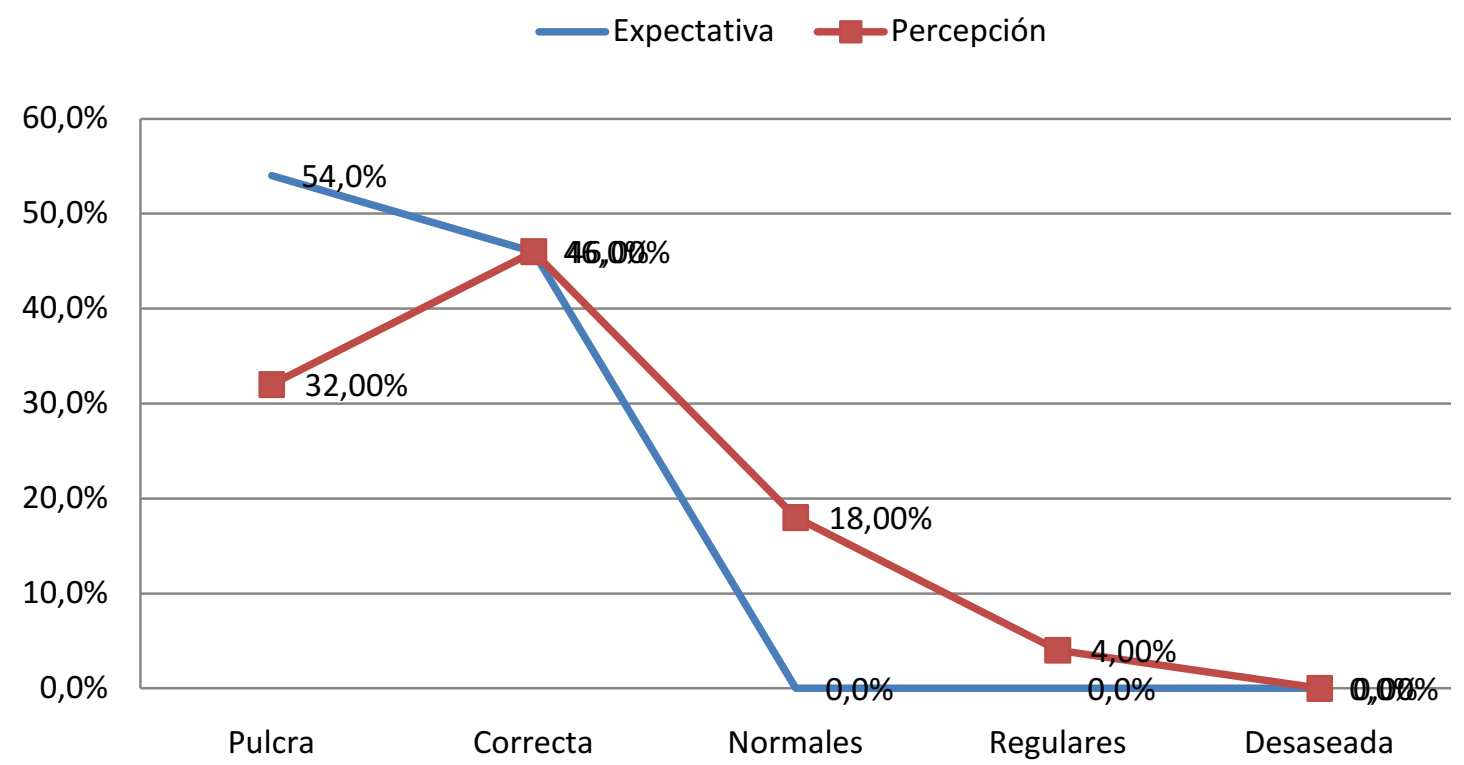

Brecha apariencia física de los empleados

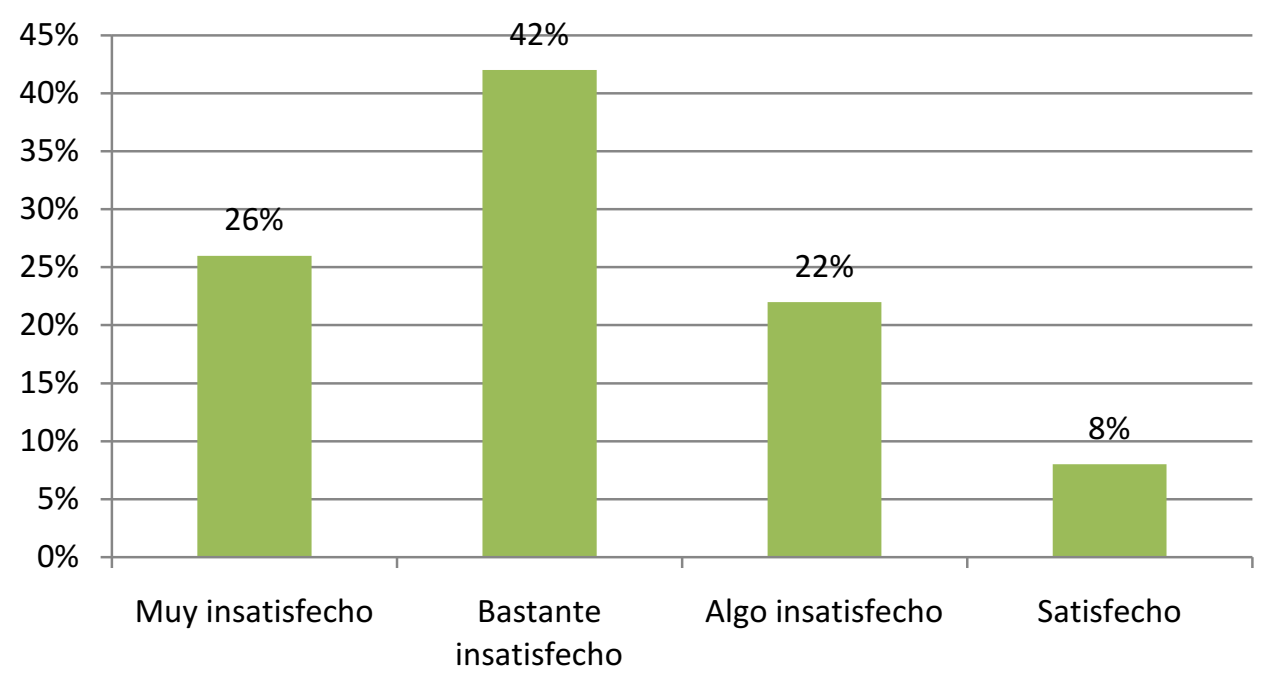

Saldo de Respuesta: -0,48 "Satisfecho" a "Algo insatisfecho". 


\subsubsection{Apariencia visual de los elementos materiales de comunicación}

\subsubsection{Expectativa}

\section{Apariencia visual de los elementos de comunicación}

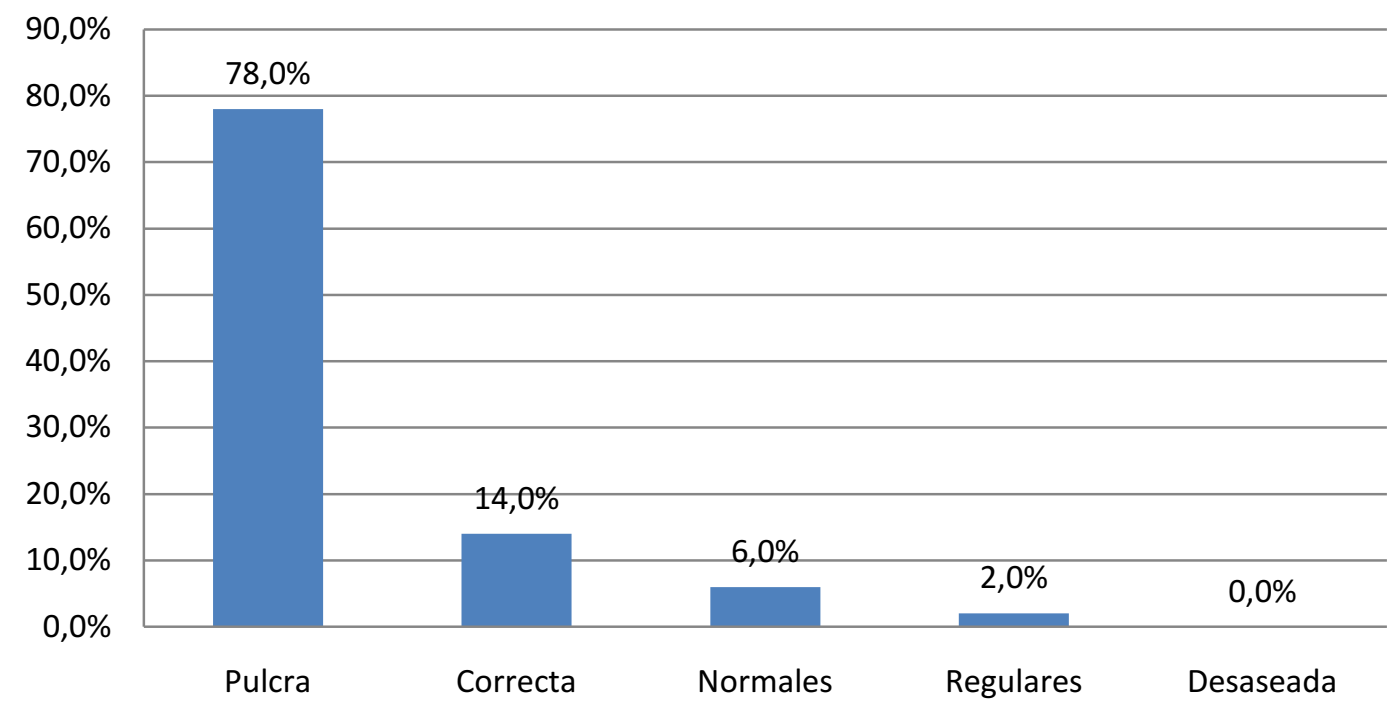

Saldo de Respuesta: 1,32 "Pulcra" con tendencia a "Correcta".

\subsubsection{Percepción}

\section{Apariencia visual de los elementos de comunicación}

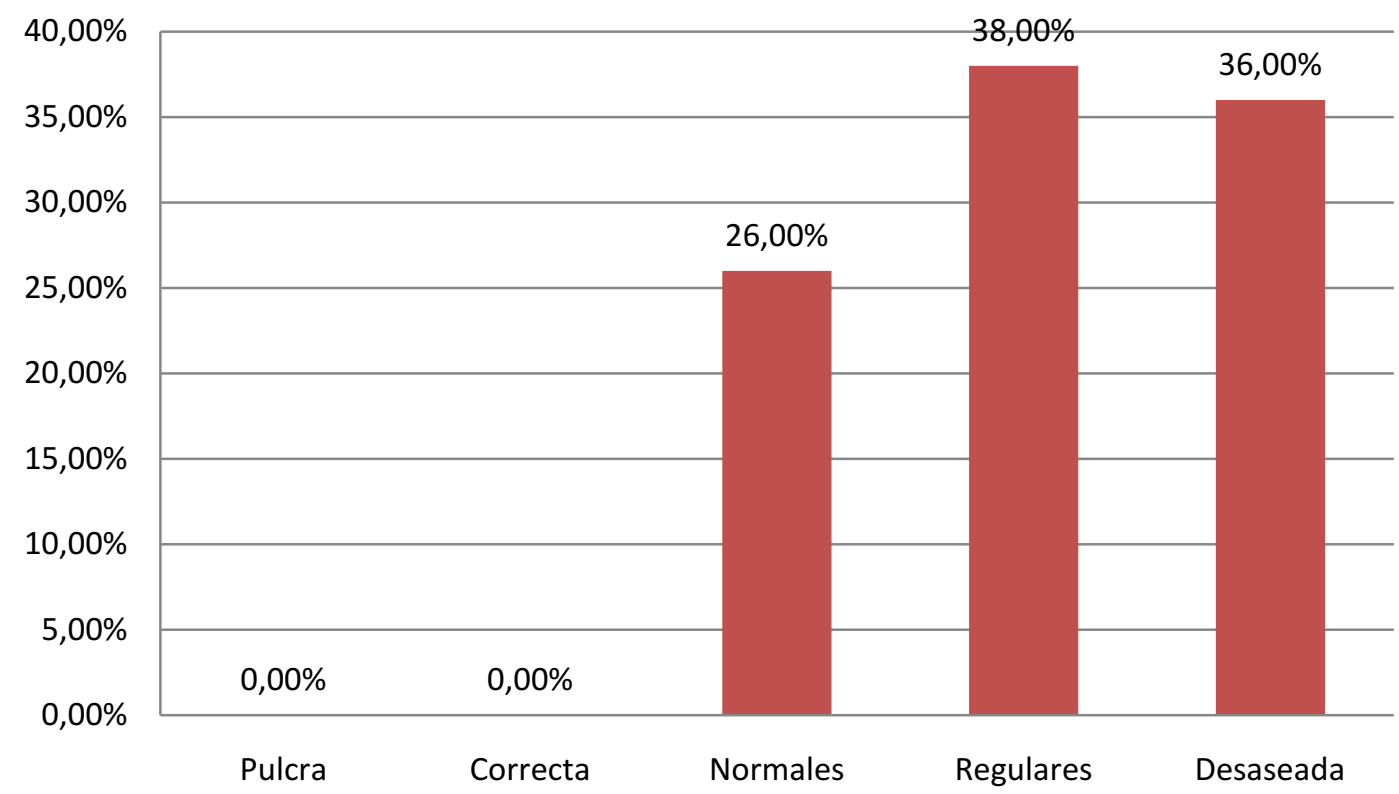


El Saldo de Respuesta correspondiente a la apariencia de los elementos de comunicación es de 4,10 lo que la ubica en el rango de regulares.

\subsubsection{Brecha}

Evaluando la separación que existe entre las expectativas y las percepciones recogidas, se obtienen los siguientes niveles de satisfacción:

\section{Apariencia visual de los elementos de comunicación}

Expectativa - Percepción

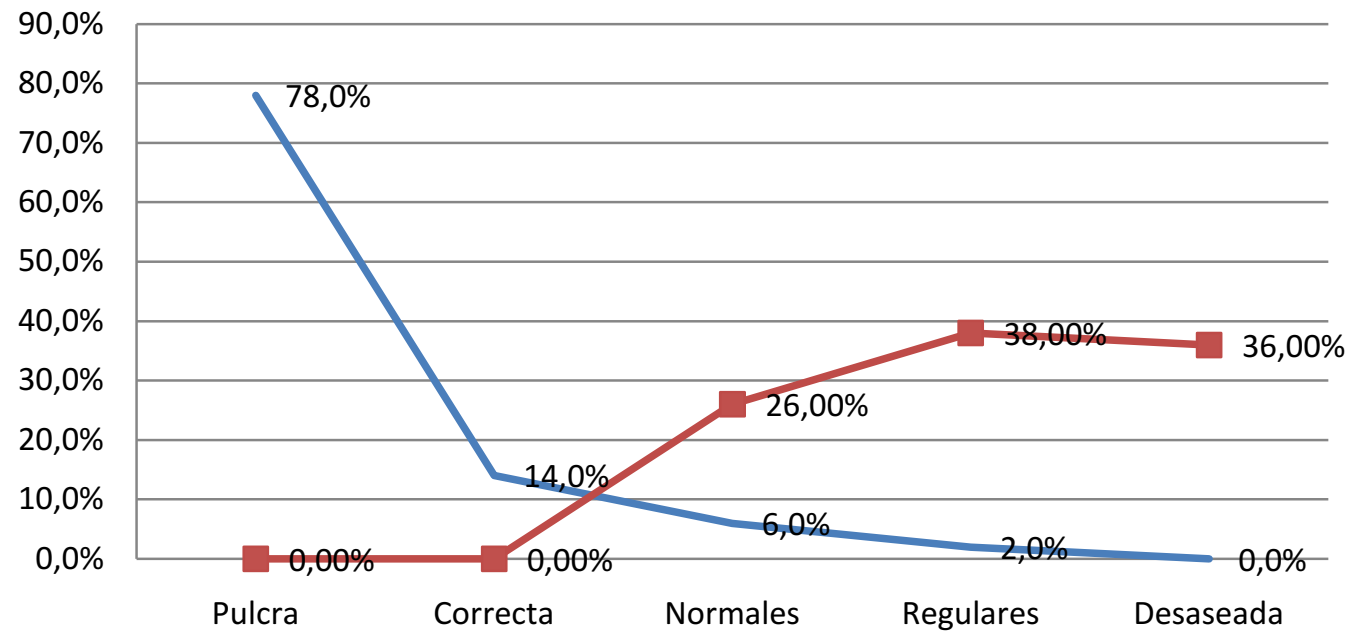

\section{Brecha apariencia visual de los elementos de comunicación}

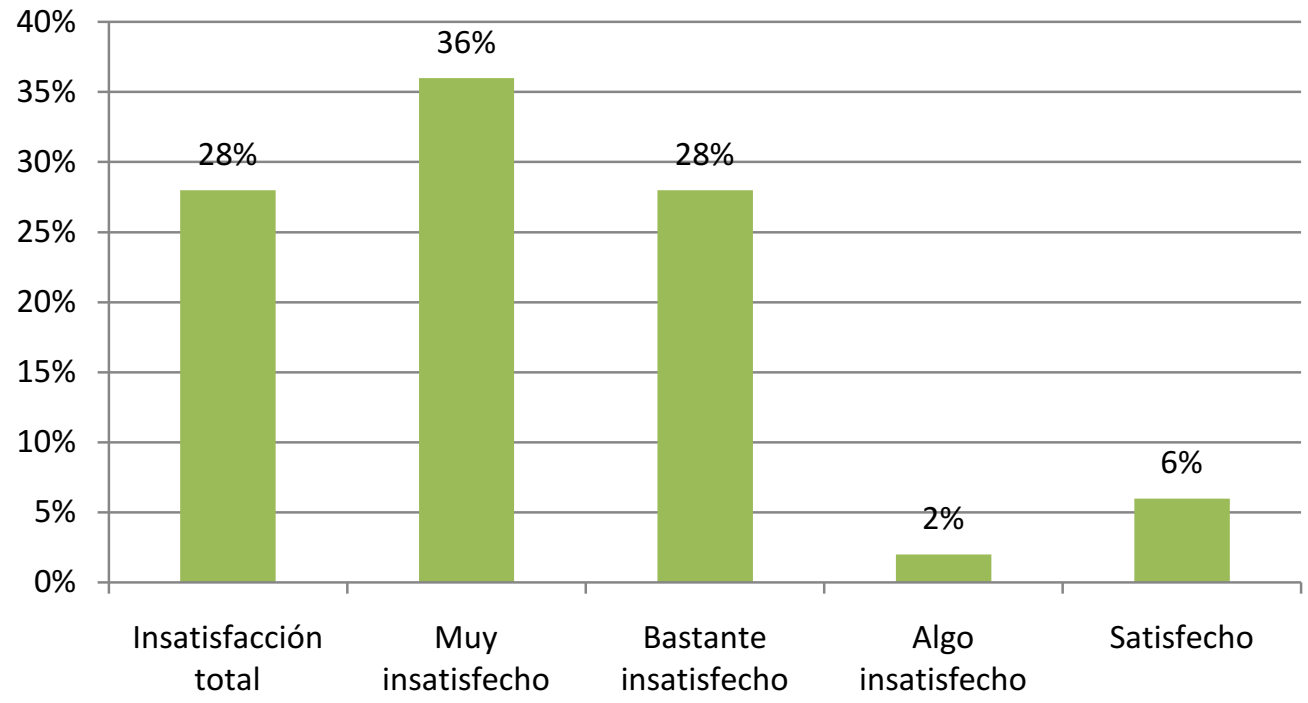


Saldo de Respuesta: -2,78 "Muy insatisfecho" con tendencia a "Bastante insatisfecho".

\subsection{Dimensión II: Confiabilidad: Habilidad para ejecutar el servicio prometido de forma confiable y cuidadosa}

En esta dimensión se obtuvieron resultados respecto del cumplimiento, el interés, la eficacia, el tiempo de cumplimiento y la eficiencia de los prestadores del servicio de Defensa del Consumidor.

\subsubsection{Los empleados del servicio municipal cumplen lo que prometen}

\subsubsection{Expectativa}

Los empleados del servicio municipal cumplen lo que prometen

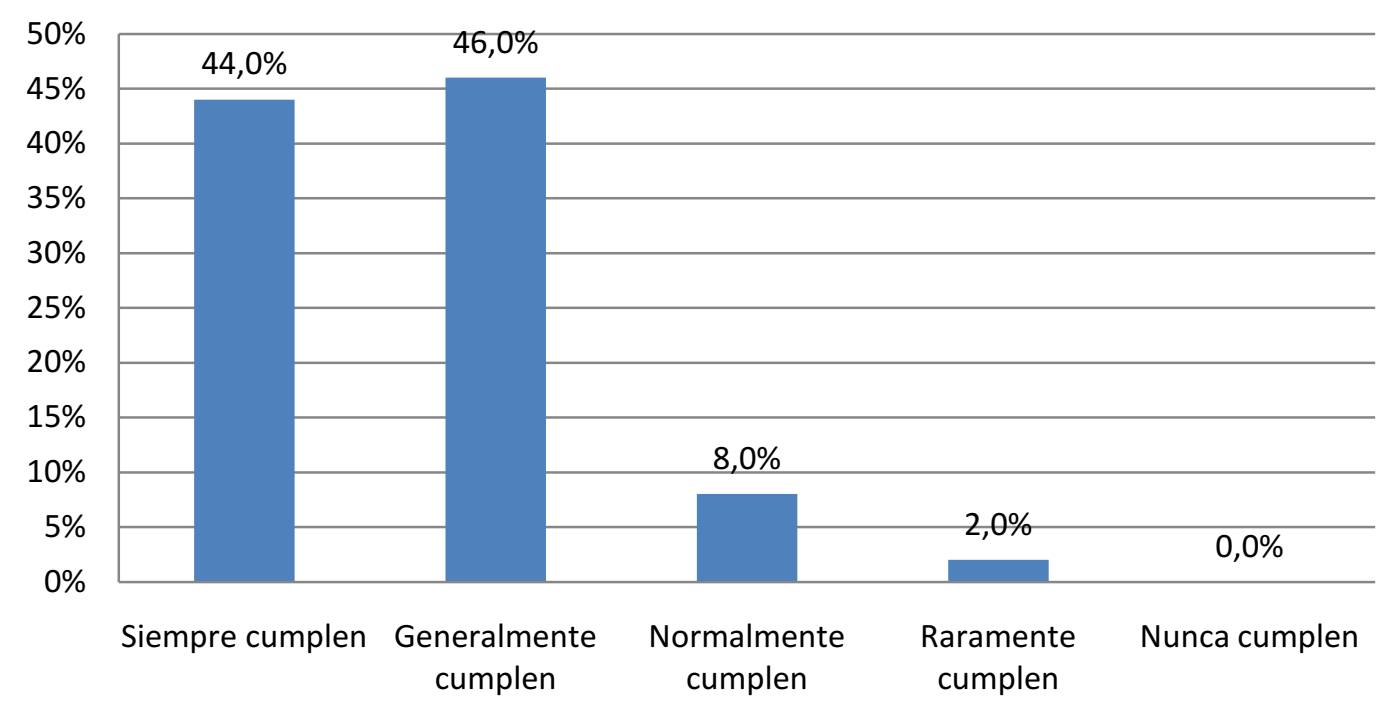

Saldo de Respuesta: 1,68 "Generalmente cumplen" a "Siempre cumplen". 


\subsubsection{Percepción}

\section{Los empleados del servicio municipal cumplen lo que prometen}

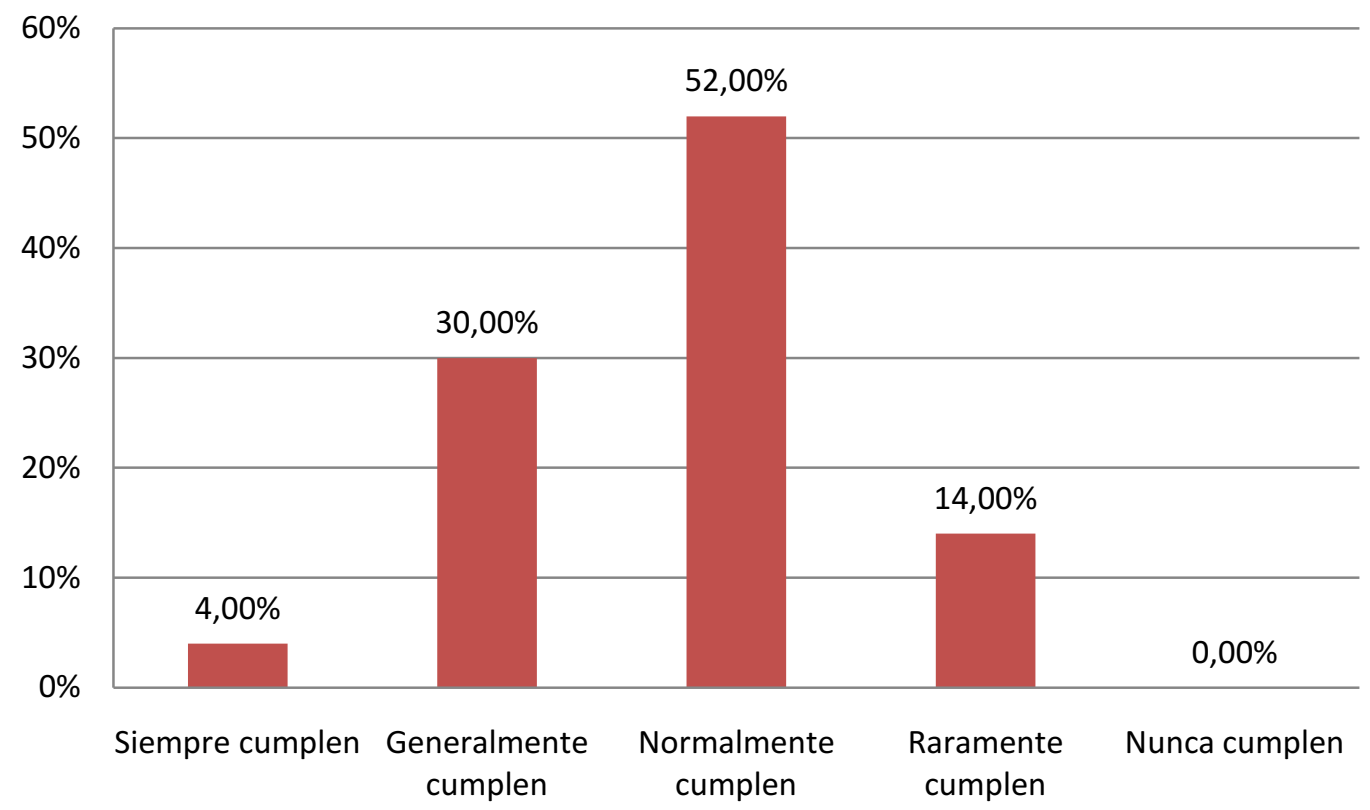

El Saldo de Respuesta en las opiniones de los usuarios es de 2,76, casi siempre los empleados municipales cumplen lo que prometen. 


\subsubsection{Brecha}

\section{Los empleados del servicio municipal cumplen lo que prometen}

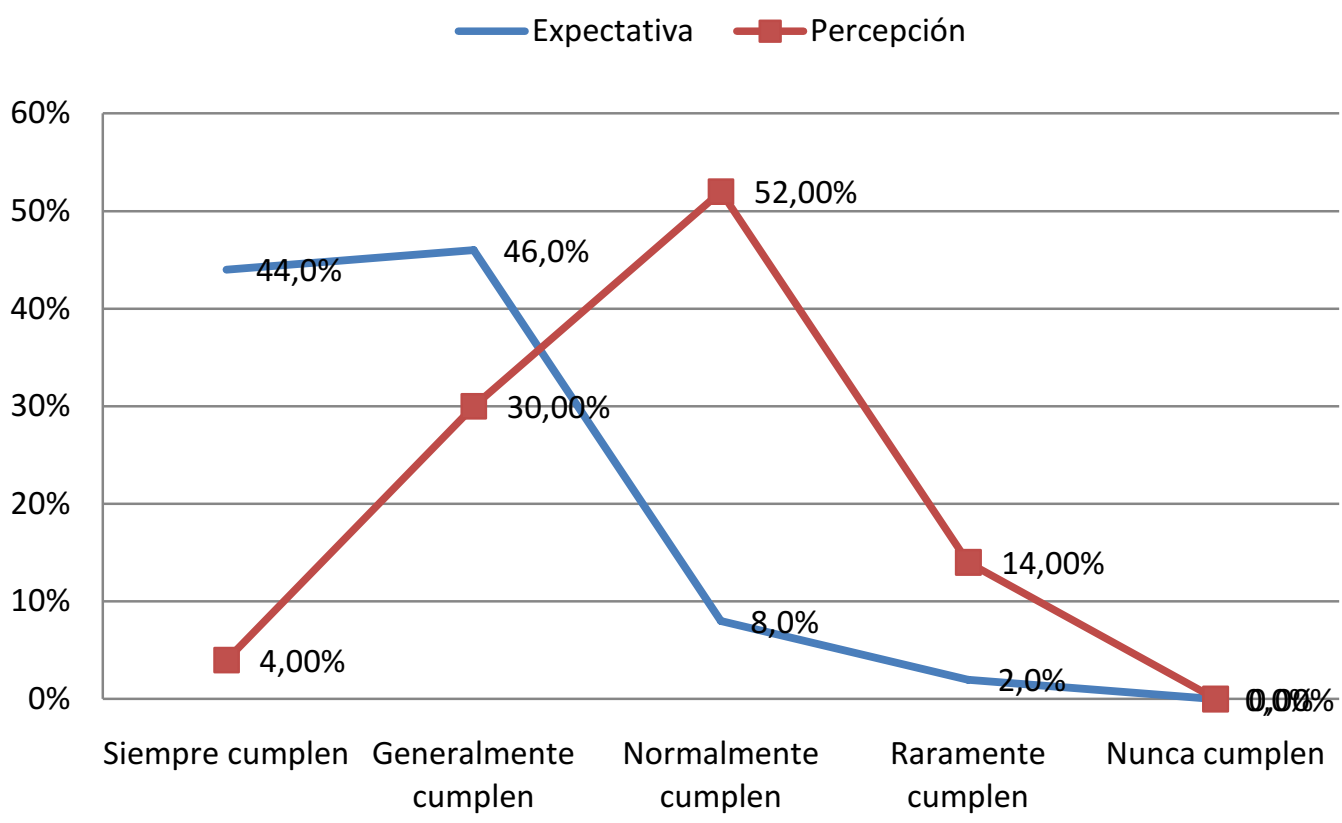

\section{Brecha empleados cumplen}

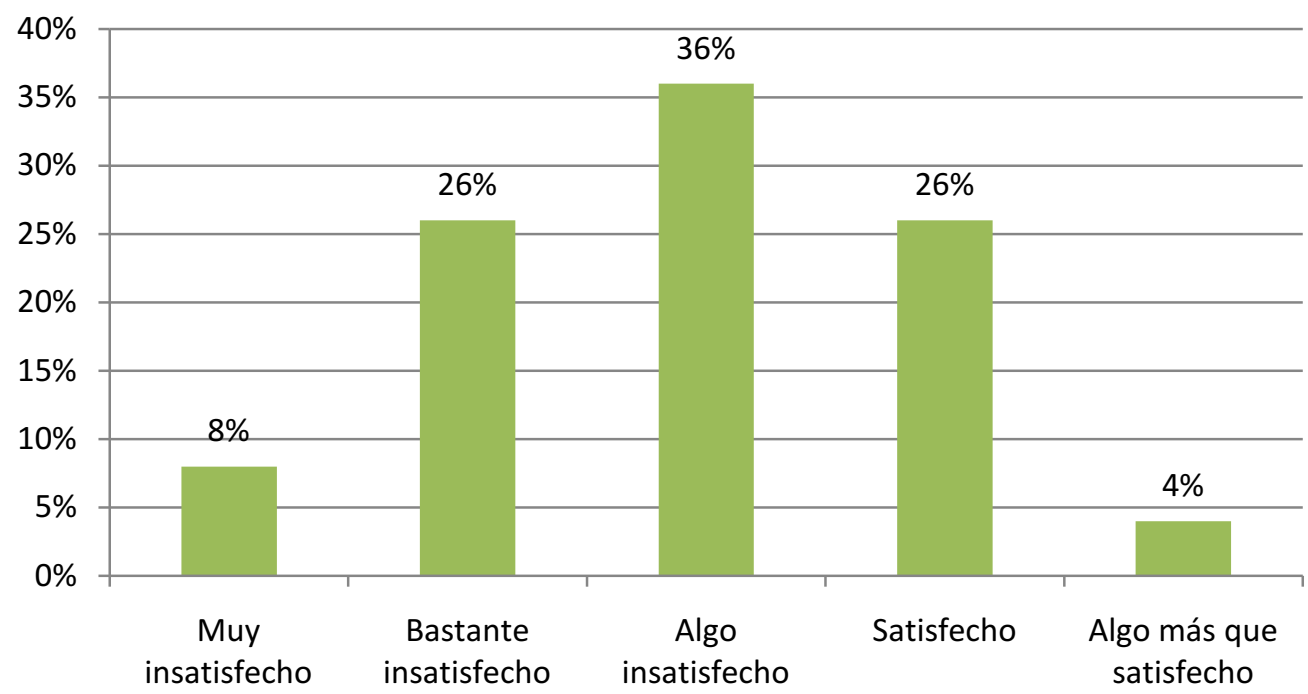

Saldo de Respuesta: -1,08 "Algo insatisfecho". 


\subsubsection{Interés que tienen los empleados del servicio municipal por} solucionar los problemas

\subsubsection{Expectativa}

Interés de los empleados del servicio en solucionar los problemas del cliente

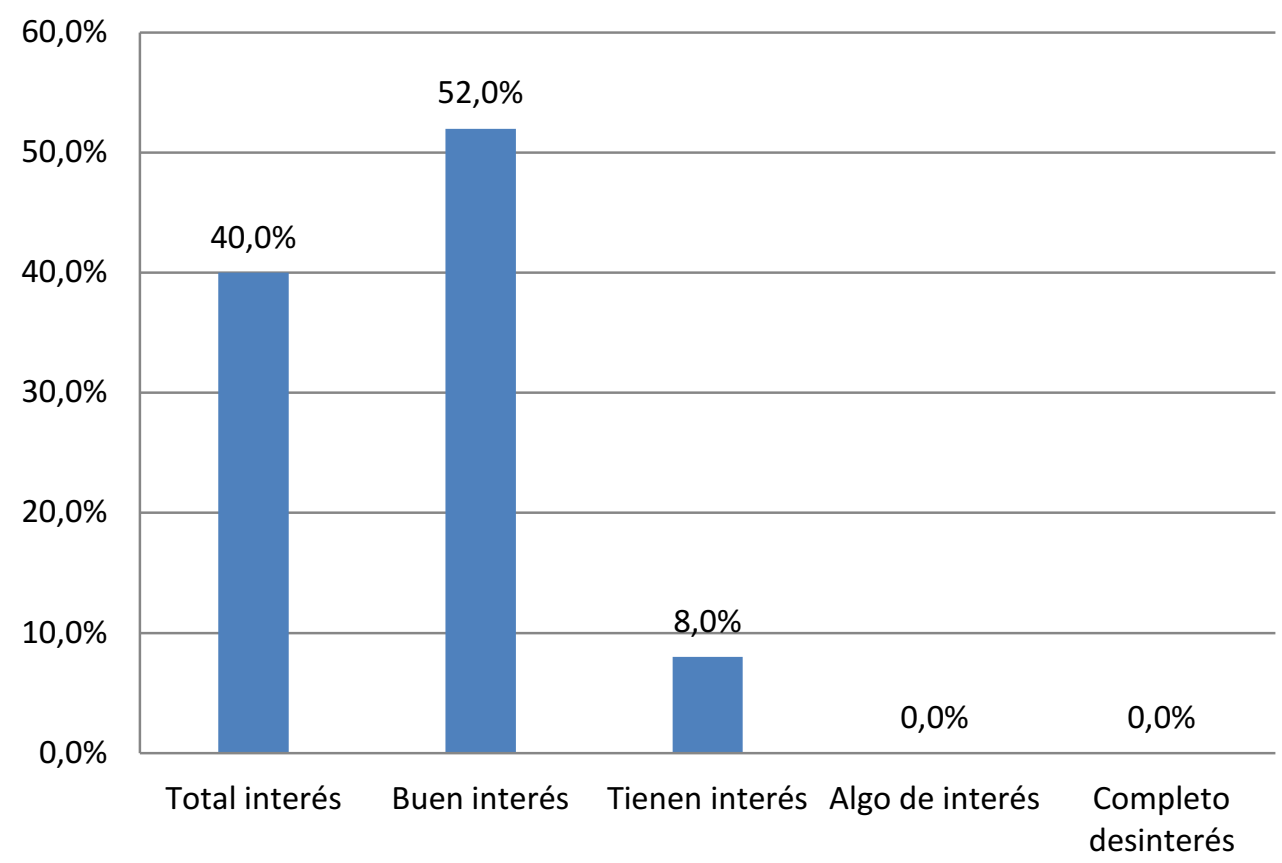

Saldo de Respuesta: 1,68 "Buen interés" a "Total interés". 


\subsubsection{Percepción}

\section{Interés de los empleados del servicio en solucionar los problemas del cliente}

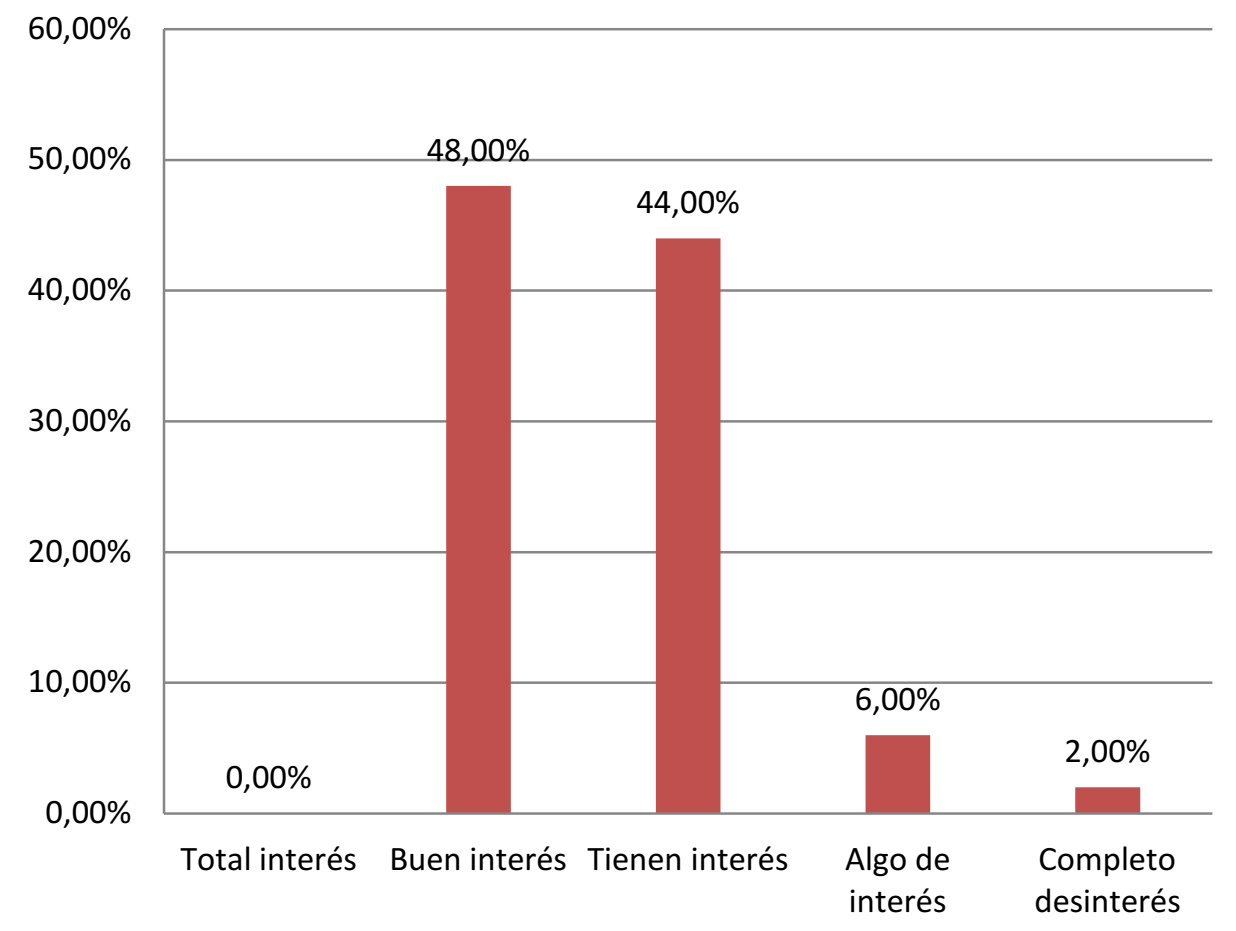

Los usuarios sienten que los empleados tienen un buen interés en solucionar sus problemas, con un Saldo de Respuesta de 2,62. 


\subsubsection{Brecha}

\section{Interés de los empleados del servicio en solucionar los problemas del cliente}

Expectativa Percepción

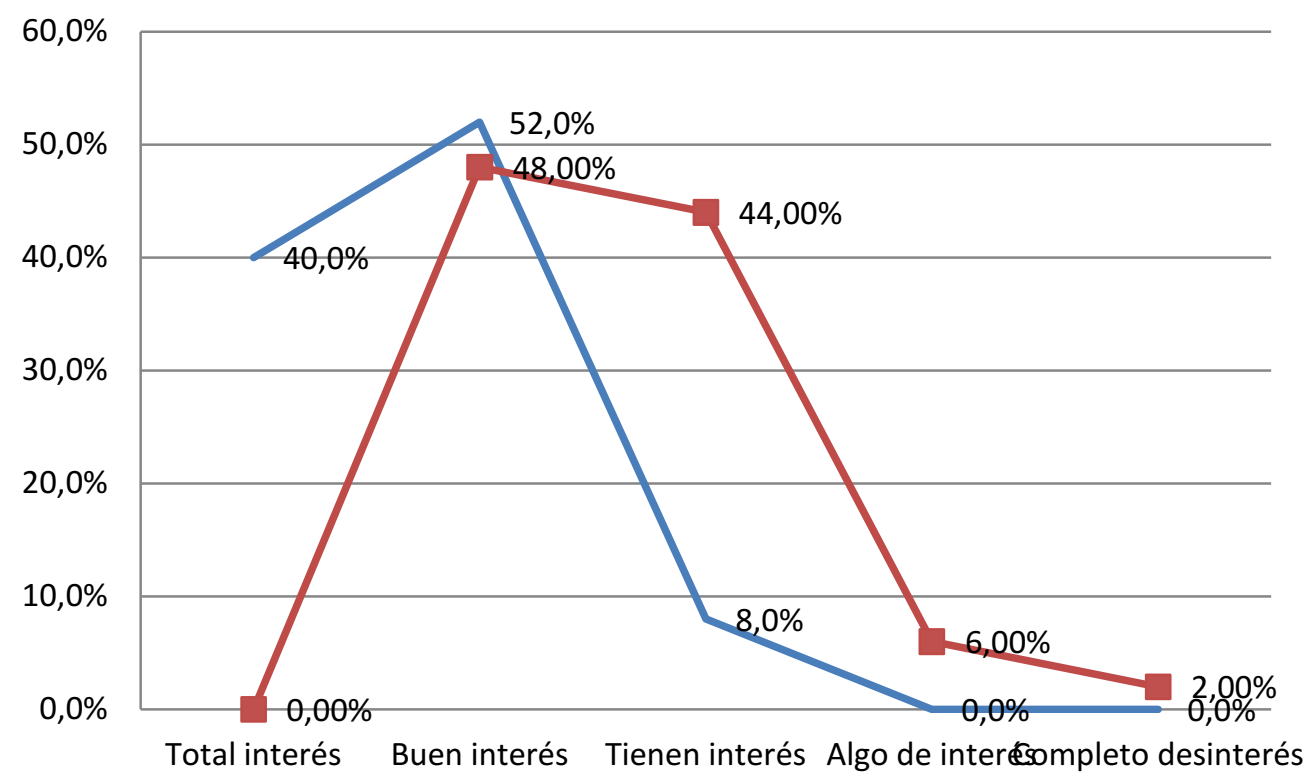

Brecha interés de empleados

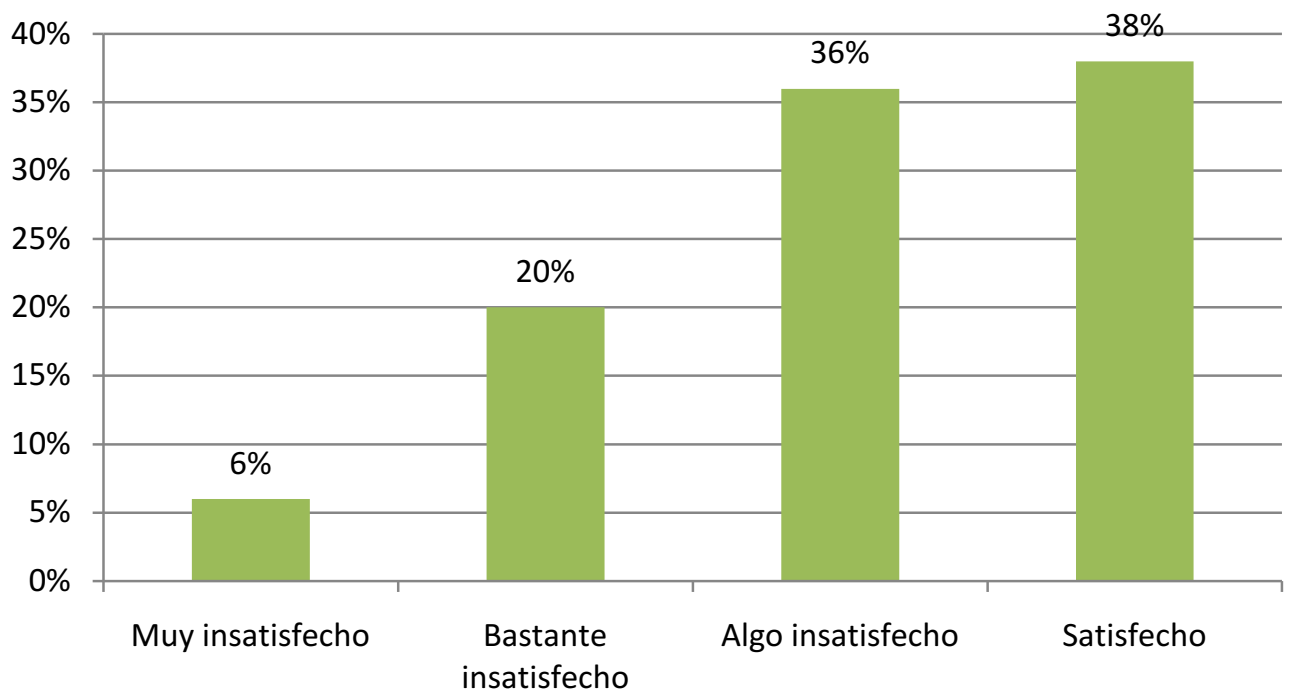

Saldo de Respuesta: -0,94 "Algo insatisfecho". 


\subsubsection{Eficacia del servicio de Defensa del Consumidor}

\subsubsection{Expectativa}

\section{Eficacia del servicio municipal}

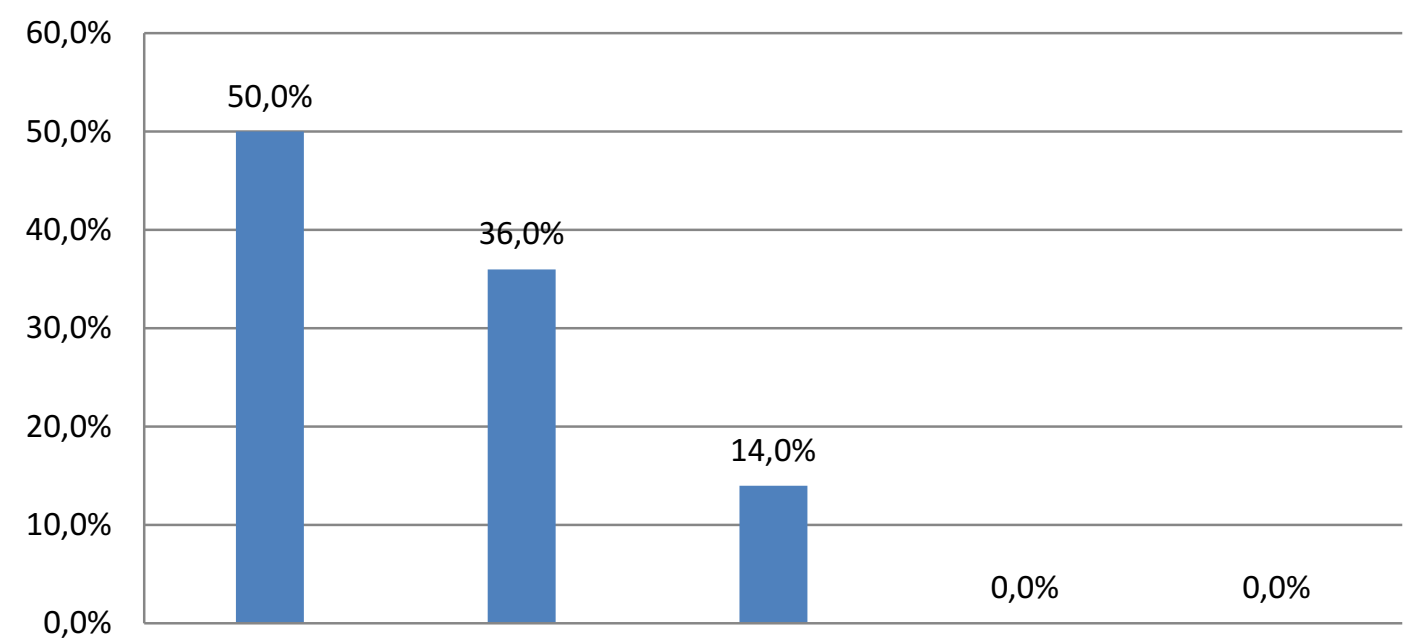

Realiza el trabajo bierRaranez se equilowcaalmente lo hAlgembisereces lo haceN bonera lo hacen bien

Saldo de Respuesta: 1,64 "Rara vez se equivocan" a "Realiza el trabajo bien $1^{\circ}$ vez". 


\subsubsection{Percepción}

\section{Eficacia del servicio municipal}

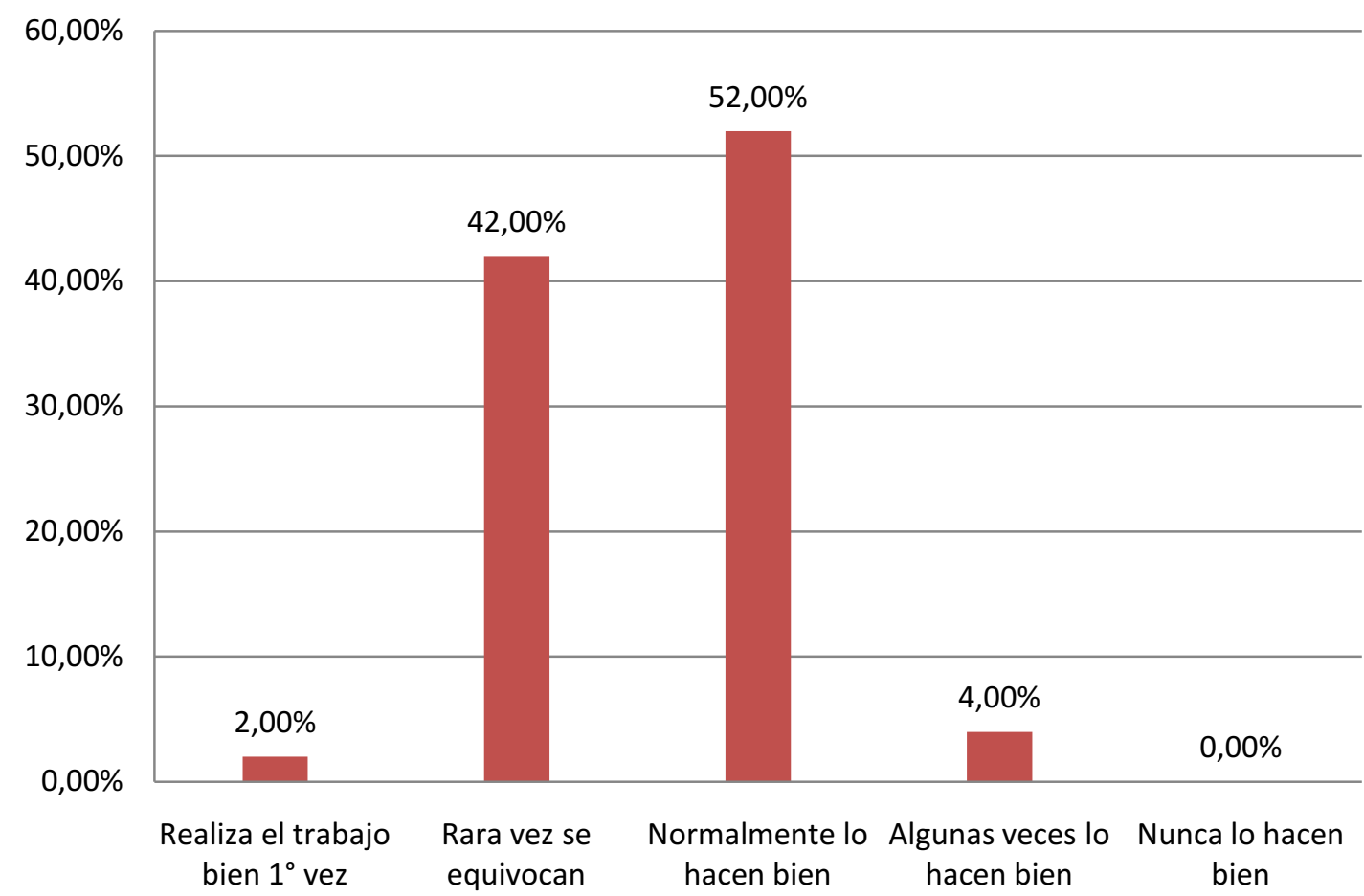

En la eficacia percibida en el servicio es positiva, con un Saldo de Respuesta de 2,58 . 


\subsubsection{Brecha}

\section{Eficacia del servicio municipal}

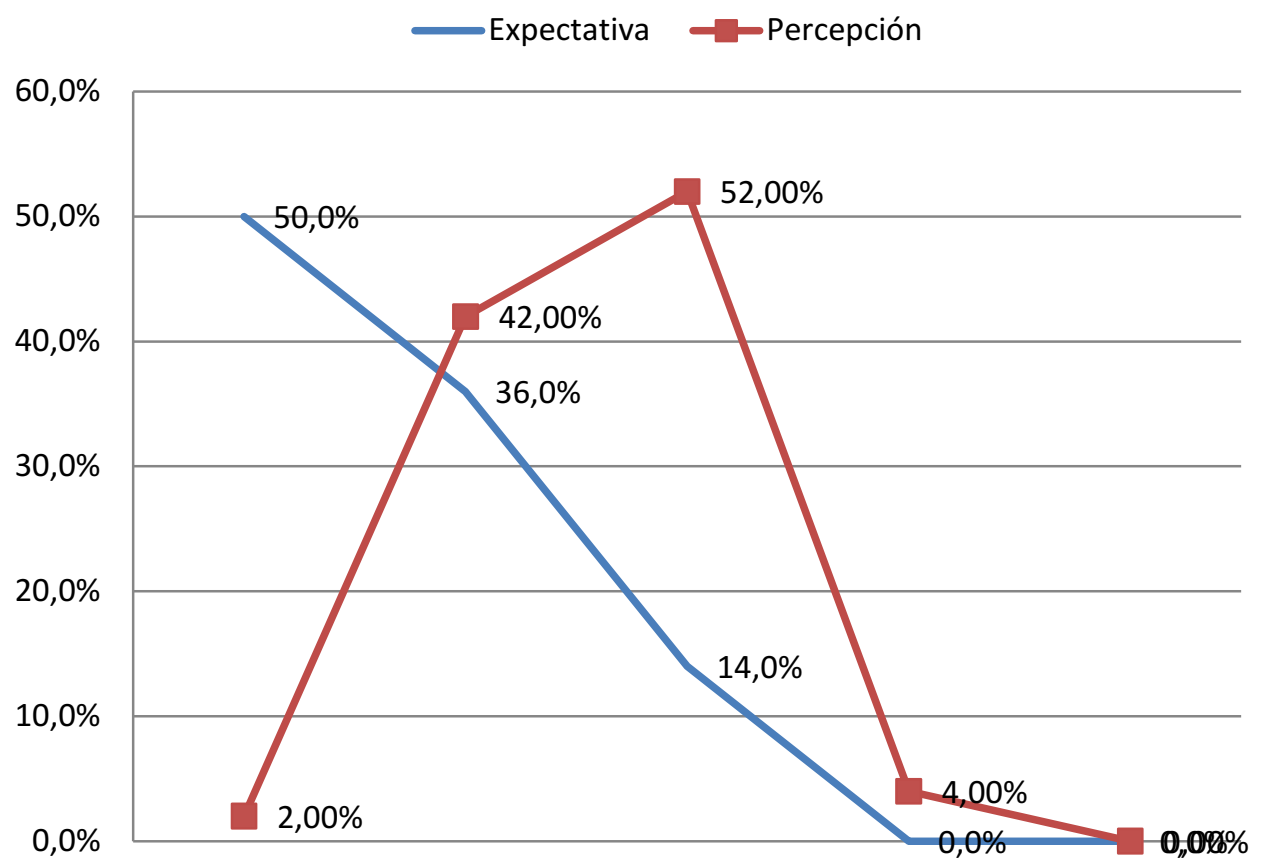

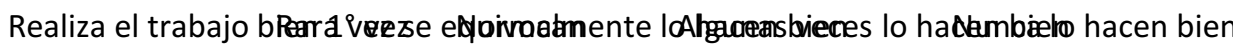

\section{Brecha eficacia}

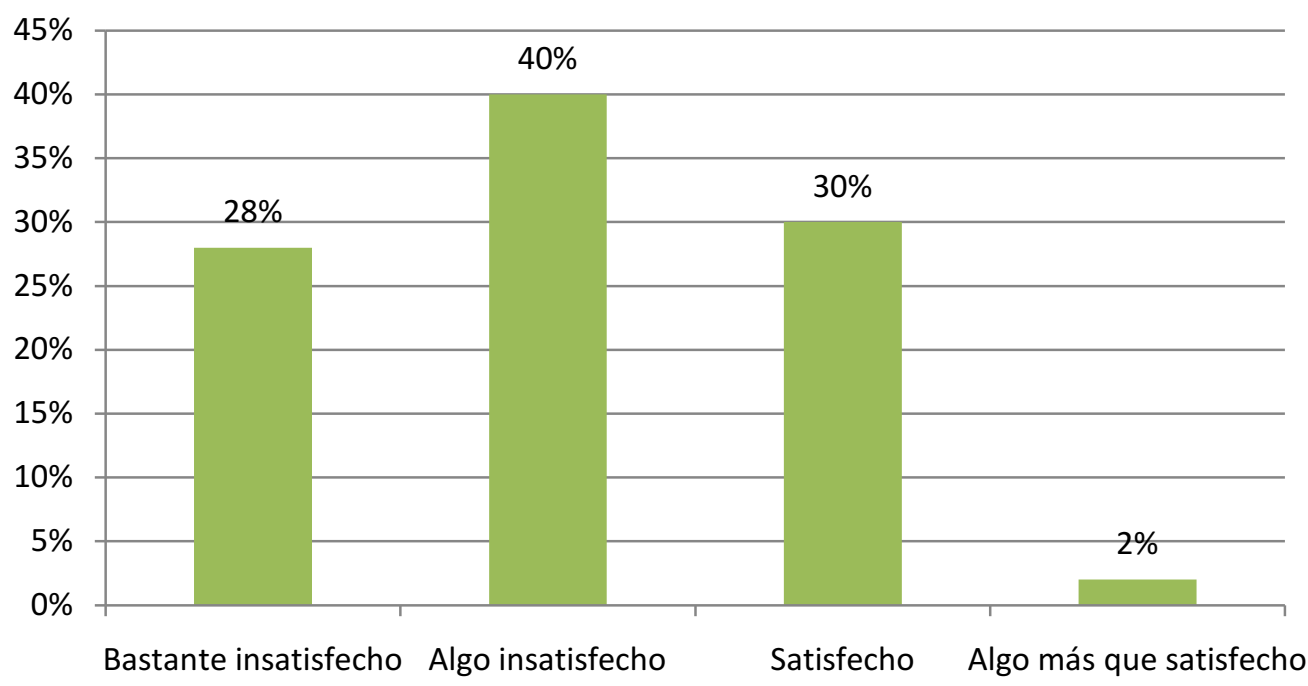

Saldo de Respuesta: -0,94 "Algo insatisfecho". 


\subsubsection{Tiempo de cumplimiento del trabajo}

\subsubsection{Expectativa}

\section{Tiempo de cumplimiento del trabajo}

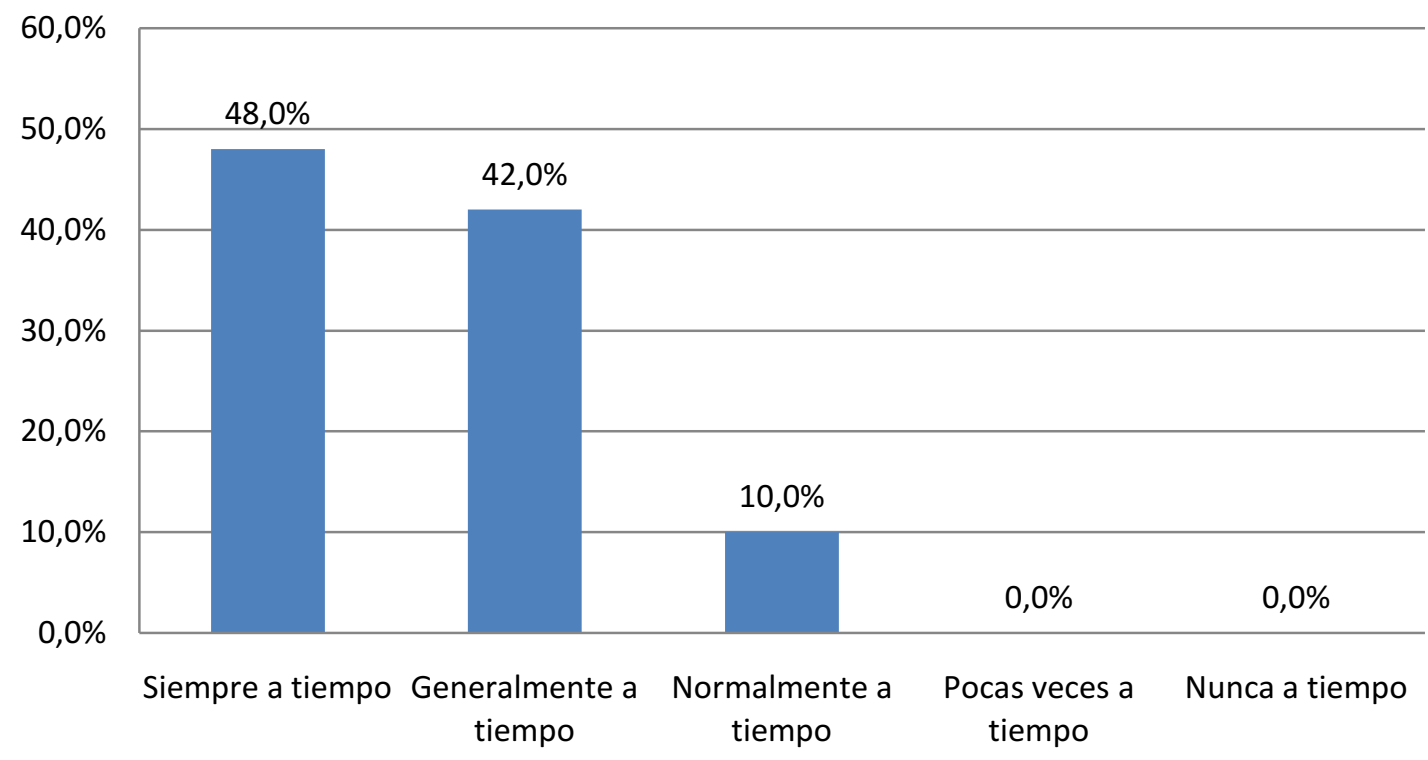

Saldo de Respuesta: 1,62 "Generalmente a tiempo" a "Siempre a tiempo". 


\subsubsection{Percepción}

Tiempo de cumplimiento del trabajo

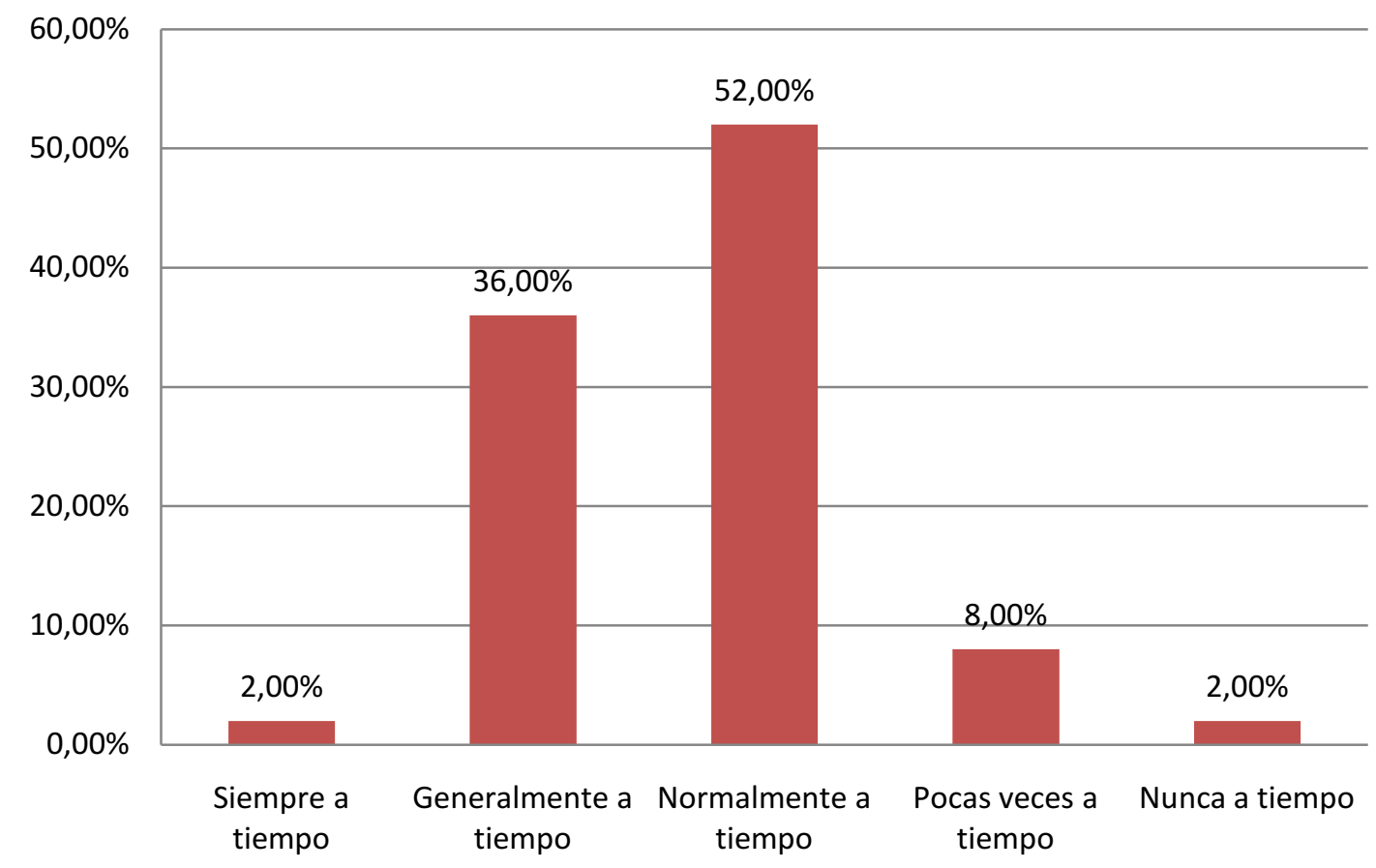

El tiempo de cumplimiento de trabajo tiene una buena calificación entre los usuarios del servicio de Defensa del Consumidor, con un Saldo de Respuesta de 2,72 . 


\subsubsection{Brecha}

Tiempo de cumplimiento del trabajo

Expectativa $\longrightarrow$ Percepción

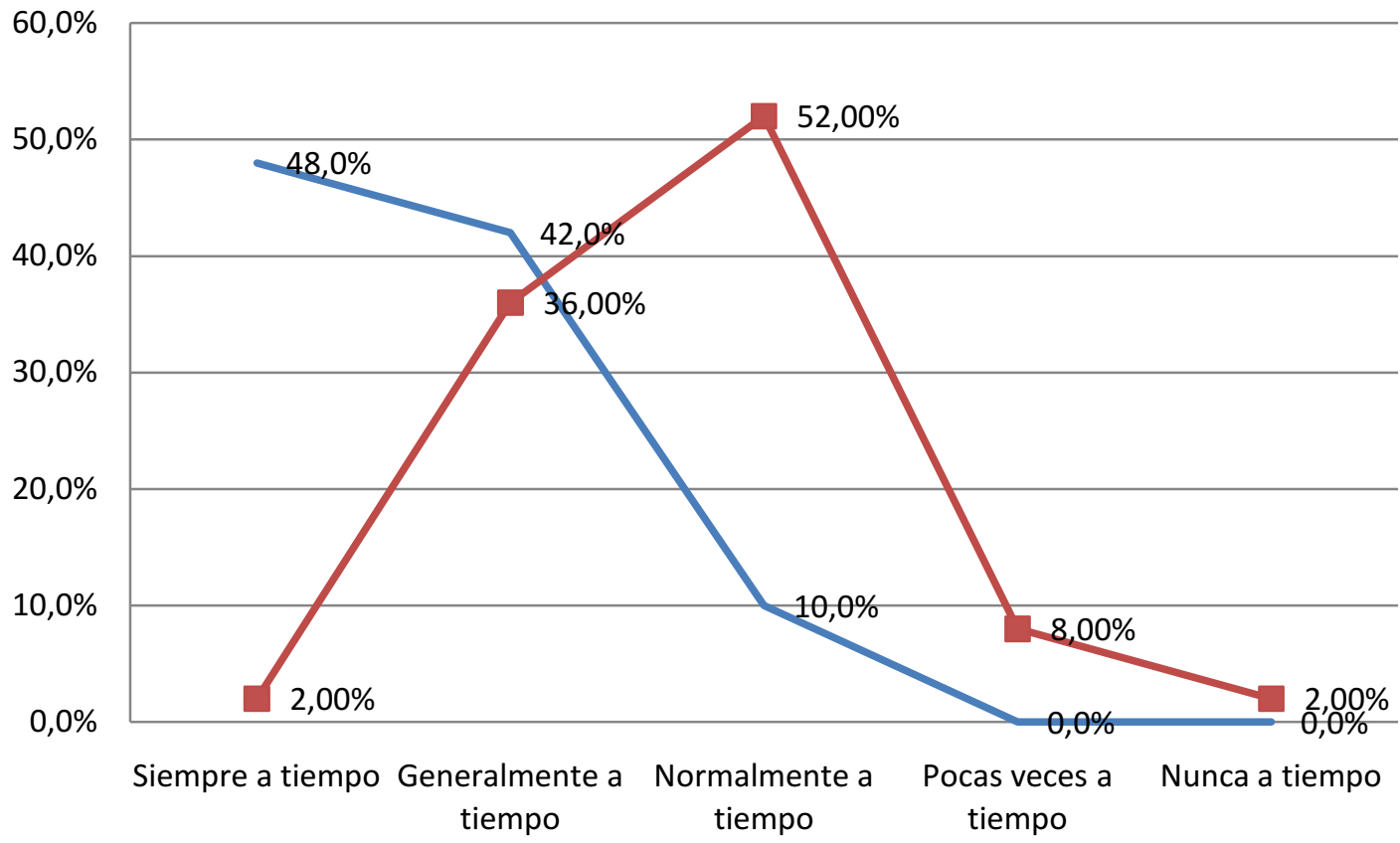

\section{Brecha tiempo de cumplimiento}

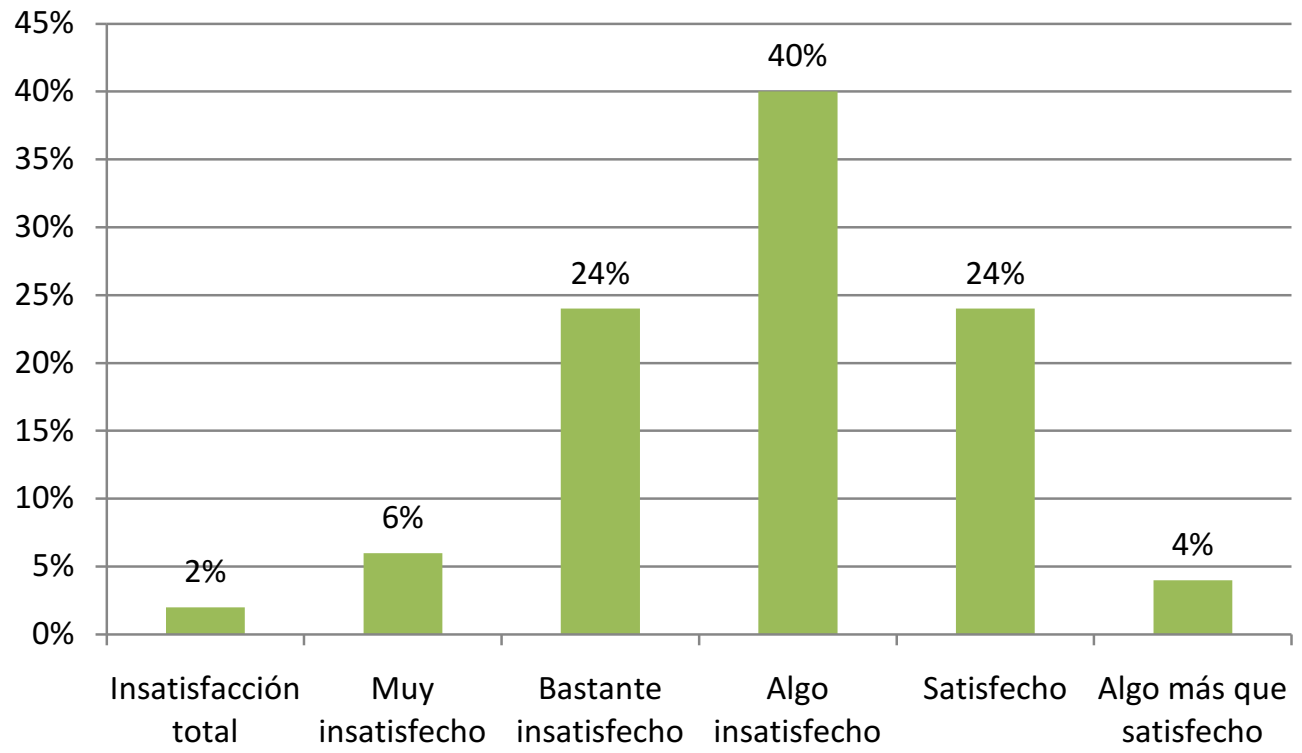

Saldo de Respuesta: $-1,10$ "Algo insatisfecho". 


\subsubsection{Eficiencia del trabajo del servicio de Defensa del Consumidor}

\subsubsection{Expectativa}

\section{Eficiencia del servicio municipal}

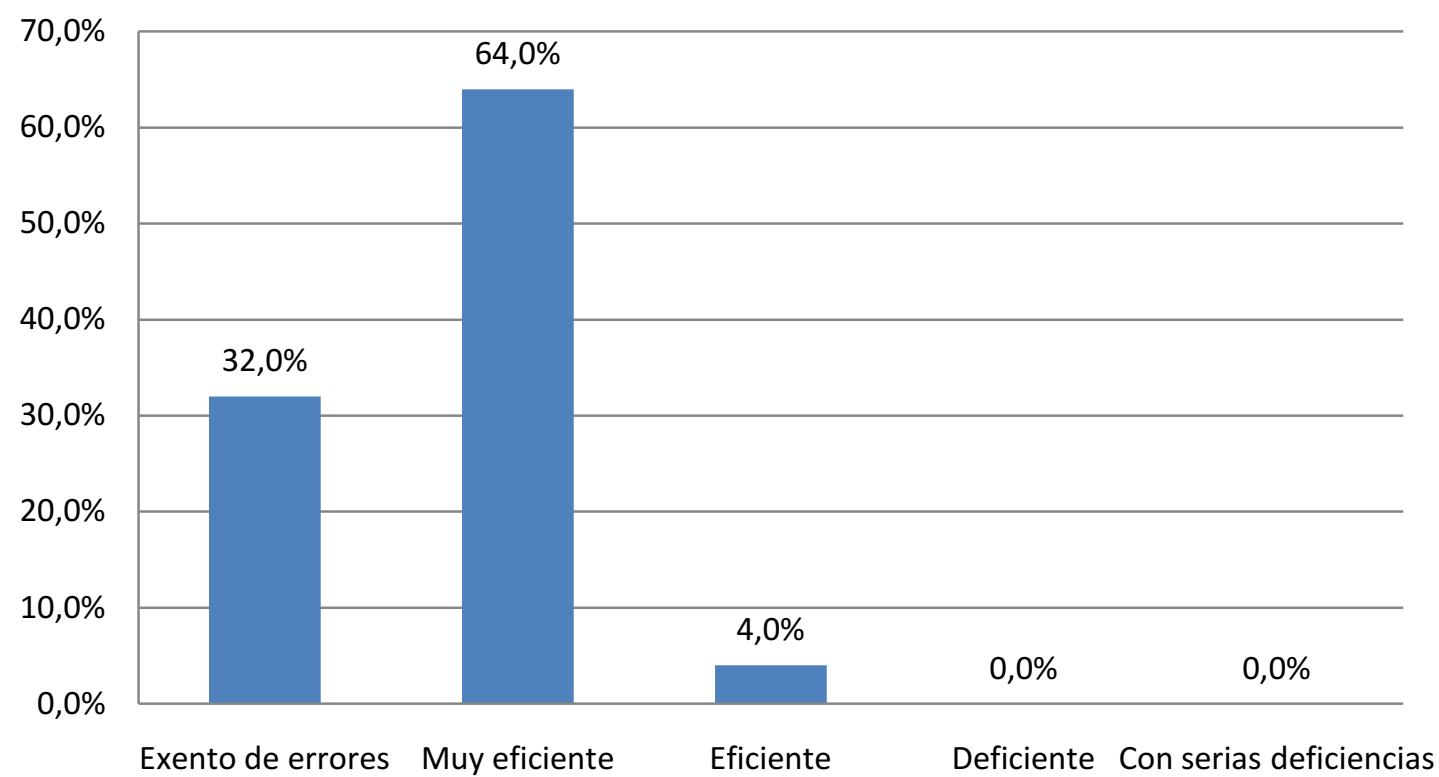

Saldo de Respuesta: 1,72 "Muy eficiente" con tendencia a "Exento de errores". 


\subsubsection{Percepción}

Eficiencia del servicio municipal

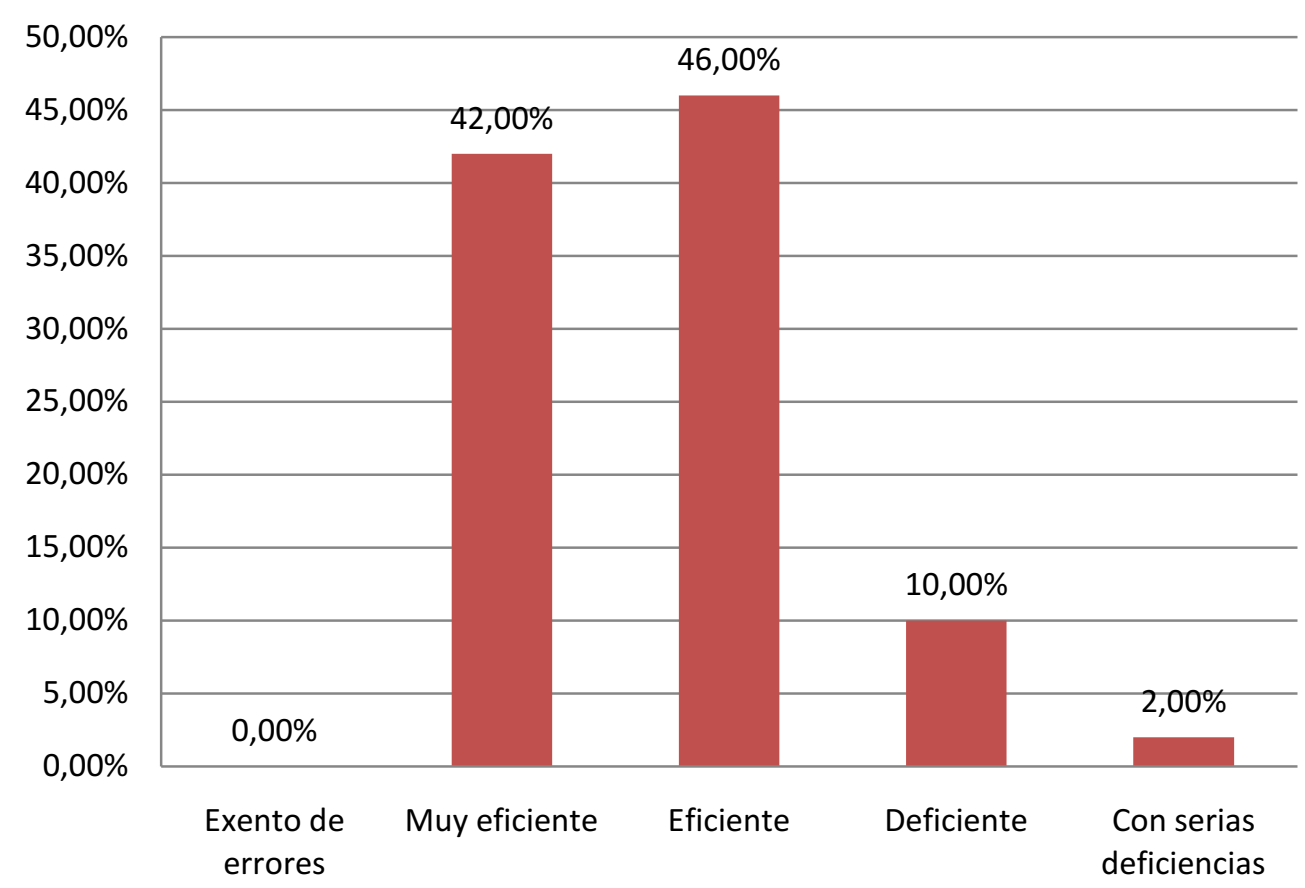

La puntuación según el Saldo de Respuesta fue de 2,72 lo que la ubica como eficiente con una tendencia a muy eficiente.

\subsubsection{Brecha}

A continuación se exponen los resultados de indicadores de eficiencia, comparando las expectativas y las percepciones relevadas una vez utilizado el servicio: 


\section{Eficiencia del servicio municipal}

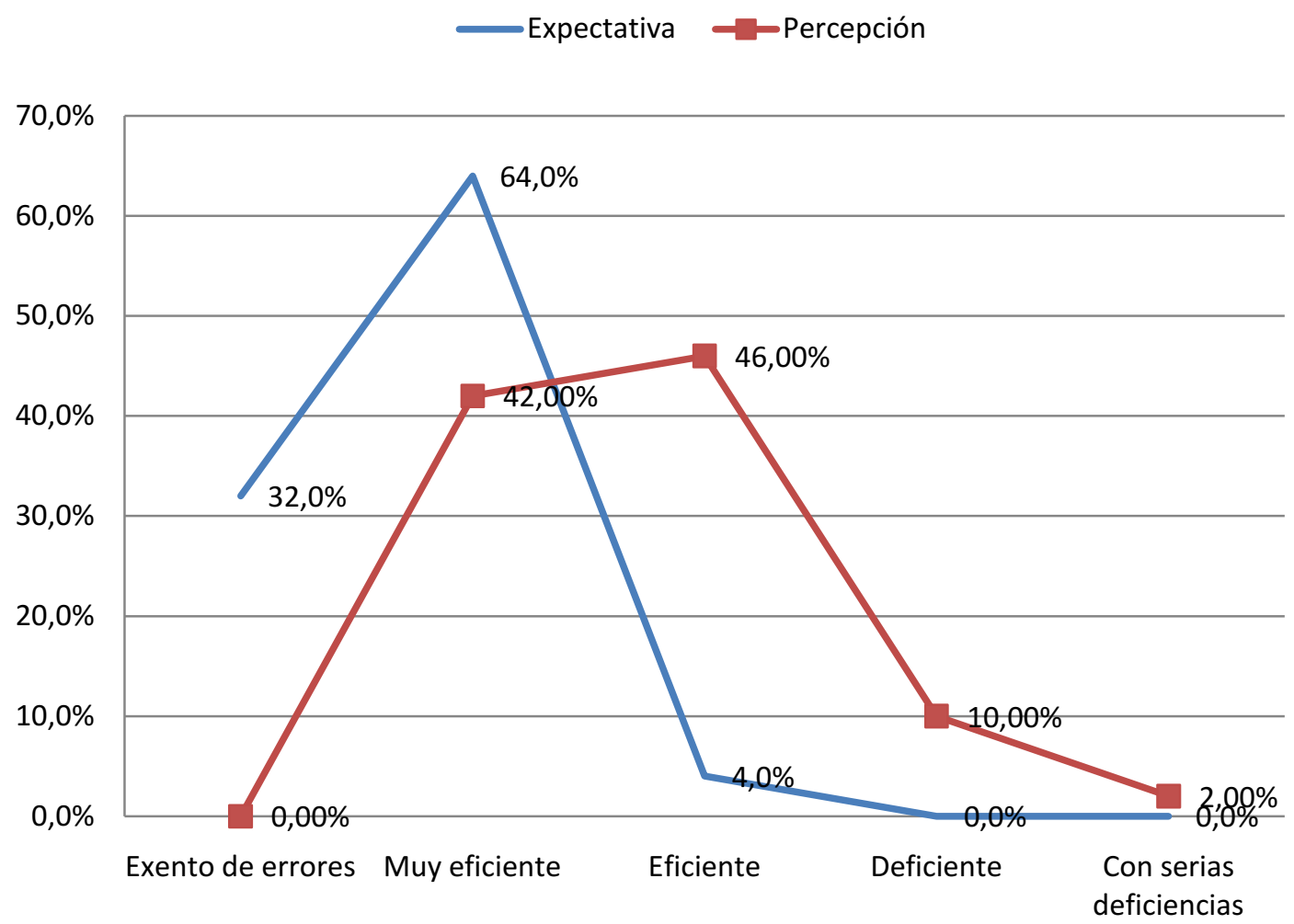

\section{Brecha eficiencia}

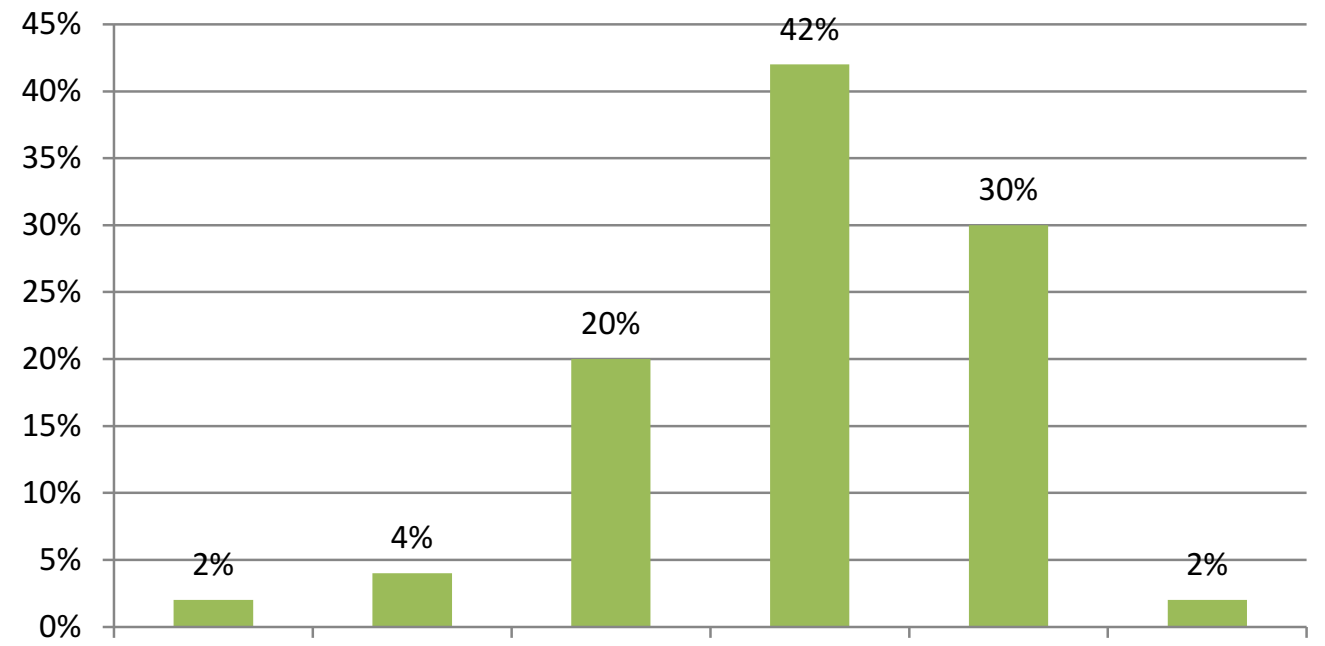

Insatisfacción tæaly insatisfBabtante insatisfakgøinsatisfecho SatisfecAlgo más que satisfecho

Saldo de Respuesta: -1,00 "Algo insatisfecho". 
7.4 Dimensión III: Capacidad de Respuesta - Disposición de los empleados para ayudar al cliente y proporcionar el servicio.

A continuación se incorporan los resultados del nivel de comunicación, la velocidad de servicio, la disponibilidad de atención, y, por último, el grado de disponibilidad frente a otras actividades.

\subsubsection{Nivel de comunicación con los empleados}

\subsubsection{Expectativa}

Nivel de comunicación con los empleados del servicio municipal

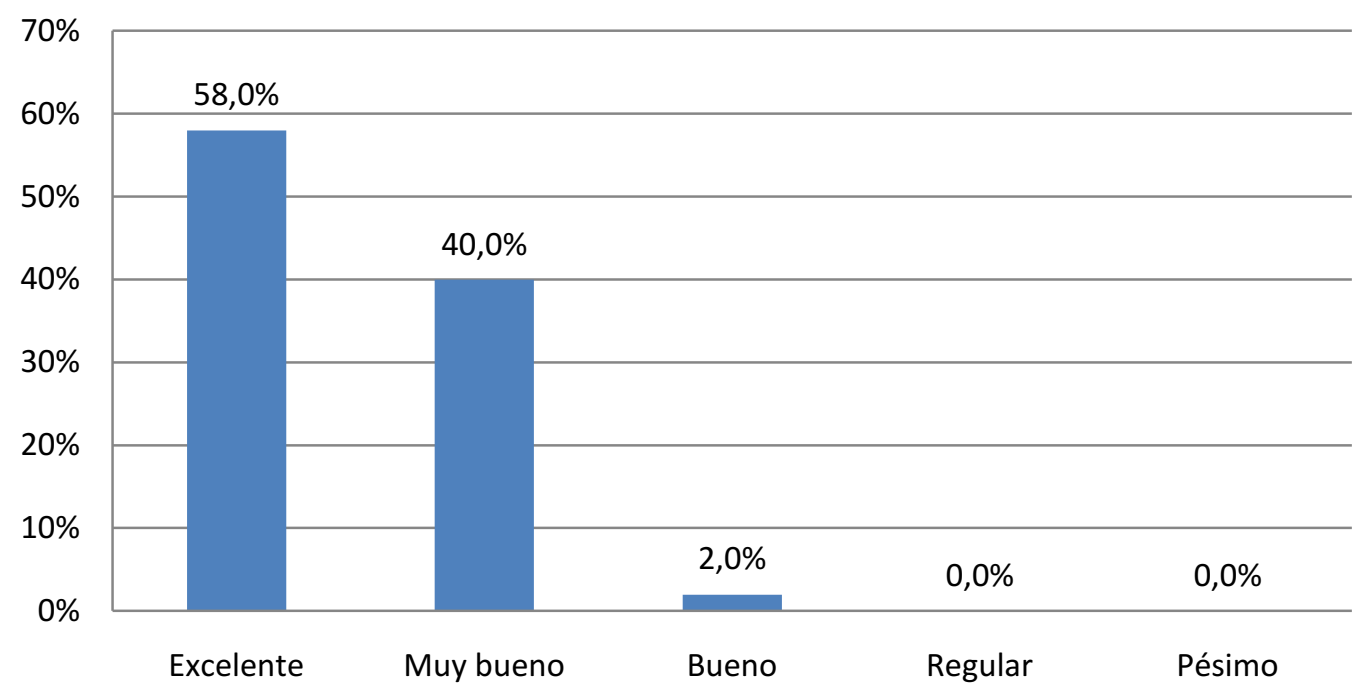

Saldo de Respuesta: 1,44 "Excelente" a "Muy bueno". 


\subsubsection{Percepción}

\section{Nivel de comunicación con los empleados del servicio municipal}

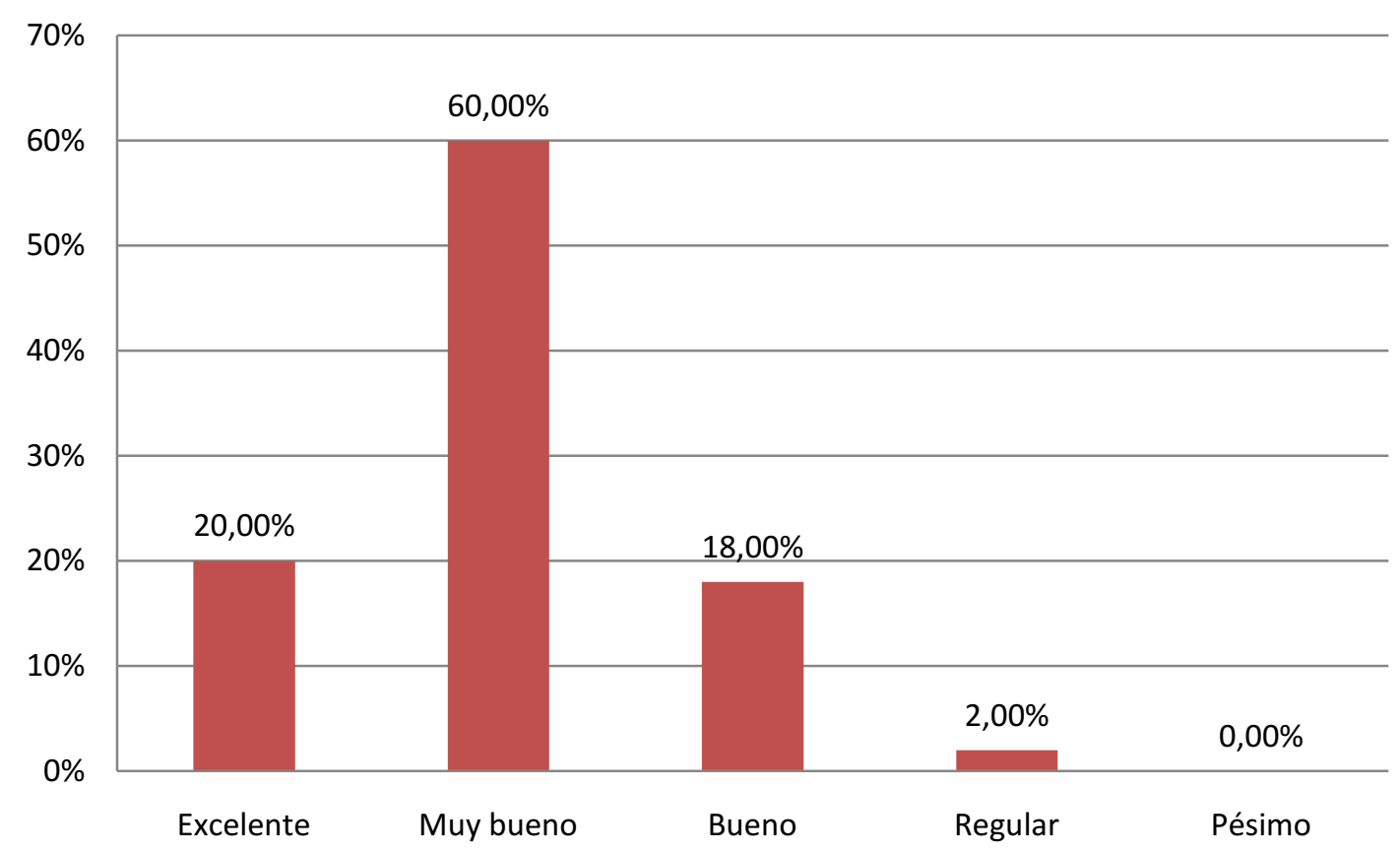

Los usuarios le asignaron una alta calificación a la comunicación con los empleados, obteniendo un Saldo de Respuesta de 2,02. 


\subsubsection{Brecha}

\section{Nivel de comunicación con los empleados del servicio municipal}

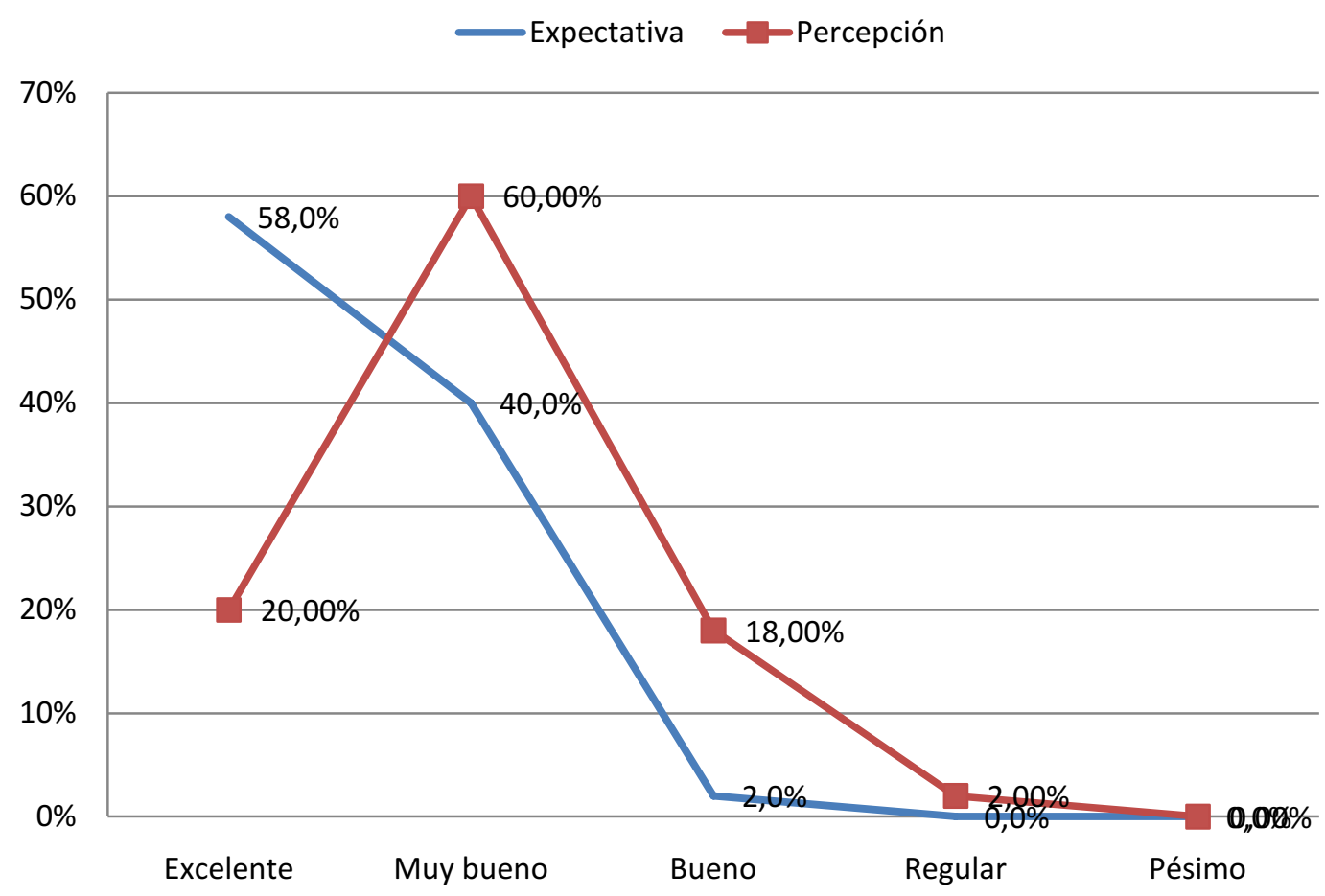

\section{Brecha nivel de comunicación}

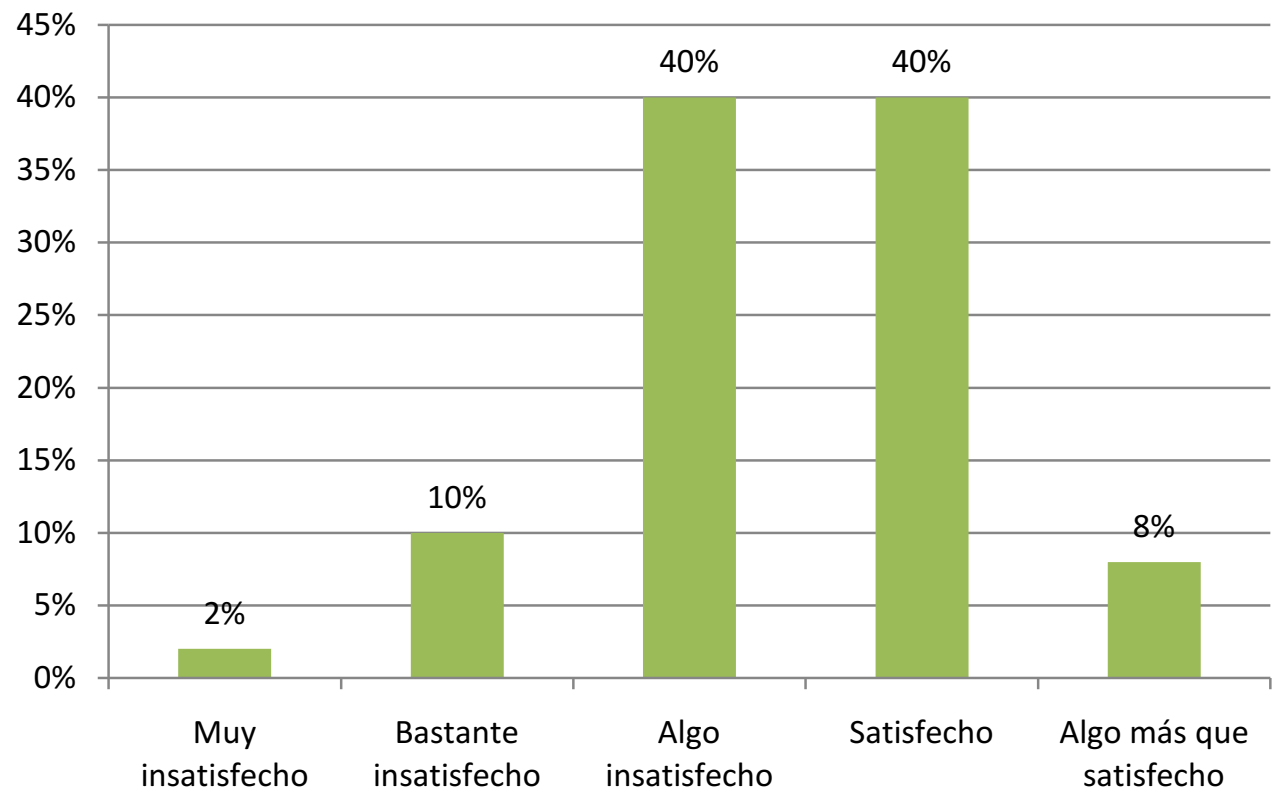

Saldo de Respuesta: -0,58 "Algo insatisfecho" a "Satisfecho". 


\subsubsection{Velocidad del servicio}

\subsubsection{Expectativa}

\section{Velocidad del servicio}

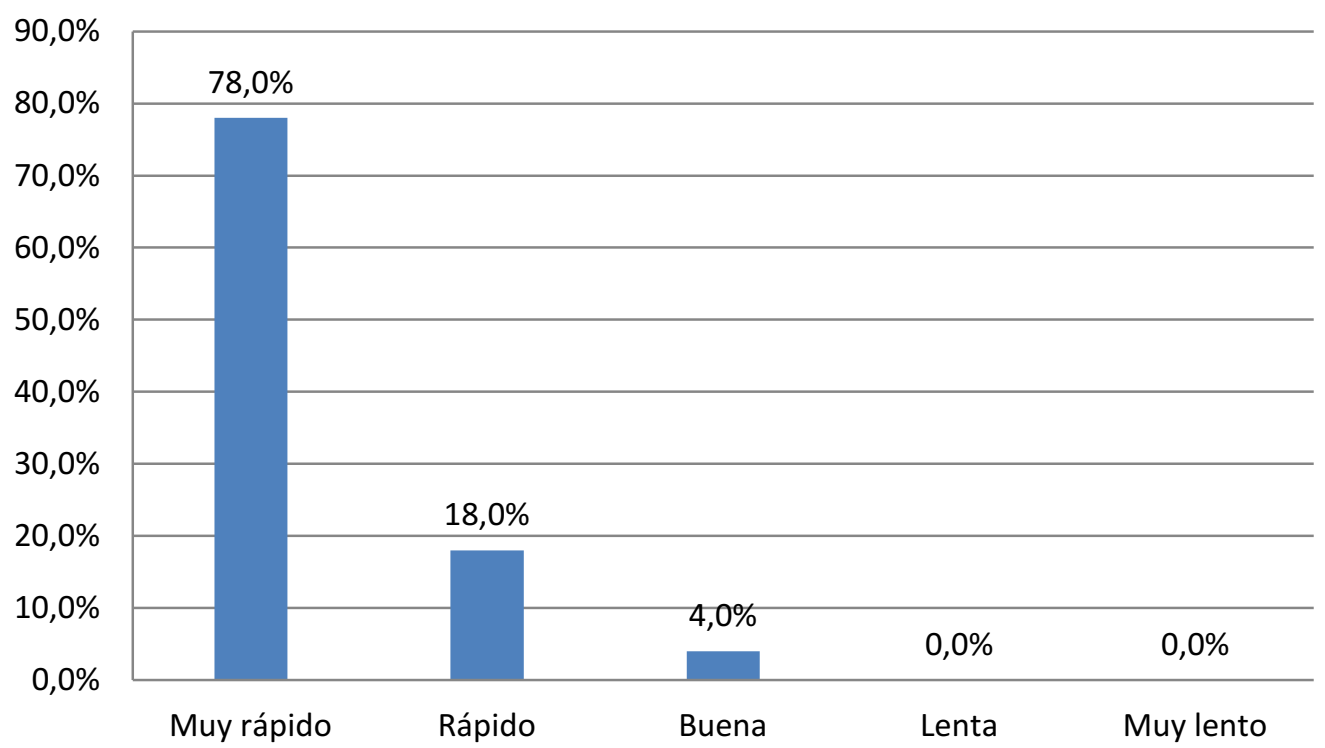

Saldo de Respuesta: 1,26 "Muy Rápido" con tendencia a "Rápido".

\subsubsection{Percepción}

\section{Velocidad del servicio}

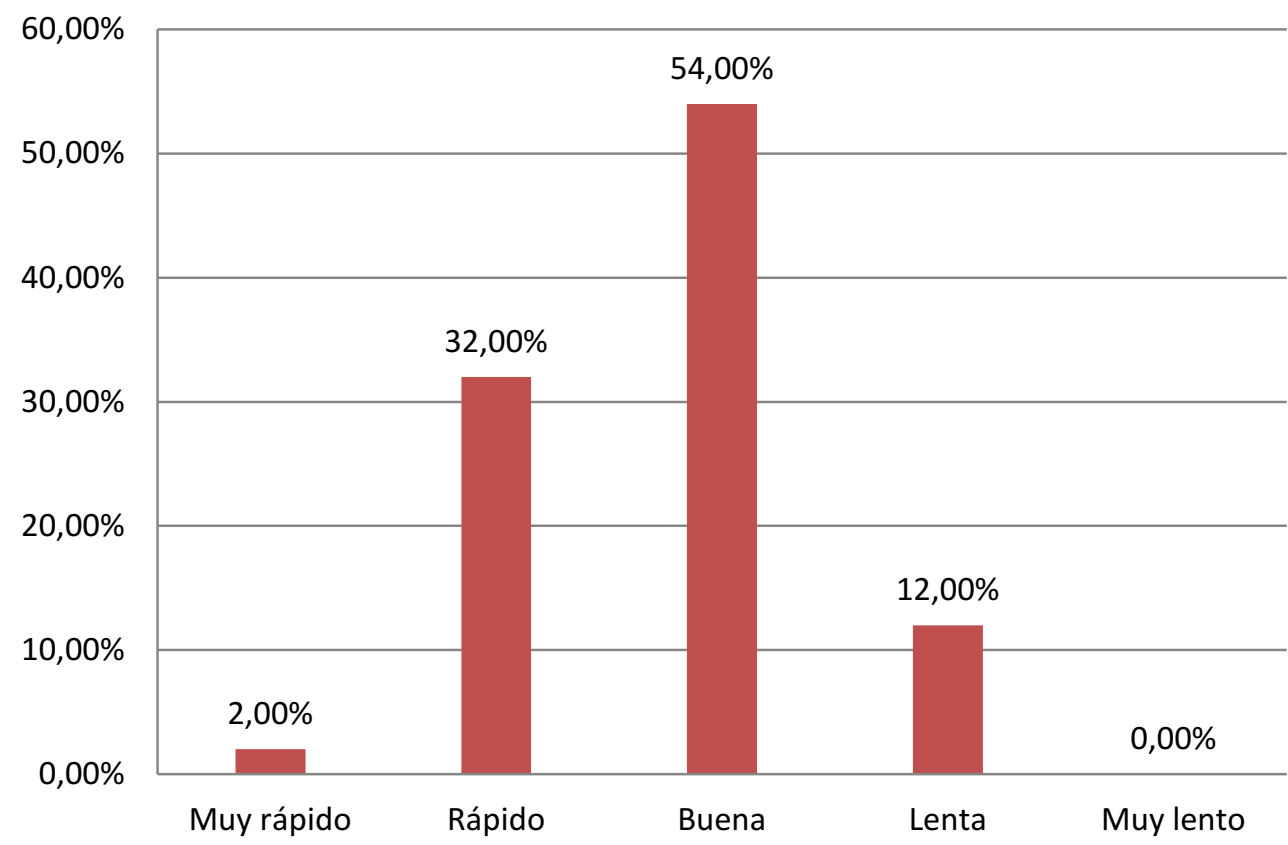


Como sucedió con el nivel de comunicación con los empleados, los usuarios calificaron a la velocidad del servicio con un Saldo de Respuesta de 2,76 lo que implica que es Buena con una leve tendencia a Rápida.

\subsubsection{Brecha}

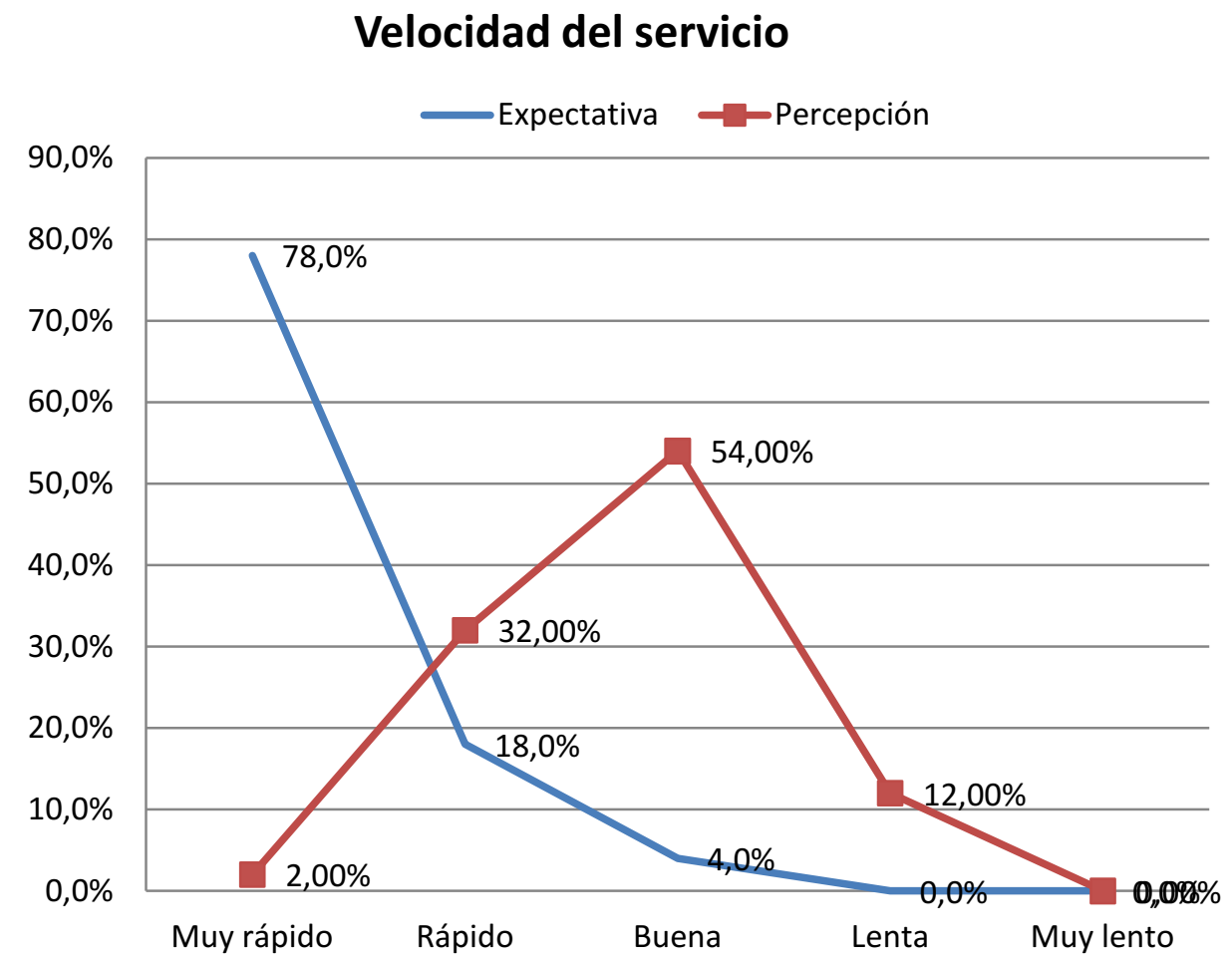

A efectos de poder observar la satisfacción de las percepciones respecto de las expectativas que traían los clientes se presenta el gráfico siguiente: 


\section{Brecha velocidad}

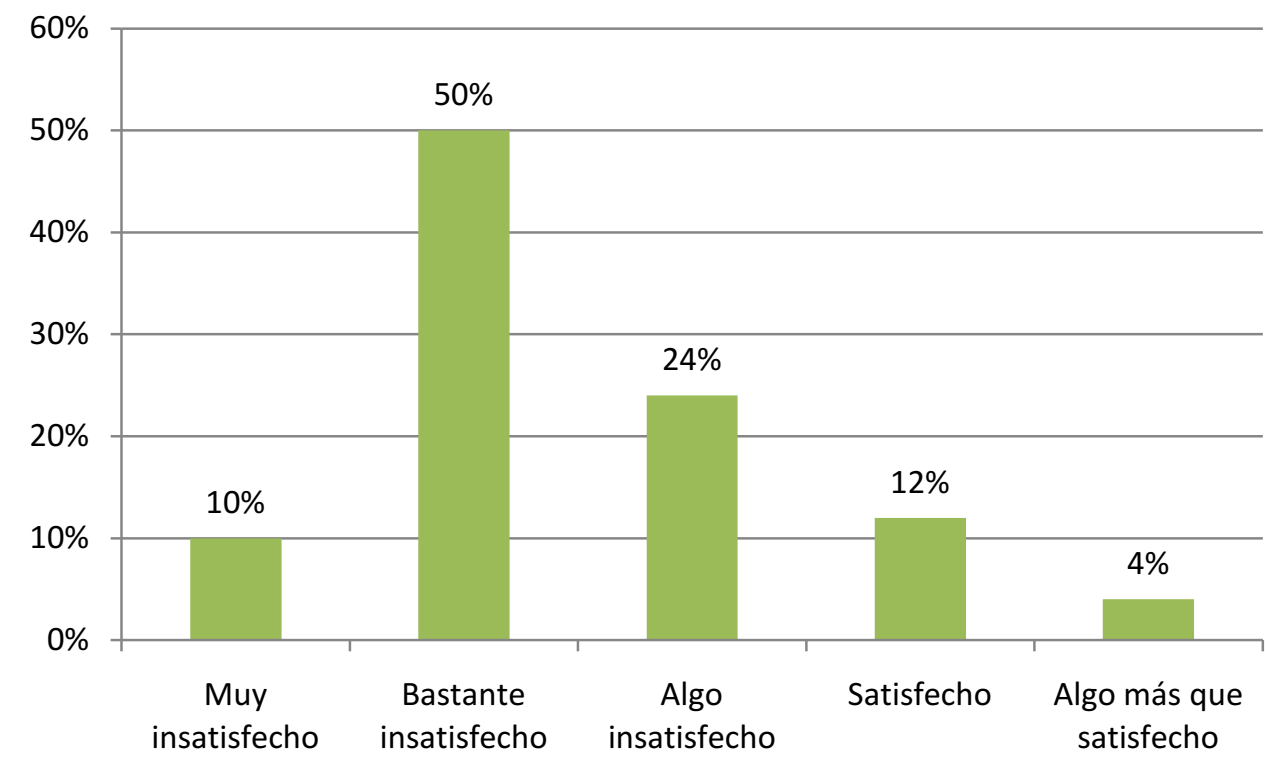

Saldo de Respuesta: -1,50 "Algo insatisfecho" a "Bastante insatisfecho". 


\subsubsection{Nivel de disponibilidad de atención}

A continuación se analiza la disponibilidad de atención, entre puntuaciones que van desde 1 para siempre disponible, a 5 para nunca disponible.

\subsubsection{Expectativa}

\section{Nivel de disponibilidad de atención}

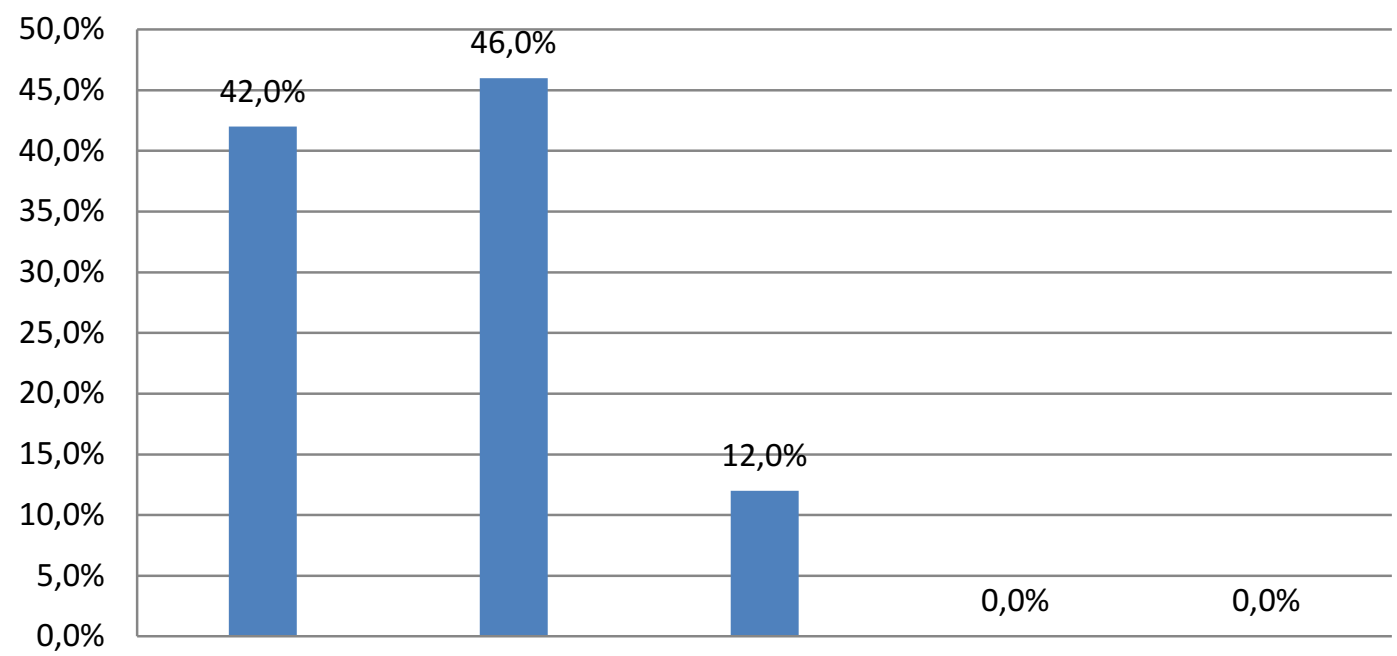

Siempre disporflełalmente dispemiblatmente disponibfeco disponible Nunca disponible

Saldo de Respuesta: 1,70 "Generalmente disponible" con tendencia a "Siempre disponible". 


\subsubsection{Percepción}

Nivel de disponibilidad de atención

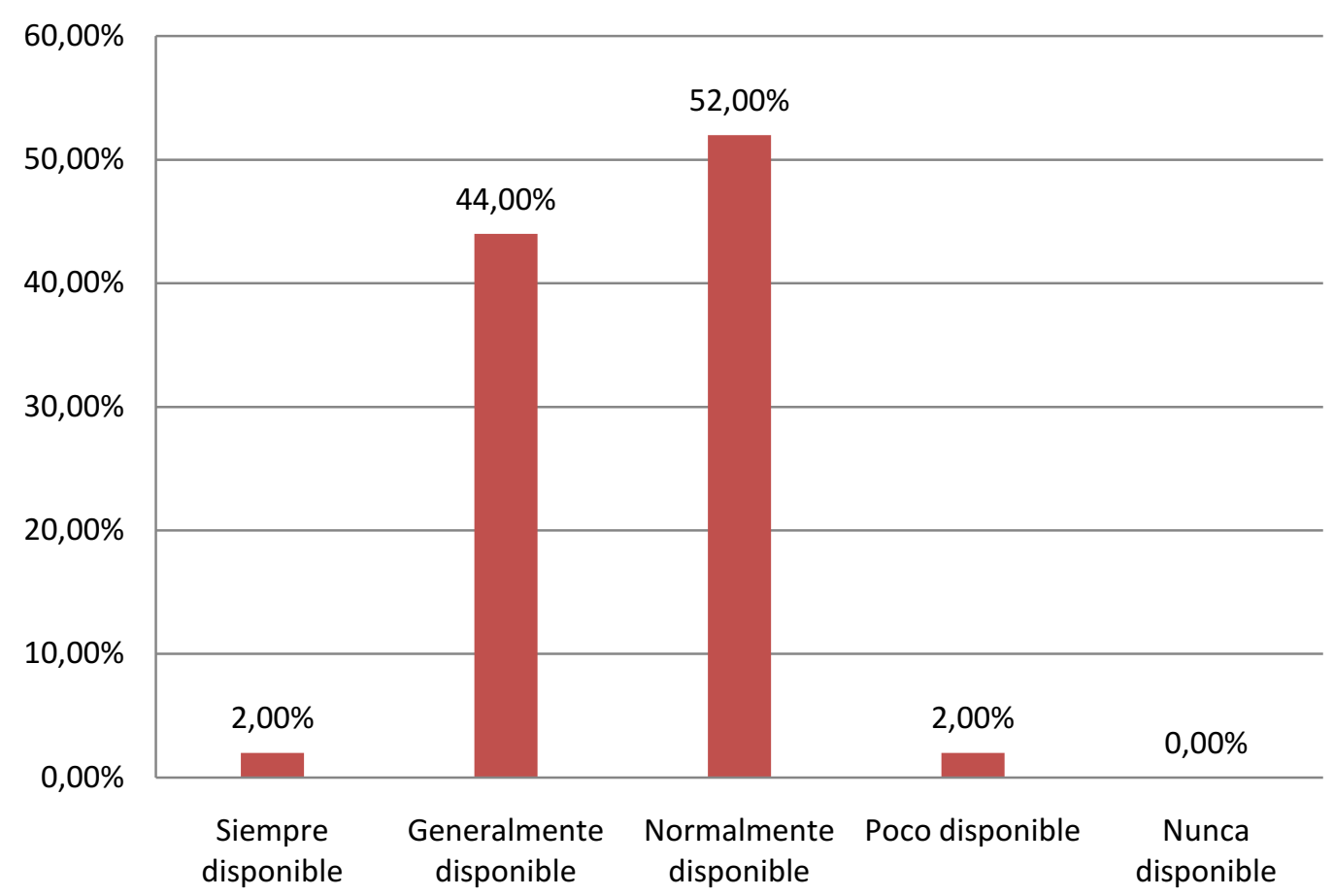

Con un Saldo de Respuesta de 2,54 el nivel de disponibilidad percibido es entre "normalmente" a "generalmente" disponible. 


\subsubsection{Brecha}

Nivel de disponibilidad de atención

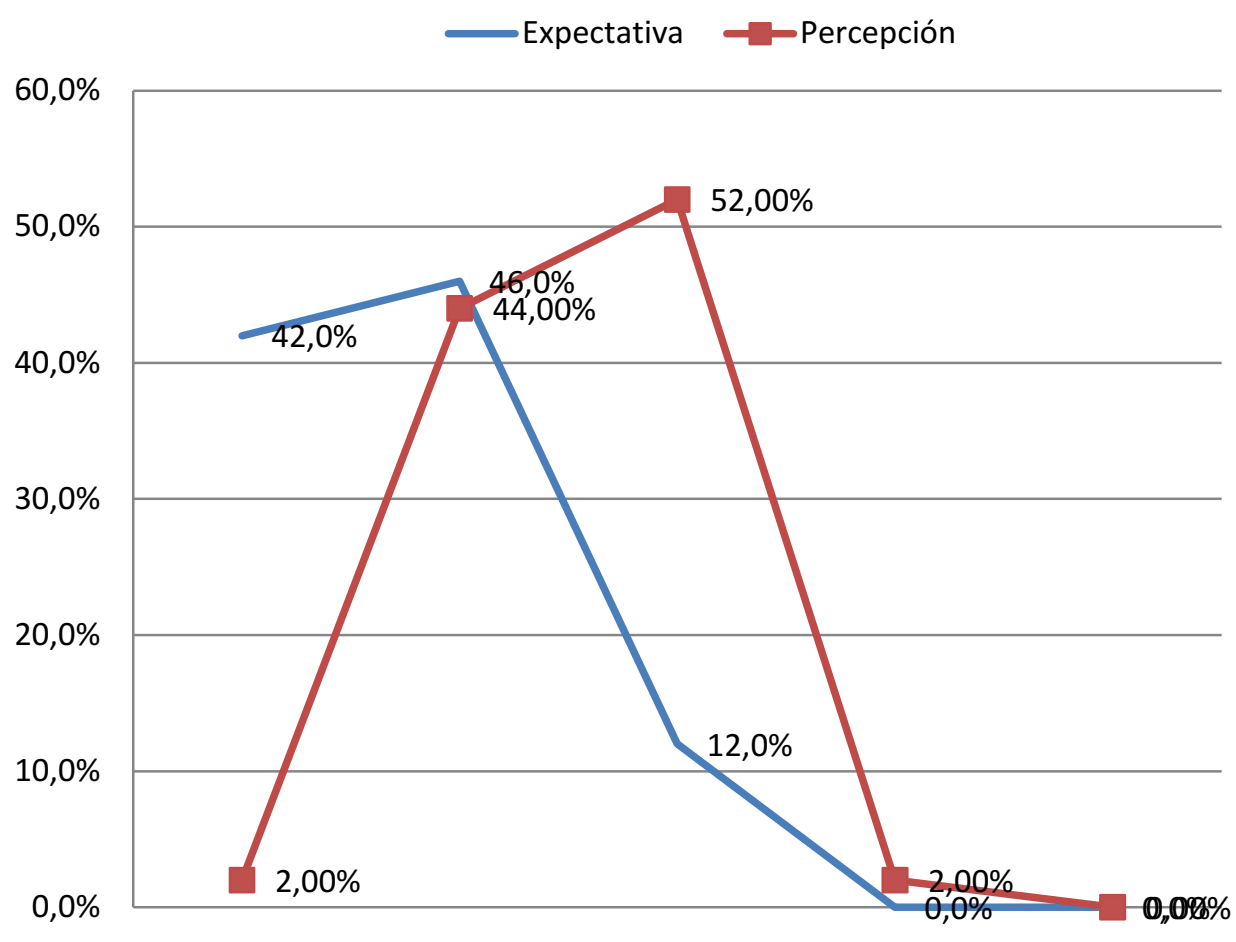

Siempre dispoerntel|ealmente dikspomäbrheente dispohidde disponiblelunca disponible

\section{Brecha disponibilidad de atención}

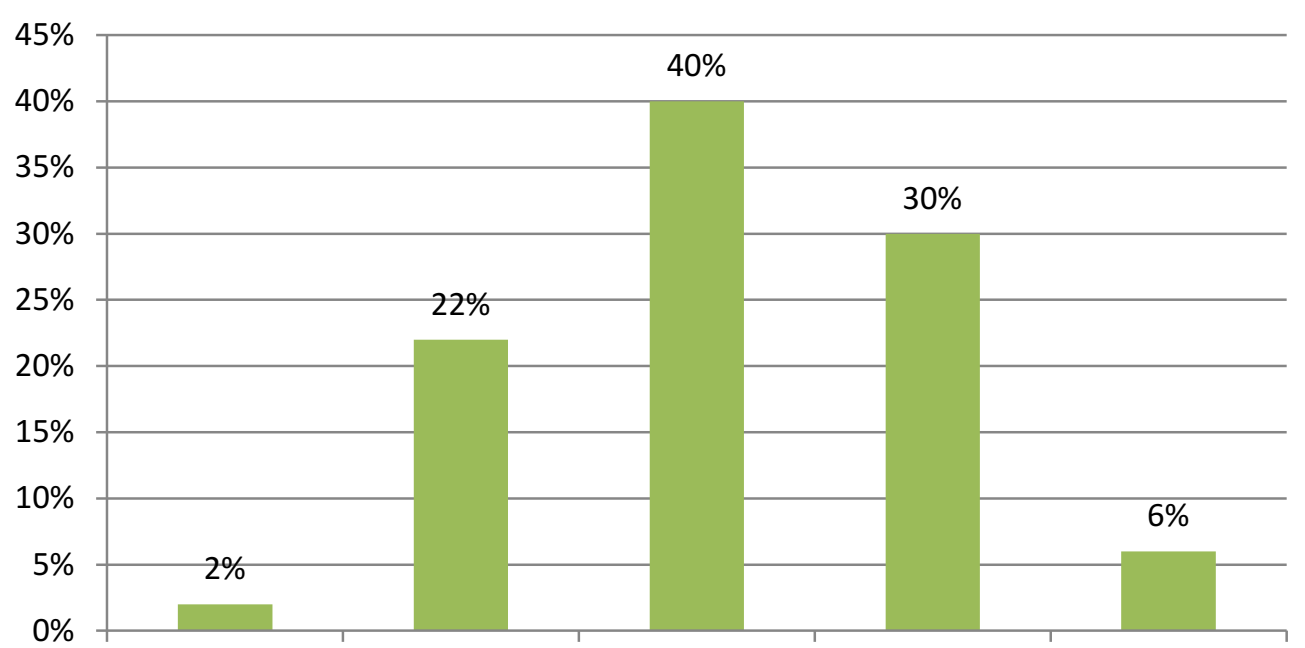

Muy insatisfec Bastante insatisfecAdgo insatisfecho SatisfechoAlgo más que satisfecho

Saldo de Respuesta: -0,84 "Algo insatisfecho" con tendencia a "Satisfecho". 


\subsubsection{Grado de disponibilidad inmediata frente a otras actividades}

\subsubsection{Expectativa}

\section{Grado de disponibilidad para atención inmediata frente a otras actividades}

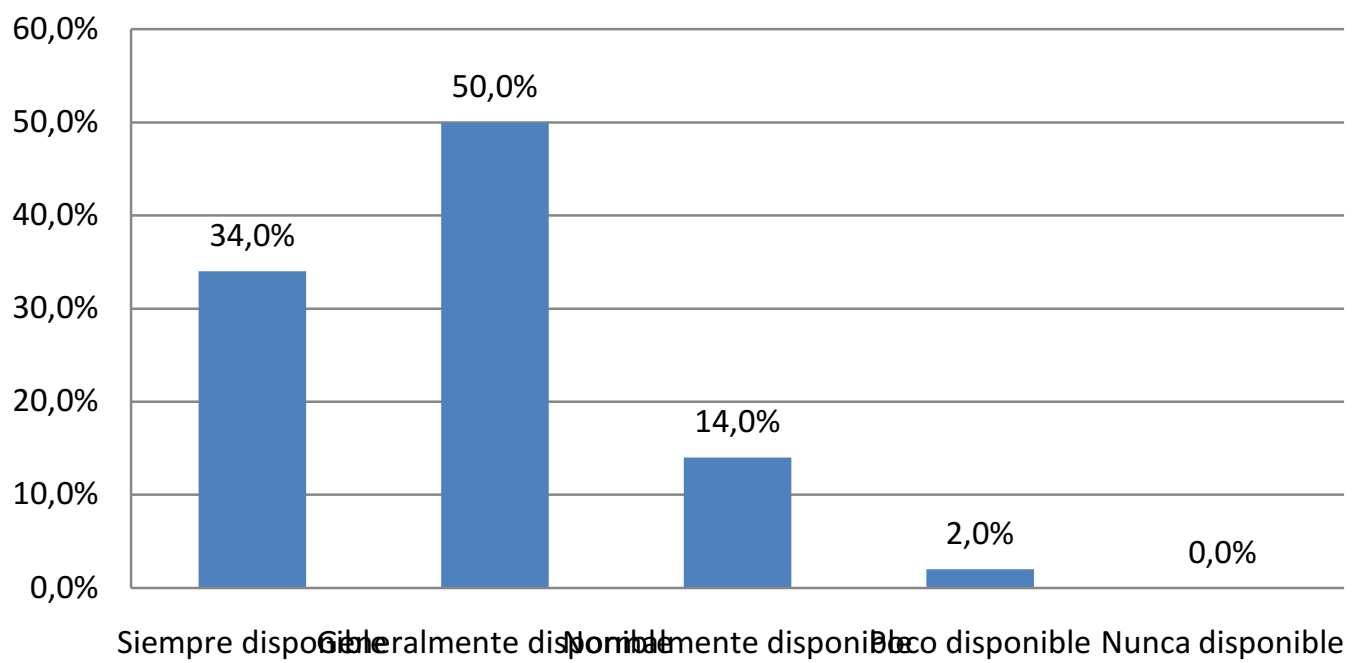

Saldo de Respuesta: 1,84 "Generalmente disponible" con tendencia a "Siempre disponible". 


\subsubsection{Percepción}

\section{Grado de disponibilida para atención inmediata frente a otras actividades}

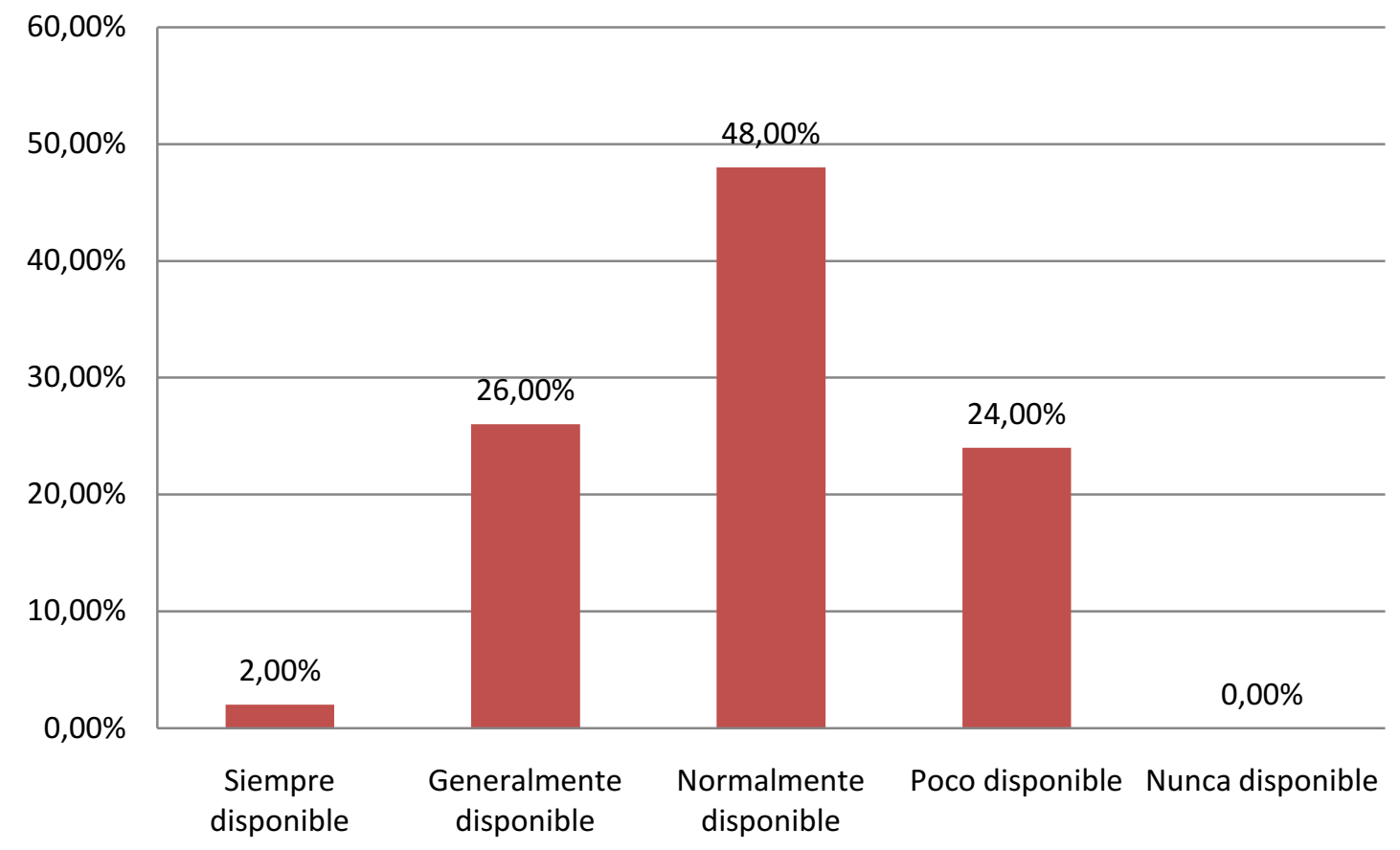

Con un Saldo de Respuesta de 2,94 el nivel de disponibilidad frente a otras actividades es de "normalmente disponible".

\subsubsection{Brecha}




\section{Grado de disponibilidad para atención inmediata frente a otras actividades}

Expectativa $\longrightarrow$ Percepción

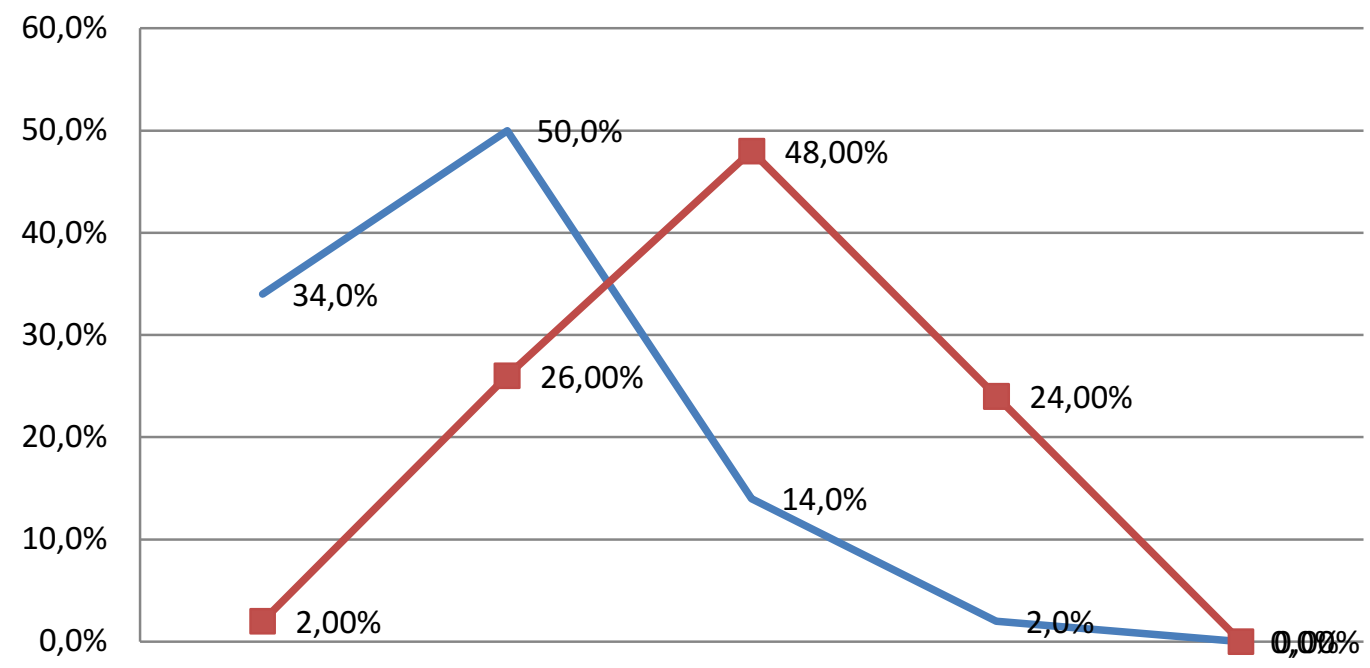

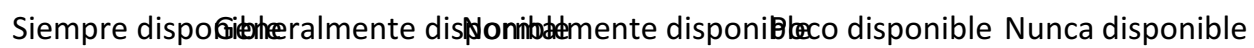

\section{Brecha atención inmediata}

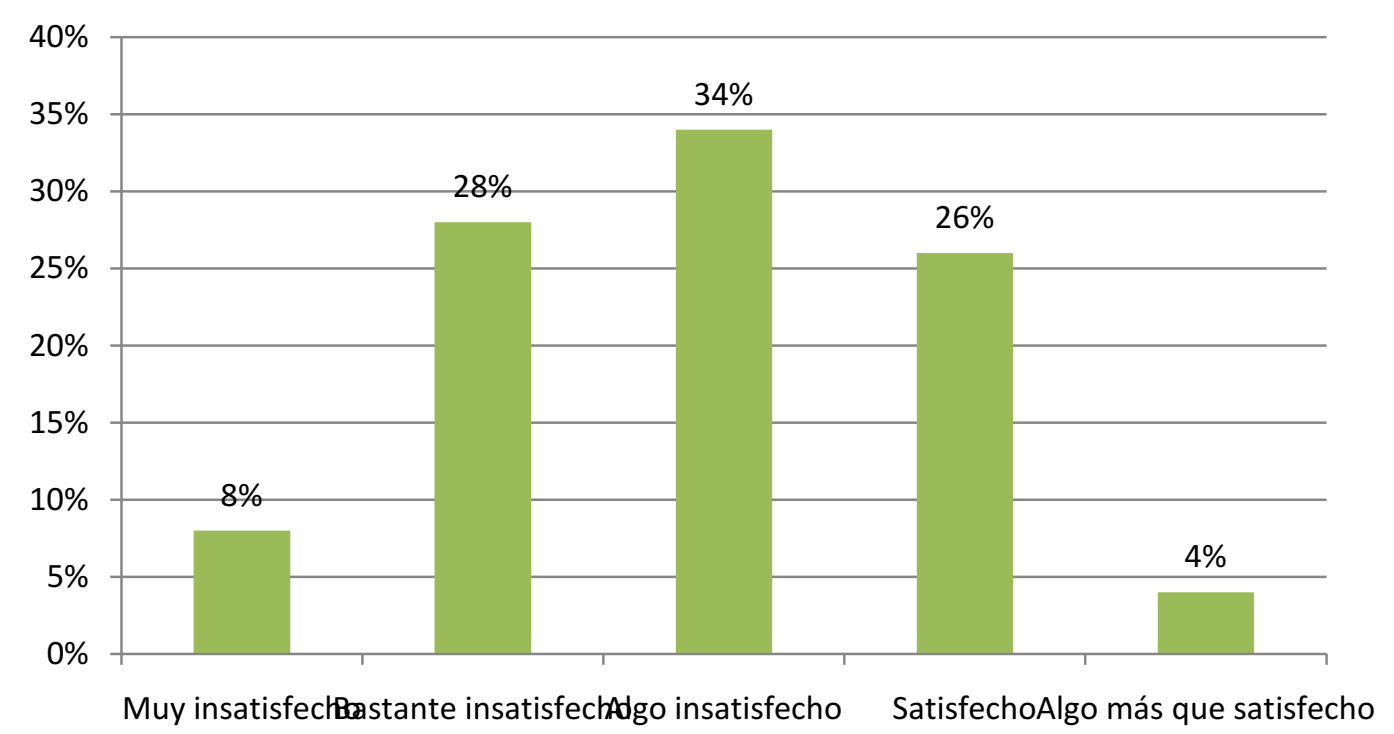

Saldo de Respuesta: -1,10 "Algo insatisfecho" con leve tendencia a "Bastante insatisfecho". 
7.5 Dimensión IV: Seguridad - Conocimiento y atención mostrados por los empleados y sus habilidades para inspirar credibilidad y confianza.

En esta dimensión se muestran los resultados obtenidos en cuatro factores: comunicación, seguridad, amabilidad y conocimiento para resolver las inquietudes de los clientes.

\subsubsection{Confianza que brinda el comportamiento de los empleados}

\subsubsection{Expectativa.}

Nivel de confianza que brinda el comportamiento de los empleados

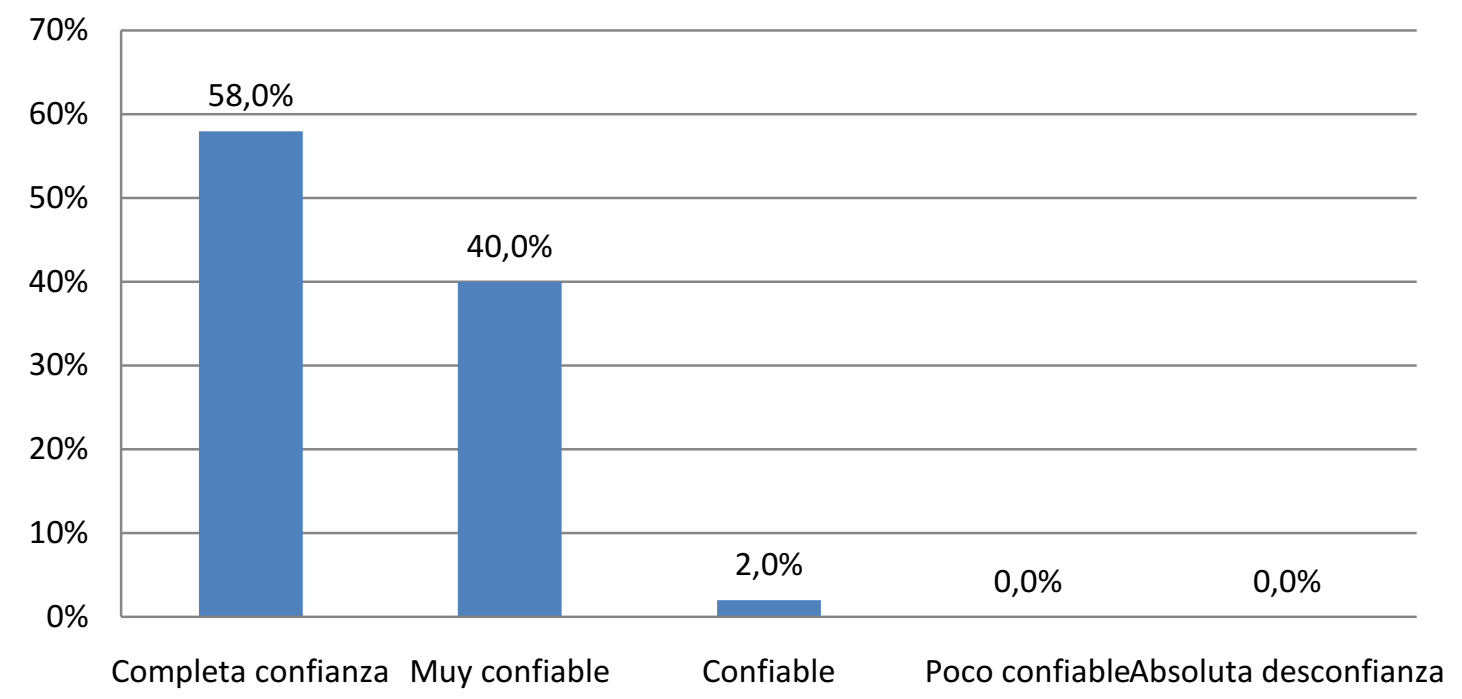

Saldo de Respuesta: 1,44 "Completa confianza" a "Muy confiable". 


\subsubsection{Percepción}

\section{Nivel de confianza que brinda el comportamiento de los empleados}

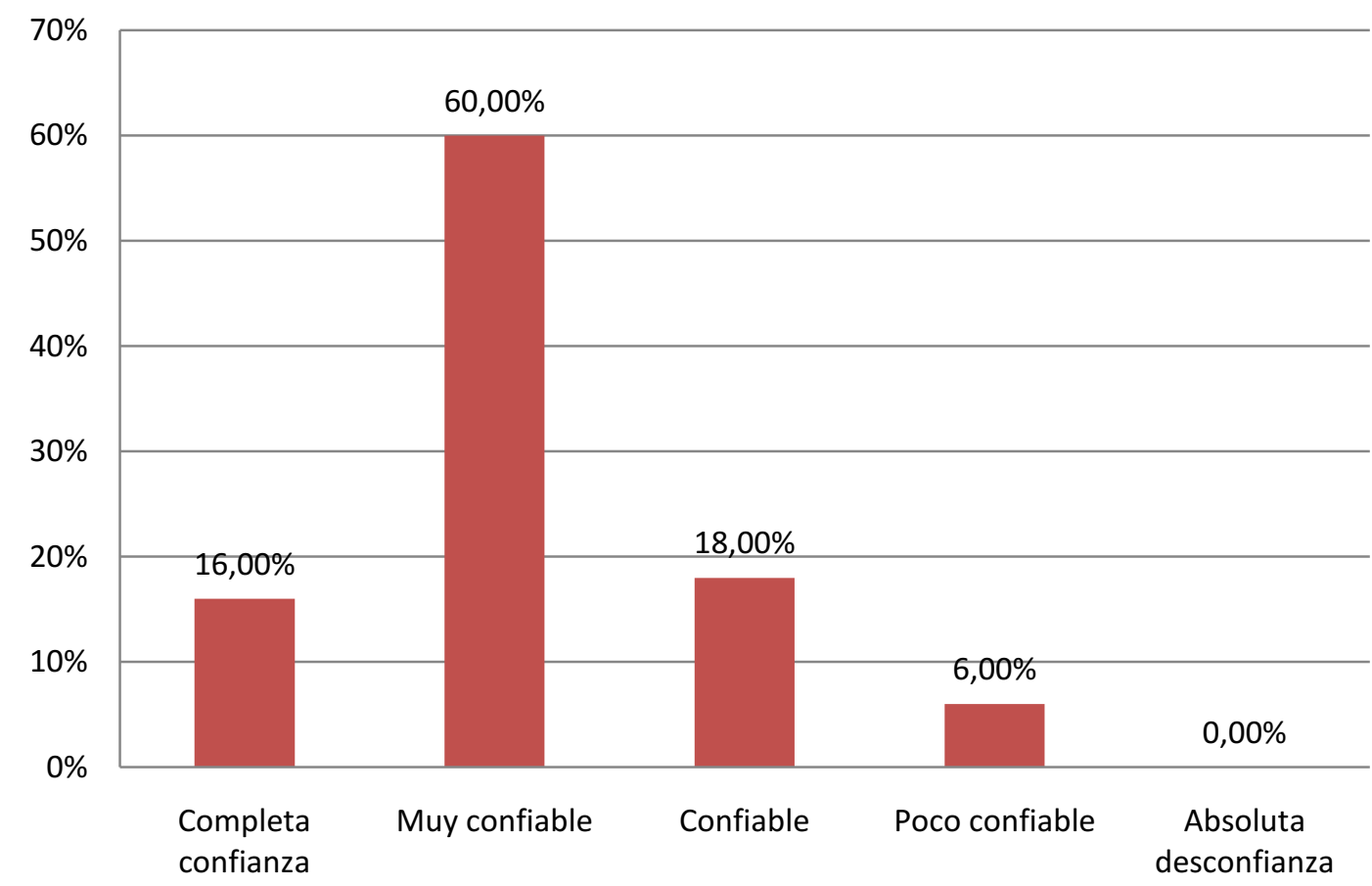

Con un Saldo de Respuesta de 2,14 el nivel de confianza que brinda el comportamiento de los empleados es "Muy confiable" con una leve tendencia a "Confiable".

\subsubsection{Brecha}




\section{Nivel de confianza que brinda el comportameinto de los empleados}

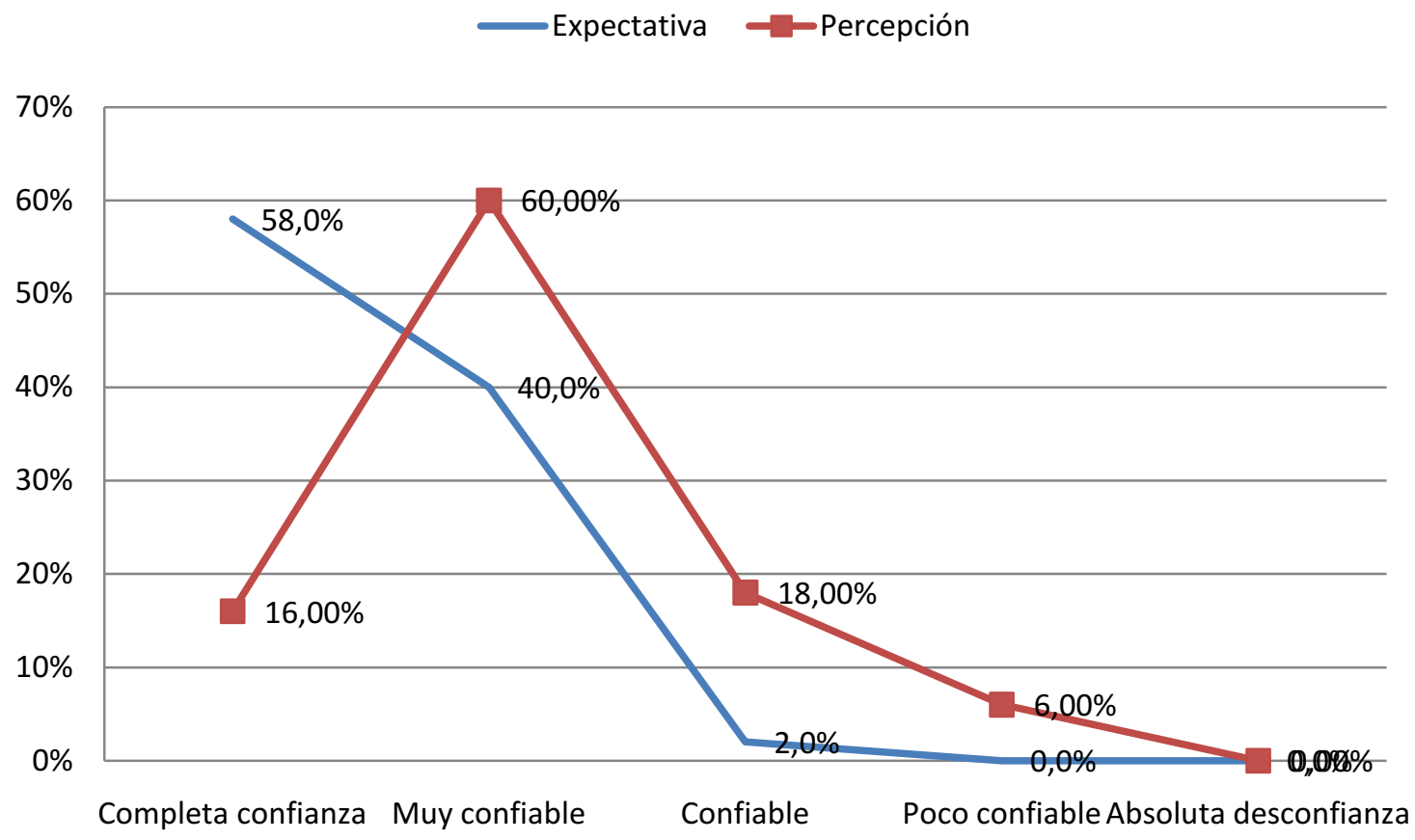

\section{Brecha confianza}

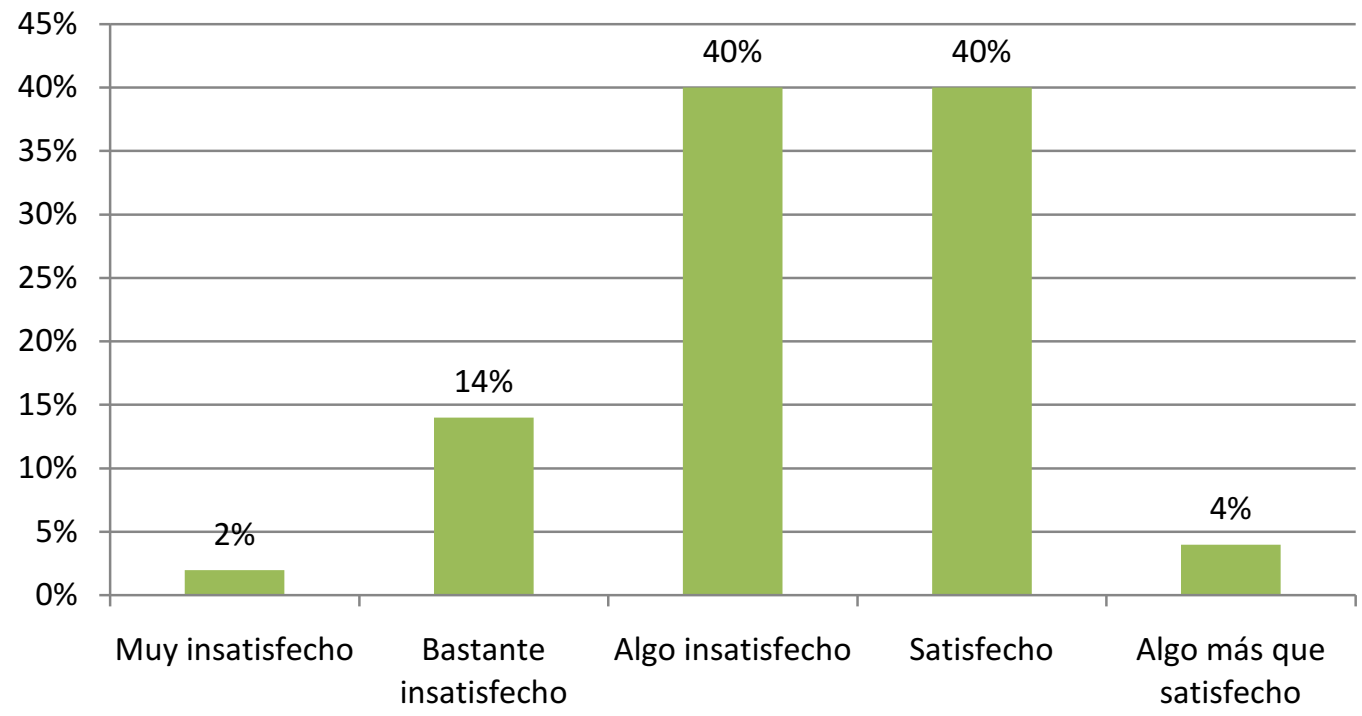

Saldo de Respuesta: -0,70 "Algo insatisfecho" con tendencia a "Satisfecho". 
7.5.2 Nivel de seguridad que se siente en las transacciones con el servicio de Defensa del Consumidor

\subsubsection{Expectativa}

Nivel de seguridad que usted tiene en sus transacciones con el servicio

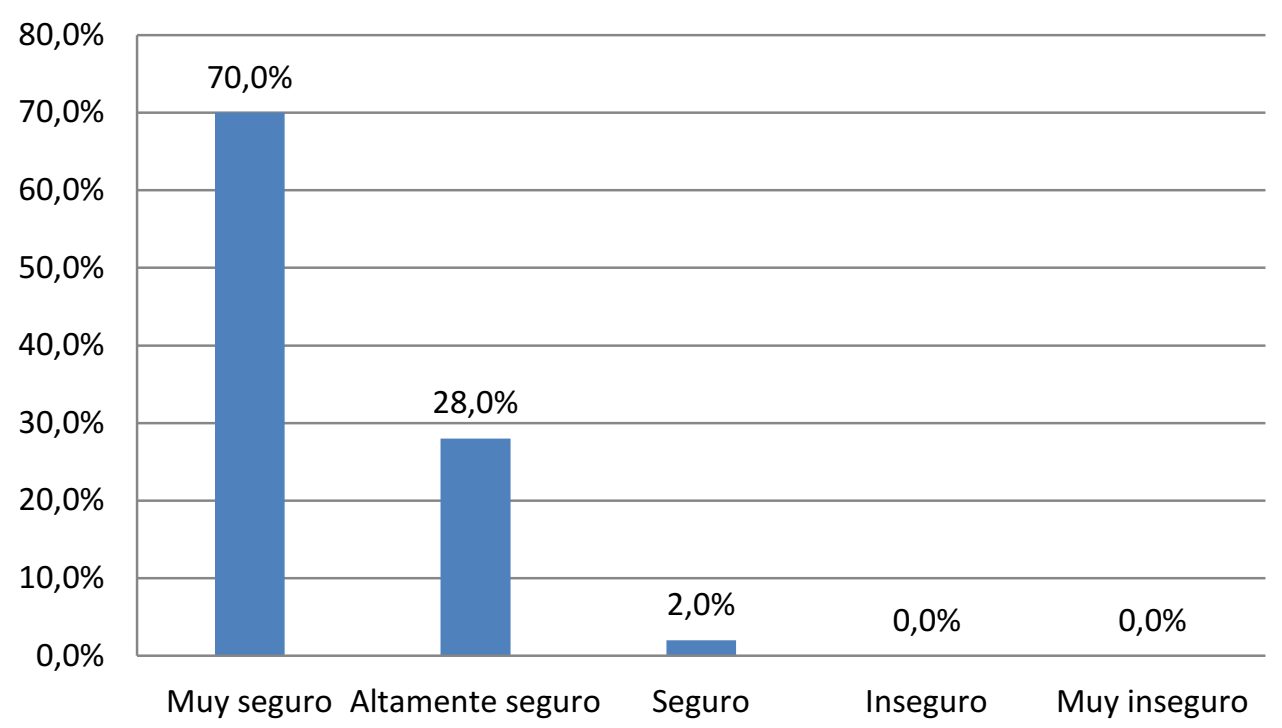

Saldo de Respuesta: 1,32 "Muy seguro" con tendencia a "Altamente seguro". 


\subsubsection{Percepción}

Nivel de seguridad que usted tiene en sus transacciones con el servicio

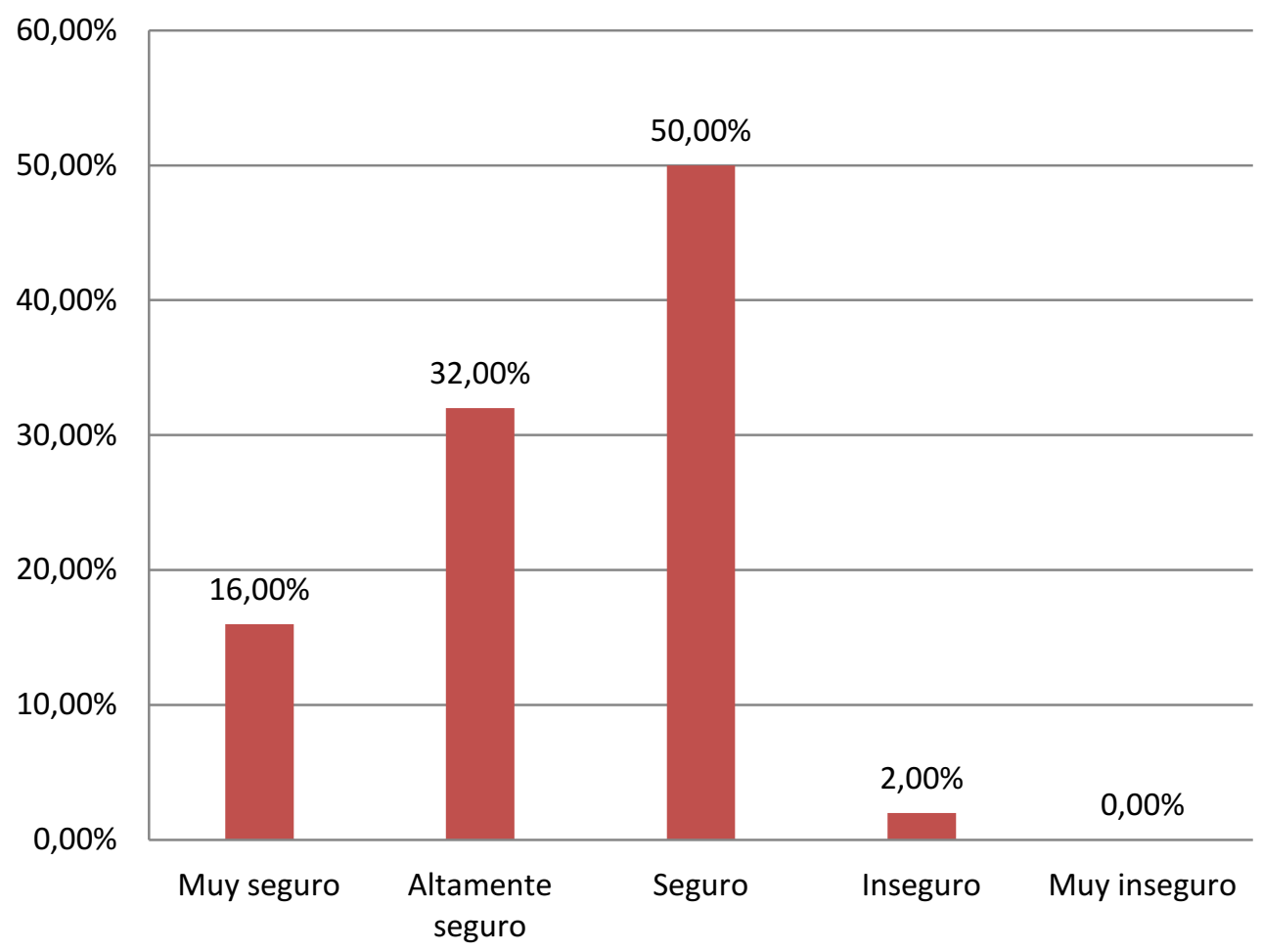

Con un Saldo de Respuesta de 2,38 el nivel de seguridad que se tiene en las transacciones con el servicio es "Altamente seguro" con una tendencia a "Seguro".

\subsubsection{Brecha}


Nivel de seguridad que usted siente en sus transacciones con el servicio

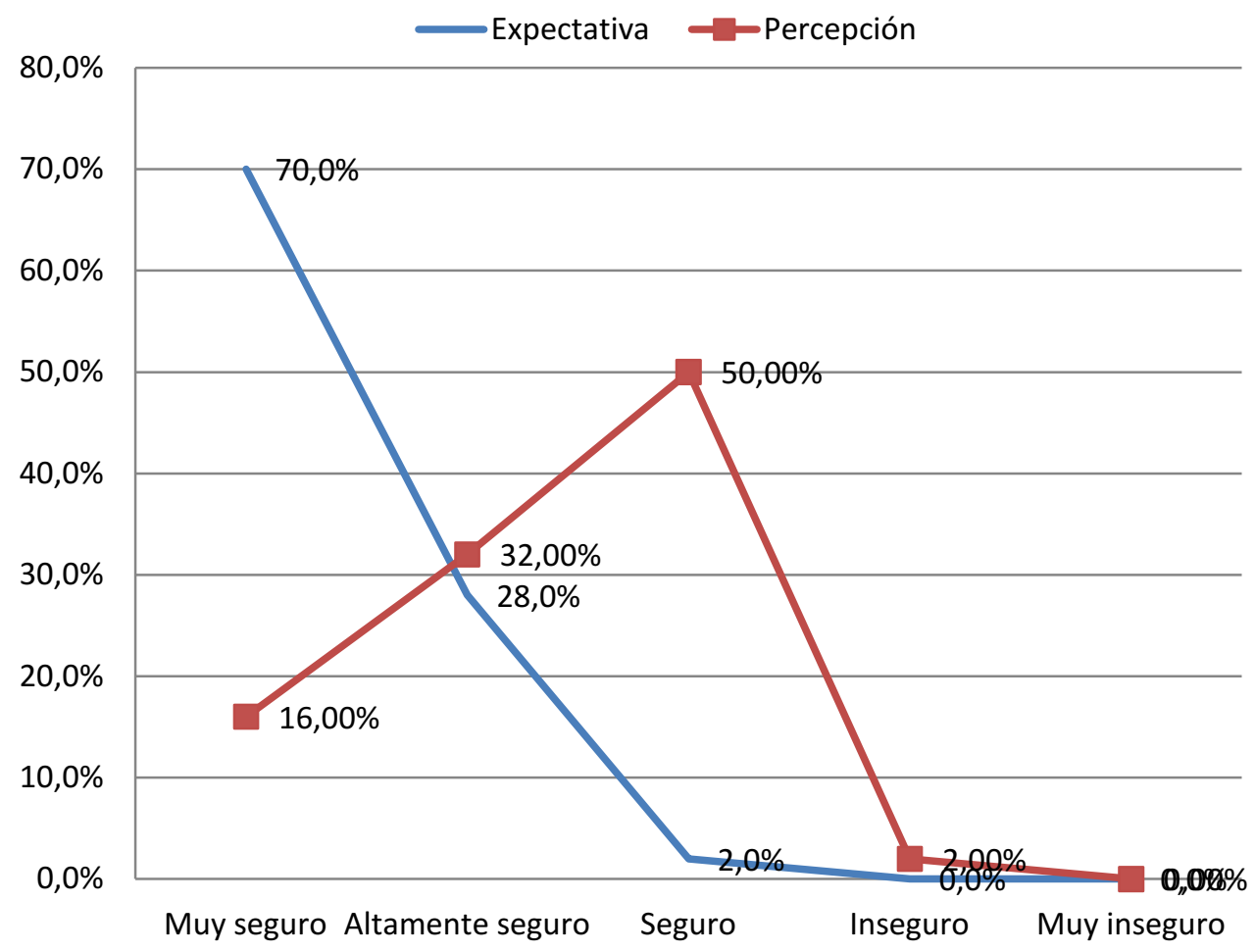

\section{Brecha nivel de seguridad}

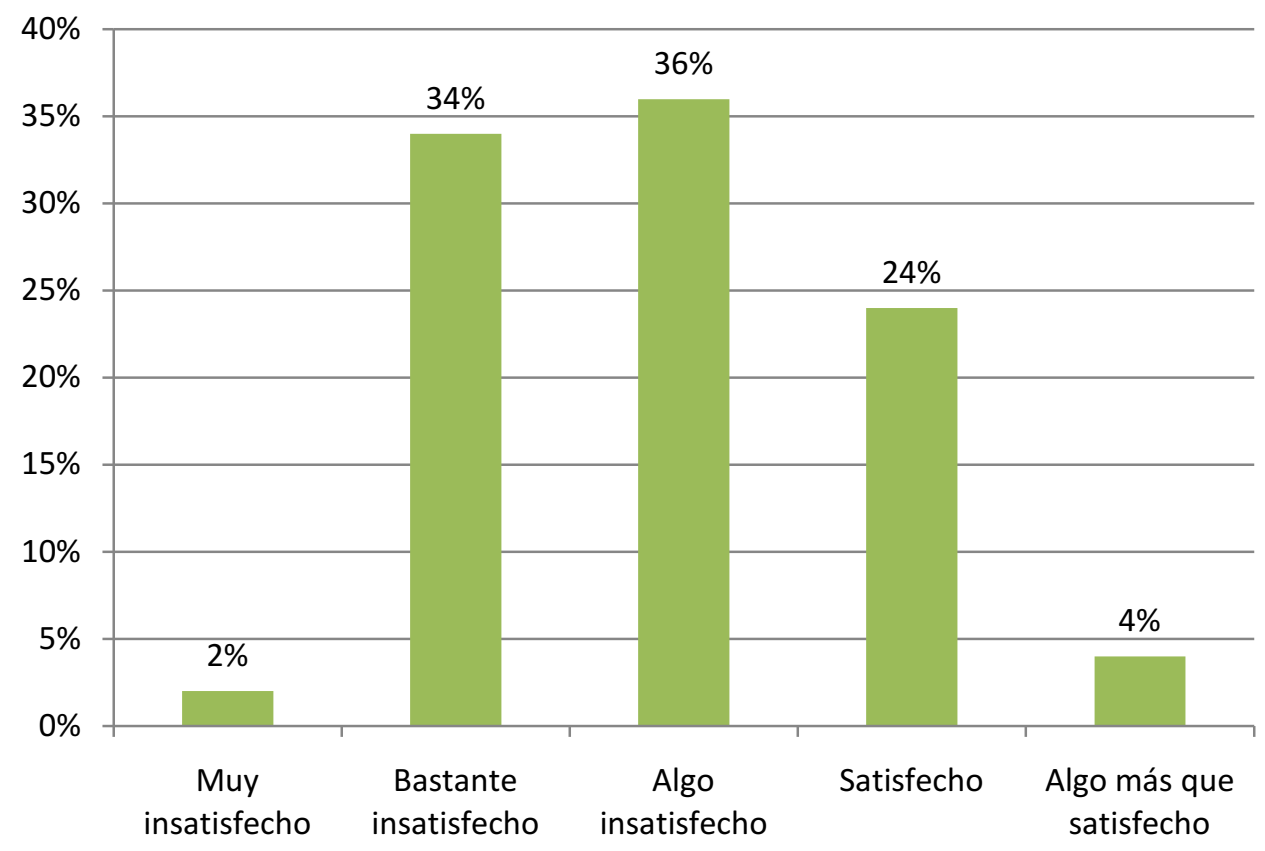

Saldo de Respuesta: -1,06 "Algo insatisfecho". 


\subsubsection{Nivel de amabilidad que muestran los empleados del servicio}

\subsubsection{Expectativa}

Nivel de amabilidad de los empleados

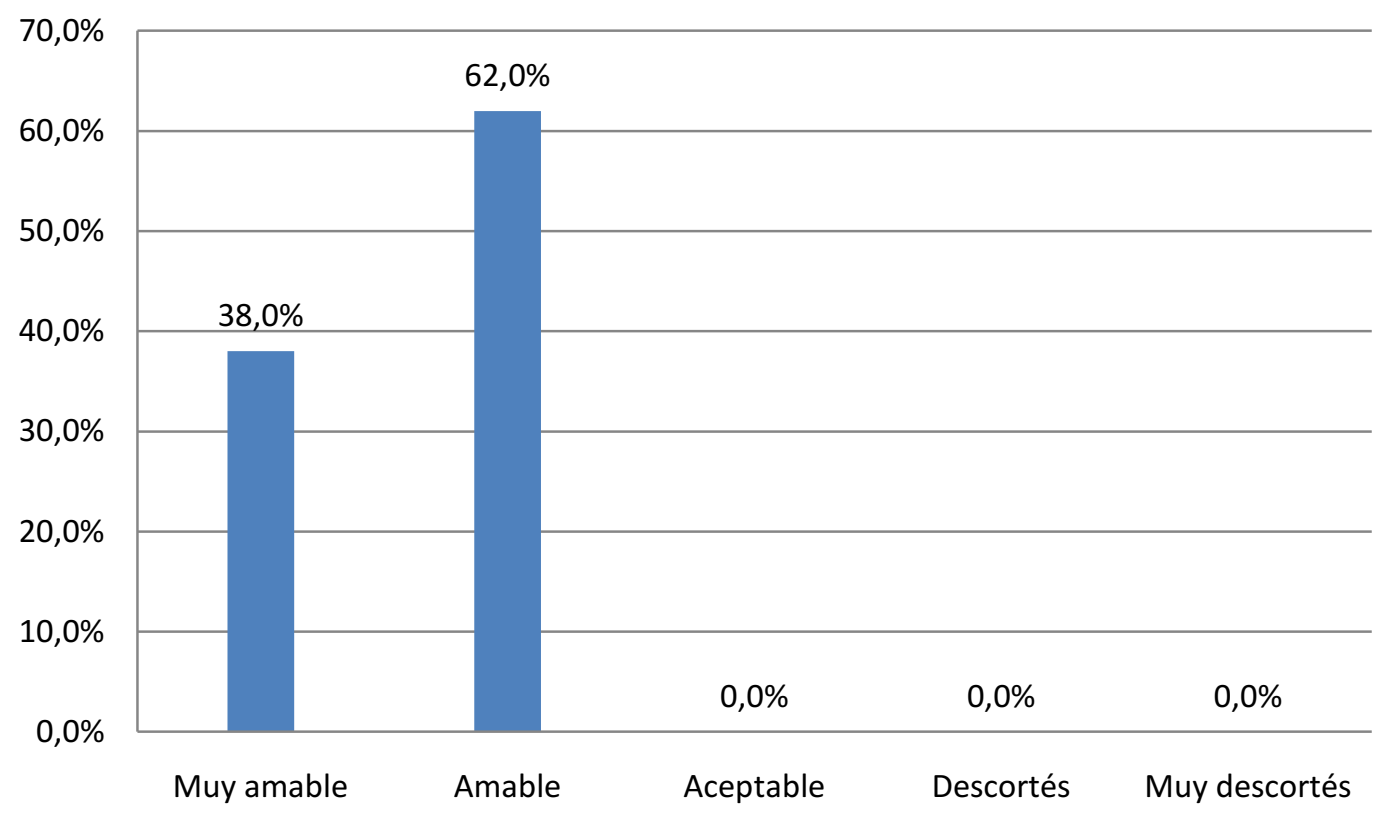

Saldo de Respuesta: 1,62 "Amable" a "Muy amable". 


\subsubsection{Percepción}

Nivel de amabilidad de los empleados

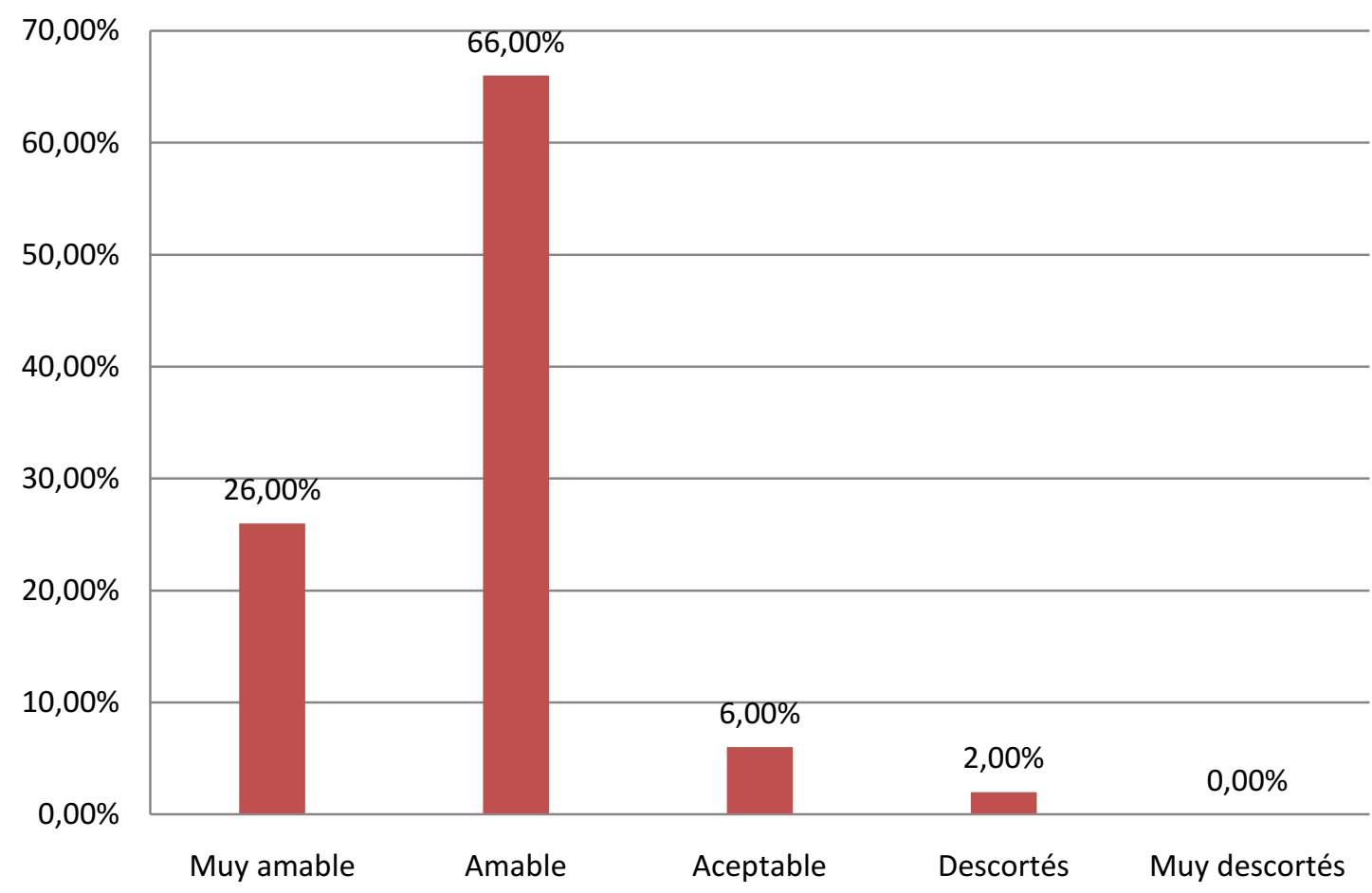

Con un Saldo de Respuesta de 1,84 el nivel de amabilidad de los empleados es "Amable" con tendencia a "Muy amable". 


\subsubsection{Brecha}

Nivel de amabilidad de los empleados

Expectativa $\rightarrow$ Percepción

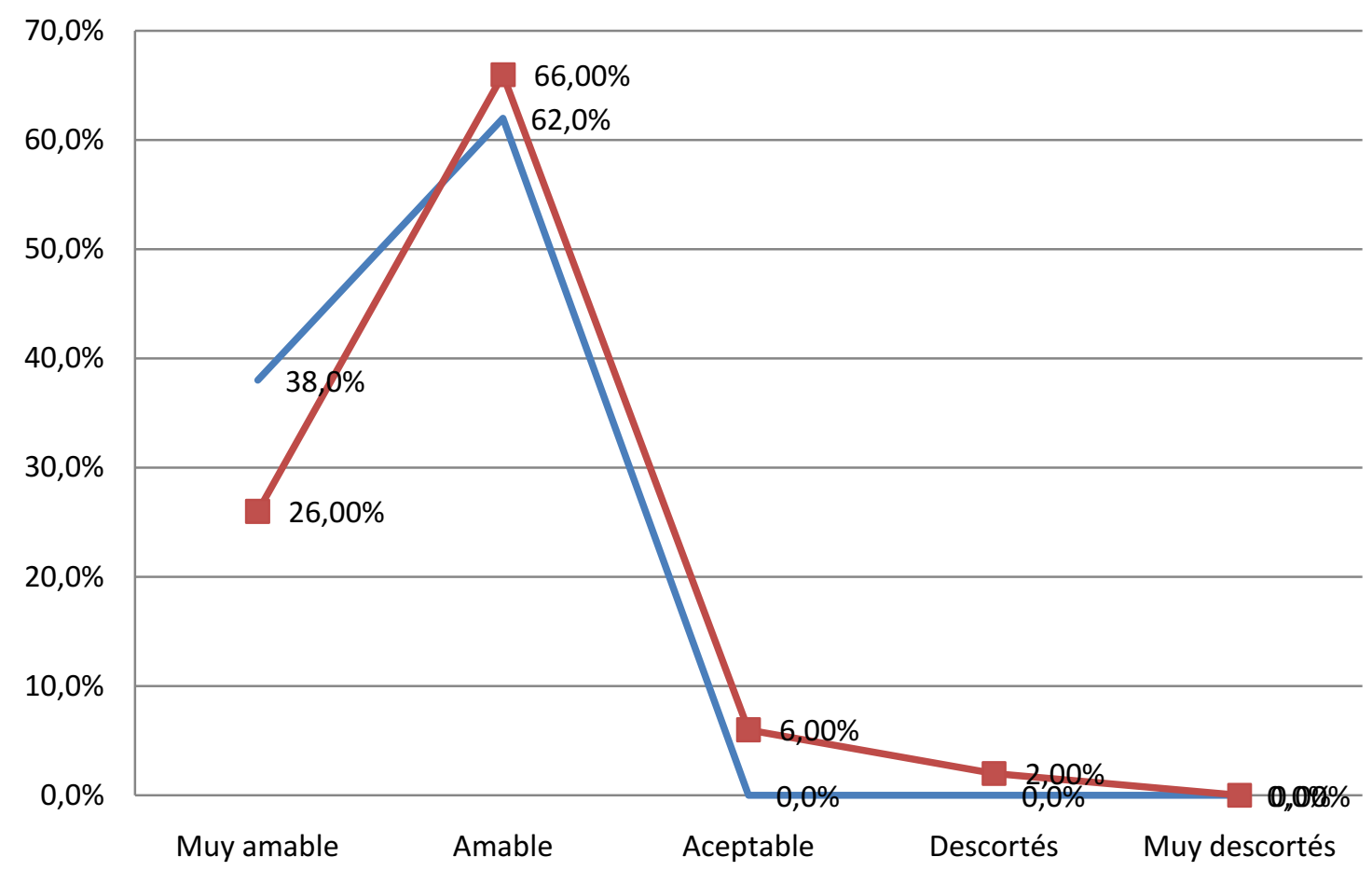

Brecha amabilidad

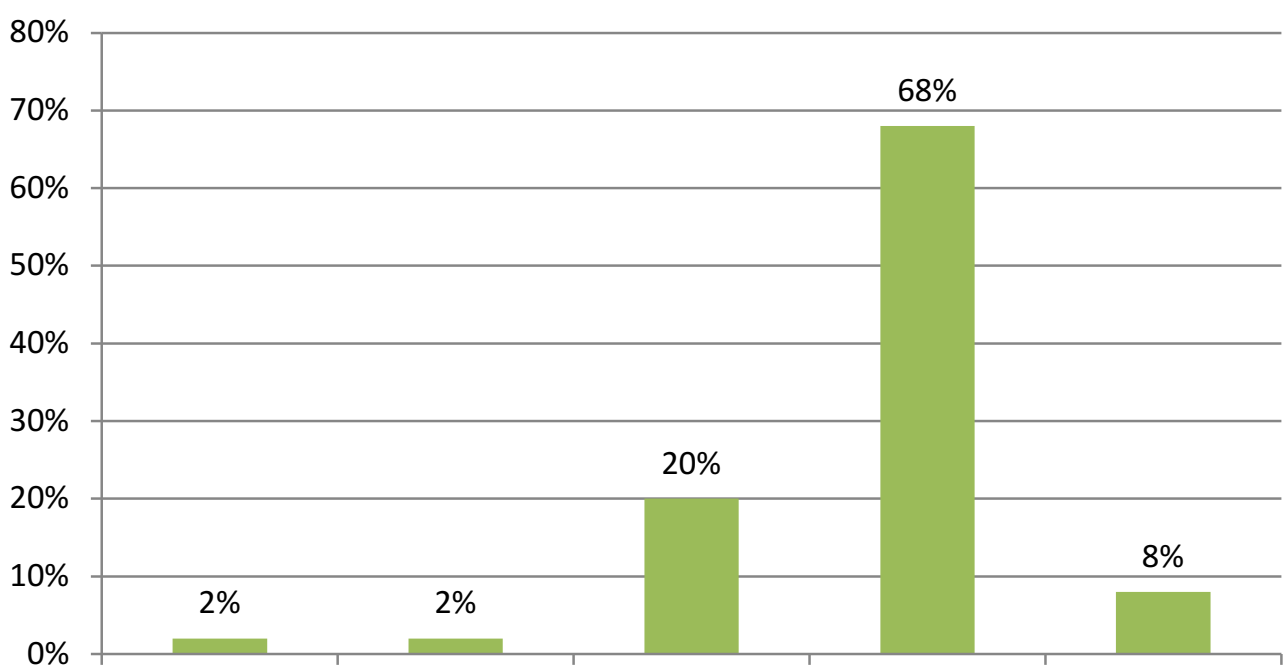

Muy insatisfec Bastante insatisfec

Saldo de Respuesta: -0,22 "Satisfecho" con tendencia a "Algo insatisfecho". 
7.5.4 Grado de conocimiento que tienen los empleados para resolver las inquietudes de los usuarios

\subsubsection{Expectativa}

\section{Grado de conocimiento que tienen los empleados para resolver sus inquietudes}

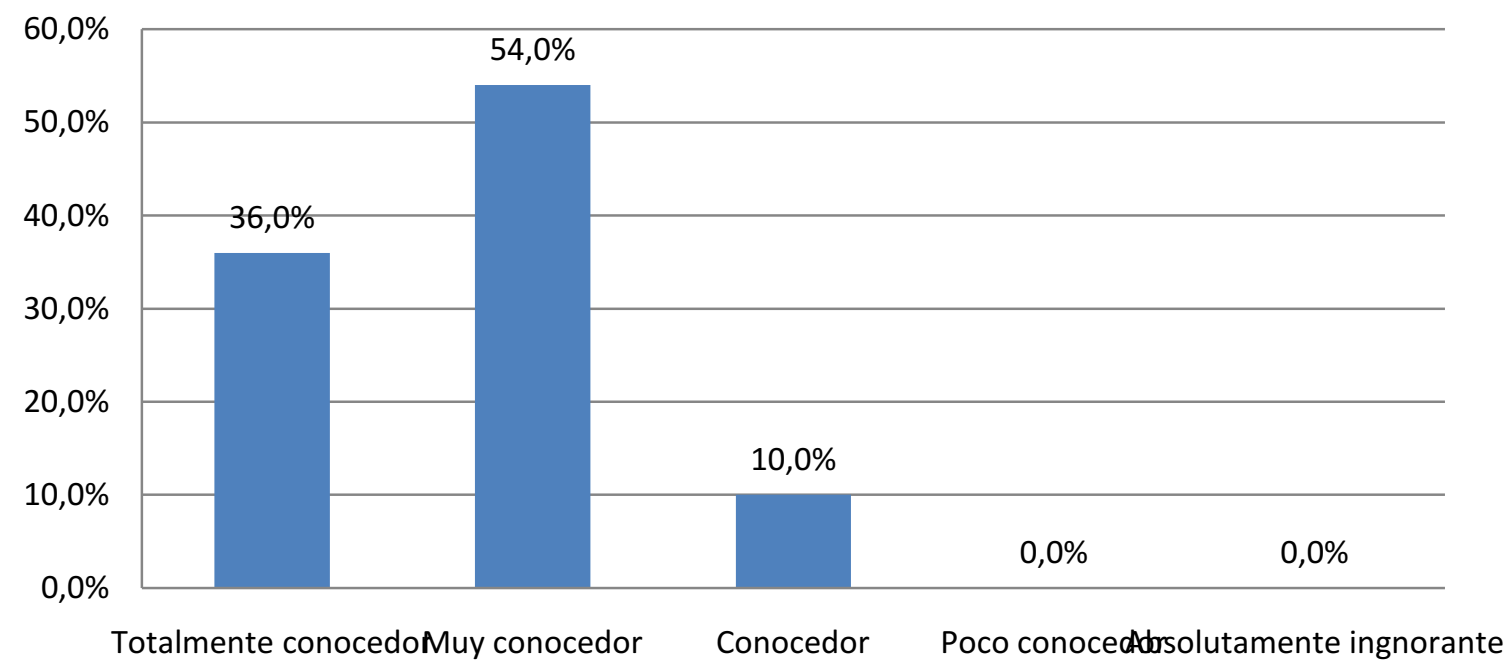

Saldo de Respuesta: 1,74 "Muy conocedor" con tendencia a "Totalmente conocedor". 


\subsubsection{Percepción}

\section{Grado de conocimiento que tienen los empleados para resolver sus inquietudes}

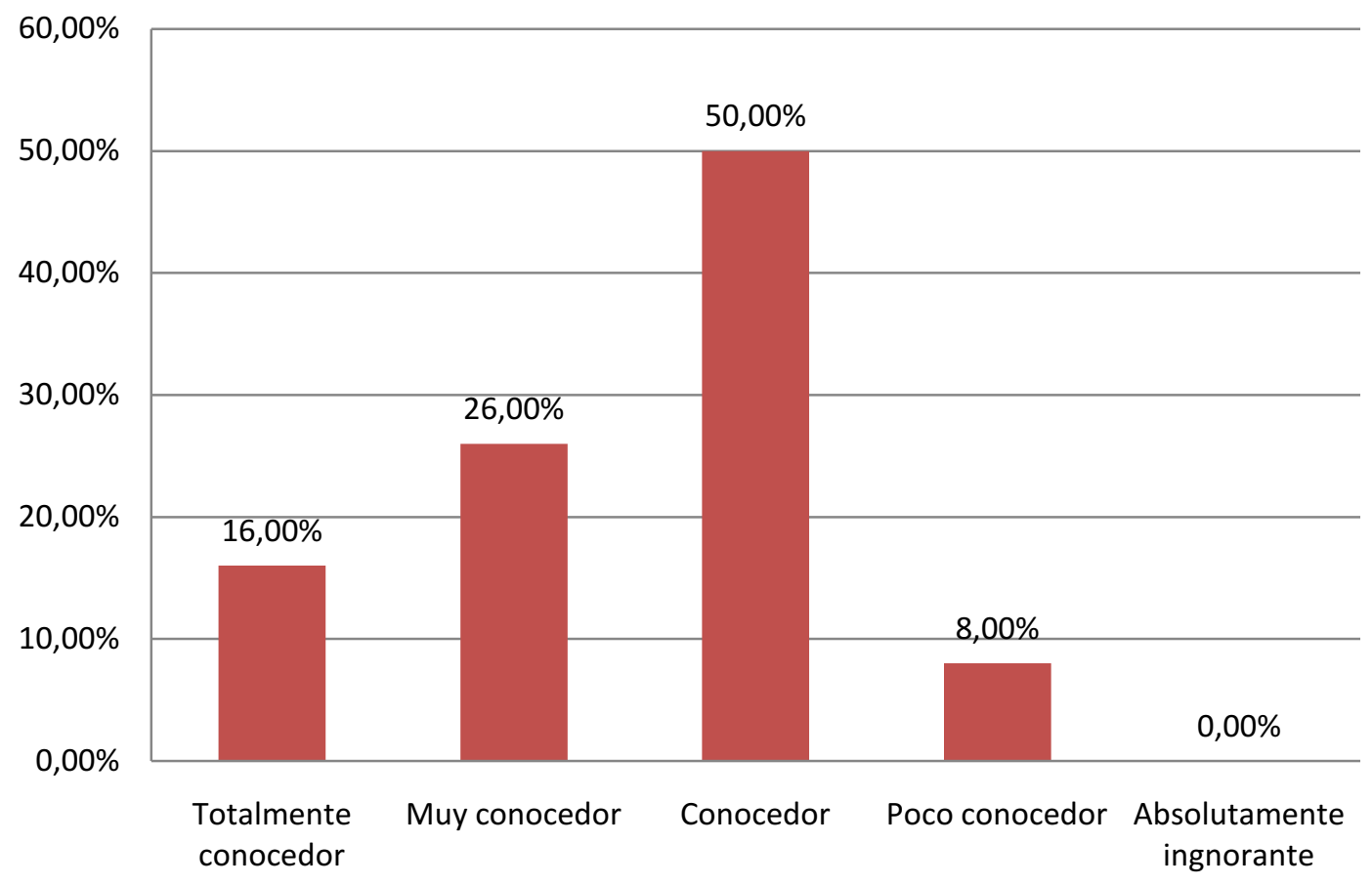

Con un Saldo de Respuesta de 2,50 el grado de conocimiento que tienen los empleados para resolver sus inquietudes es entre "Conocedor" y "Muy conocedor". 


\subsubsection{Brecha}

\section{Grado de conocimiento que tienen los empleados para} resolver sus inquietudes

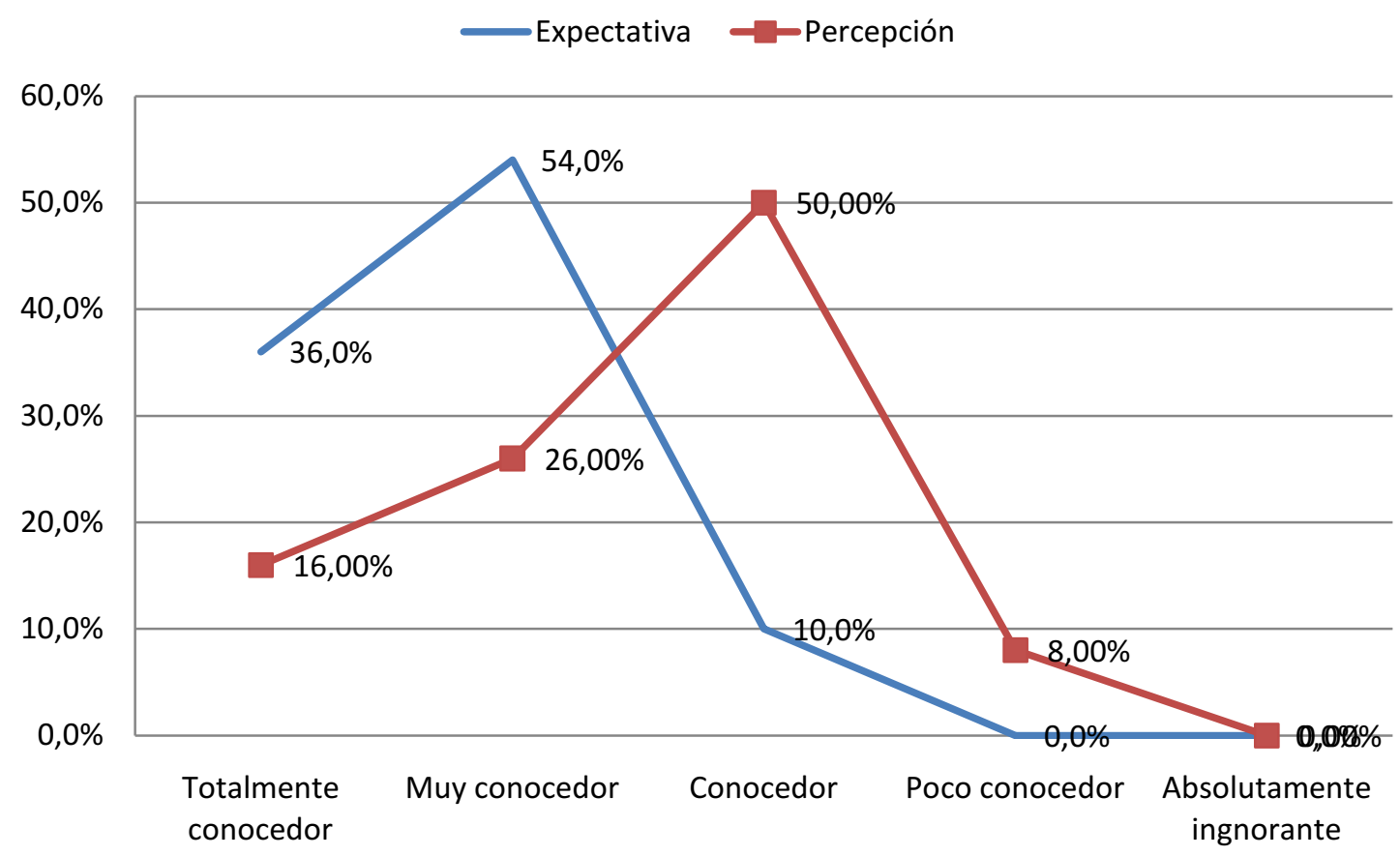

\section{Brecha conocimiento}

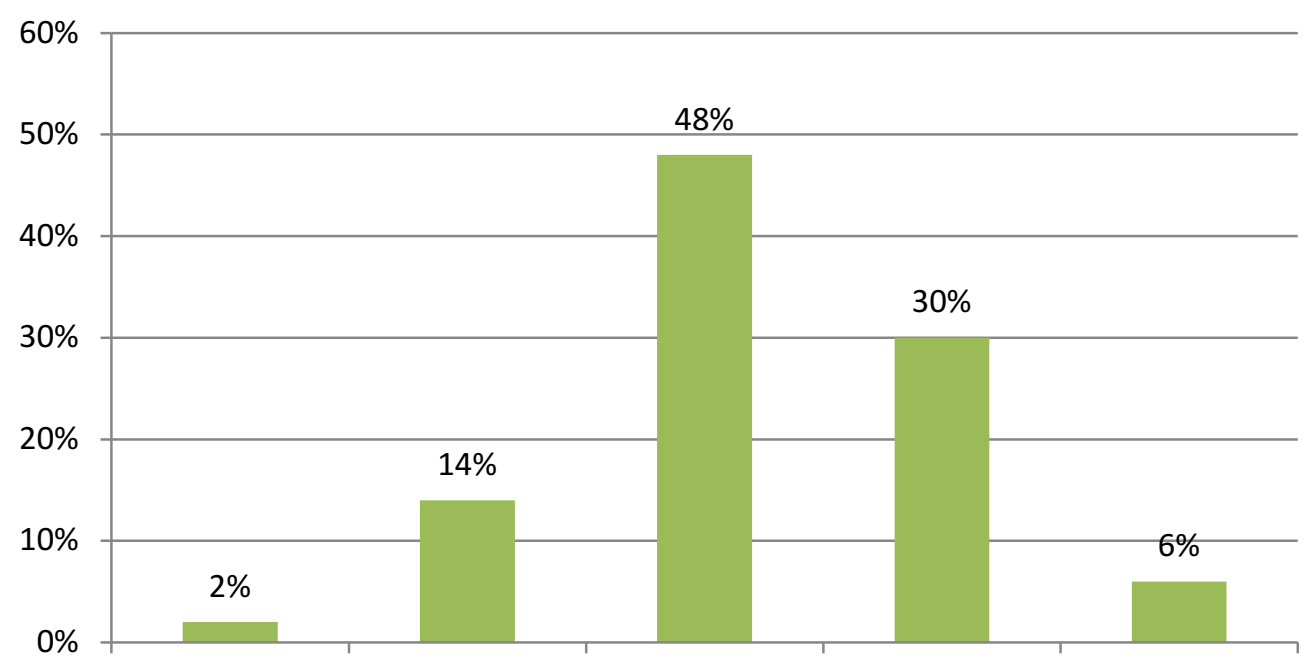

Muy insatisfec|Bastante insatisfechadgo insatisfecho SatisfechoAlgo más que satisfecho

Saldo de Respuesta: -0,76 "Algo insatisfecho" con tendencia a "Satisfecho". 
7.6 Dimensión V: Empatía - Atención individualizada que ofrece la organización a los clientes.

A continuación se exponen las expectativas y las percepciones de los usuarios respecto de la individualización, los horarios de trabajo, la personalización en la atención, la preocupación, y, la comprensión de sus necesidades.

\subsubsection{Nivel de individualización en la atención del servicio}

\subsubsection{Expectativa}

\section{La atención del servicio según su individualización es:}

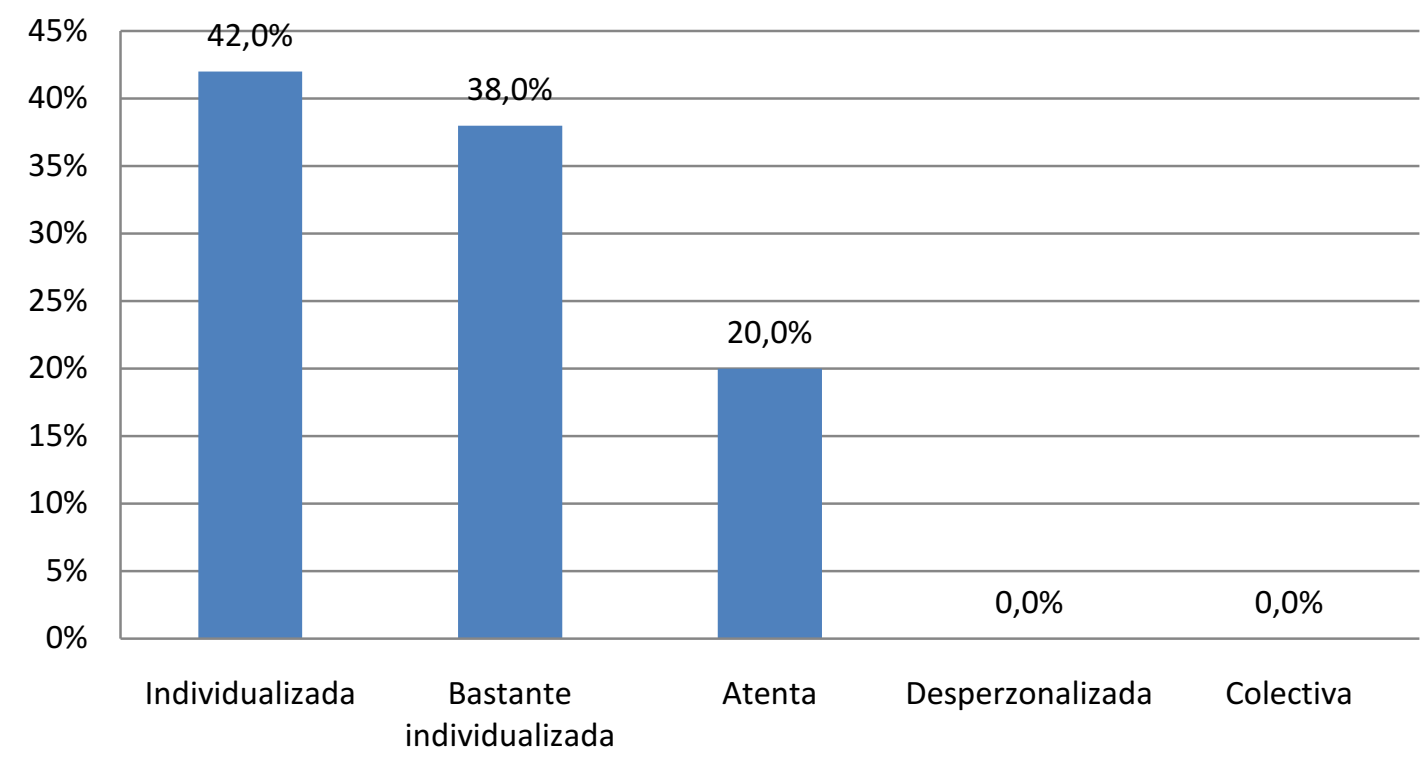

Saldo de Respuesta: 1,78 "Bastante individualizada" con tendencia a "Individualizada".

\subsubsection{Percepción}


La atención del servicio según su individualización es:

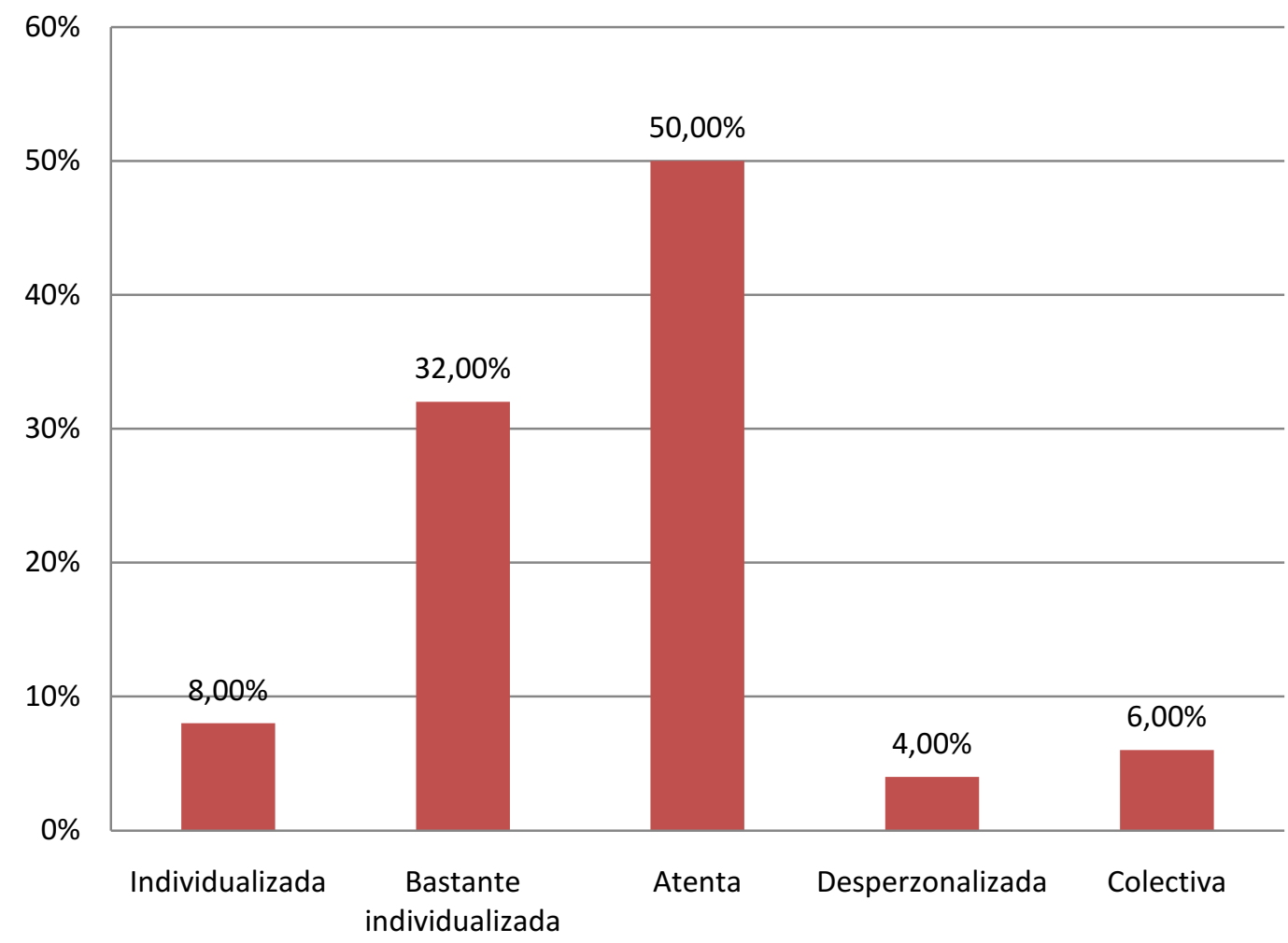

Con un Saldo de Respuesta de 2,68 la atención del servicio según su individualización es "Atenta" con tendencia a "Bastante individualizada". 


\subsubsection{Brecha}

\section{La atención del servicio según su individualización es:}

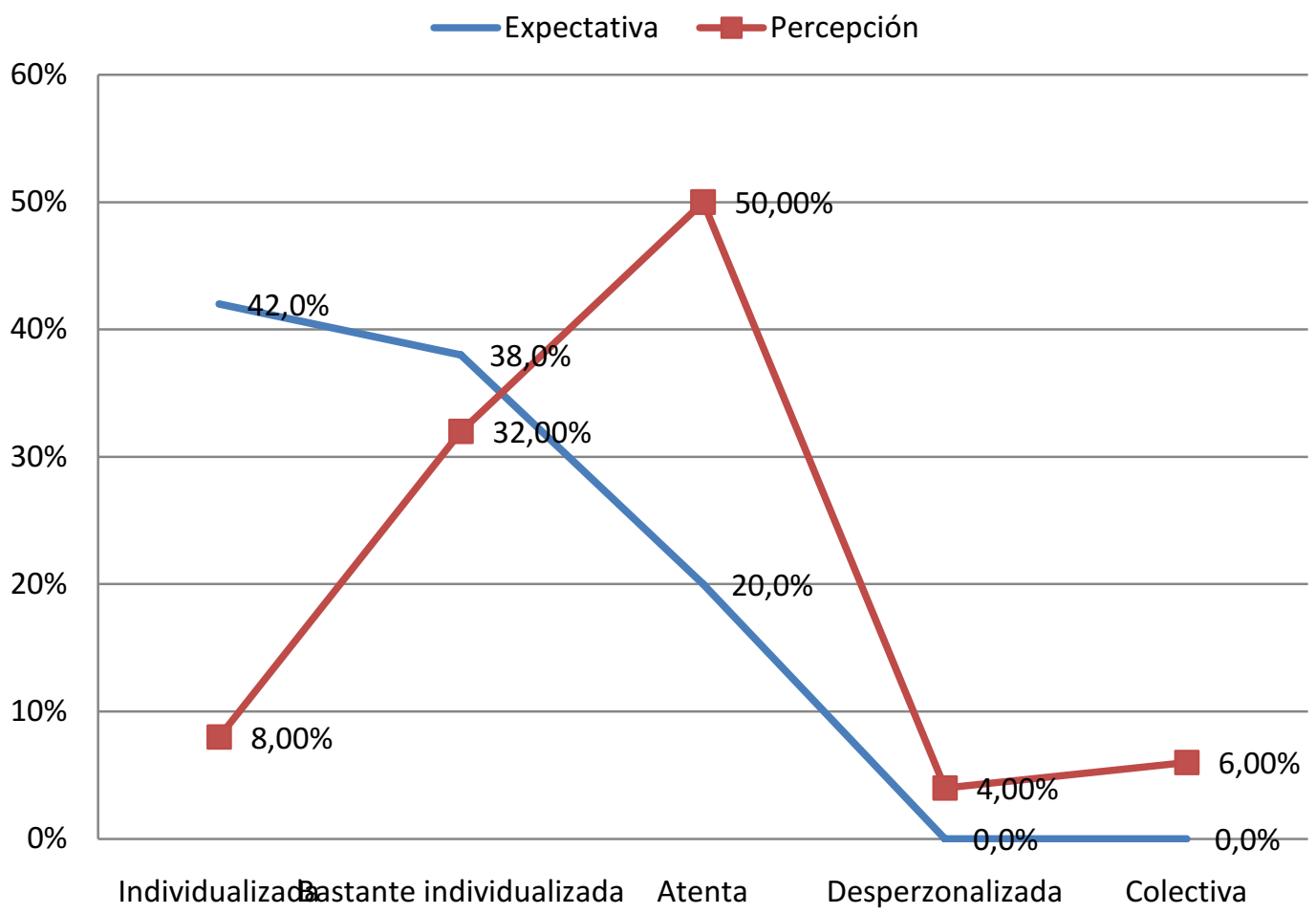

\section{Brecha individualización}

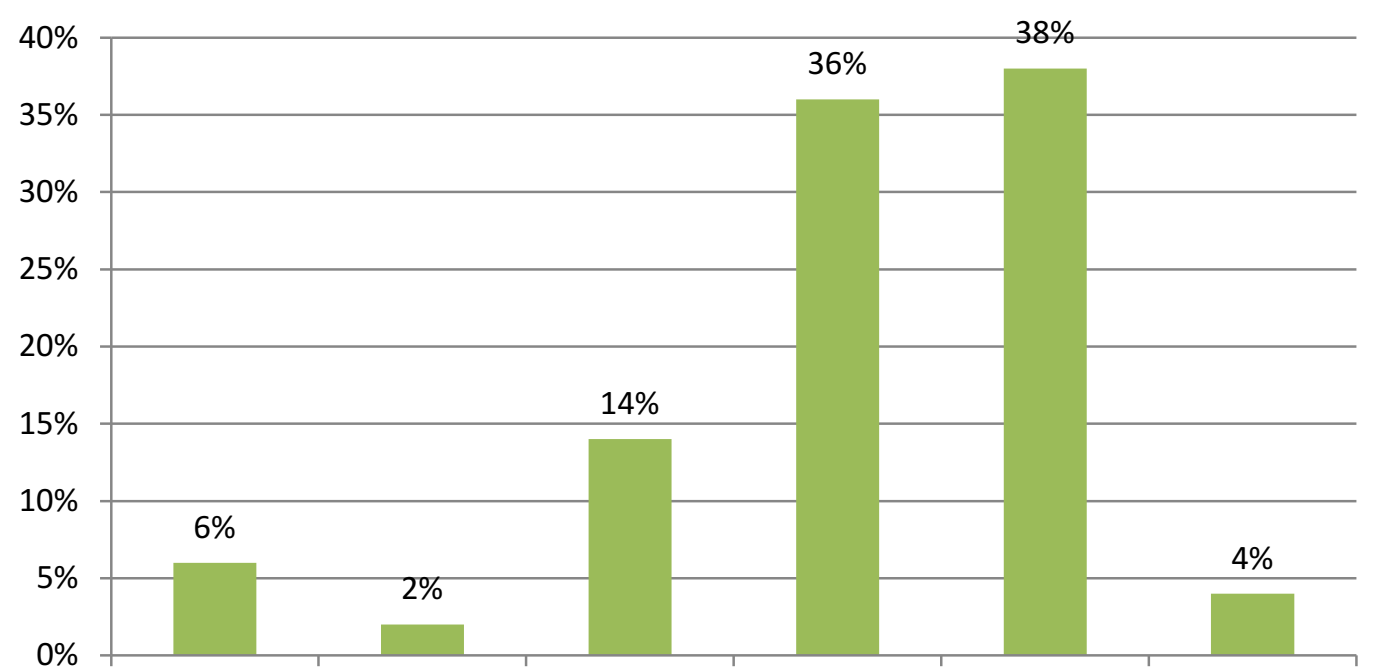

Insatisfacción tołkaly insatisfeßdsøante insatisfeddgo insatisfecho SatisfecAdgo más que satisfecho

Saldo de Respuesta: -0,90 "Algo insatisfecho" con leve tendencia a "Satisfecho". 


\subsubsection{Conveniencia de los horarios de trabajo}

\subsubsection{Expectativa}

\section{Conveniencia de los horarios de trabajo del servicio}

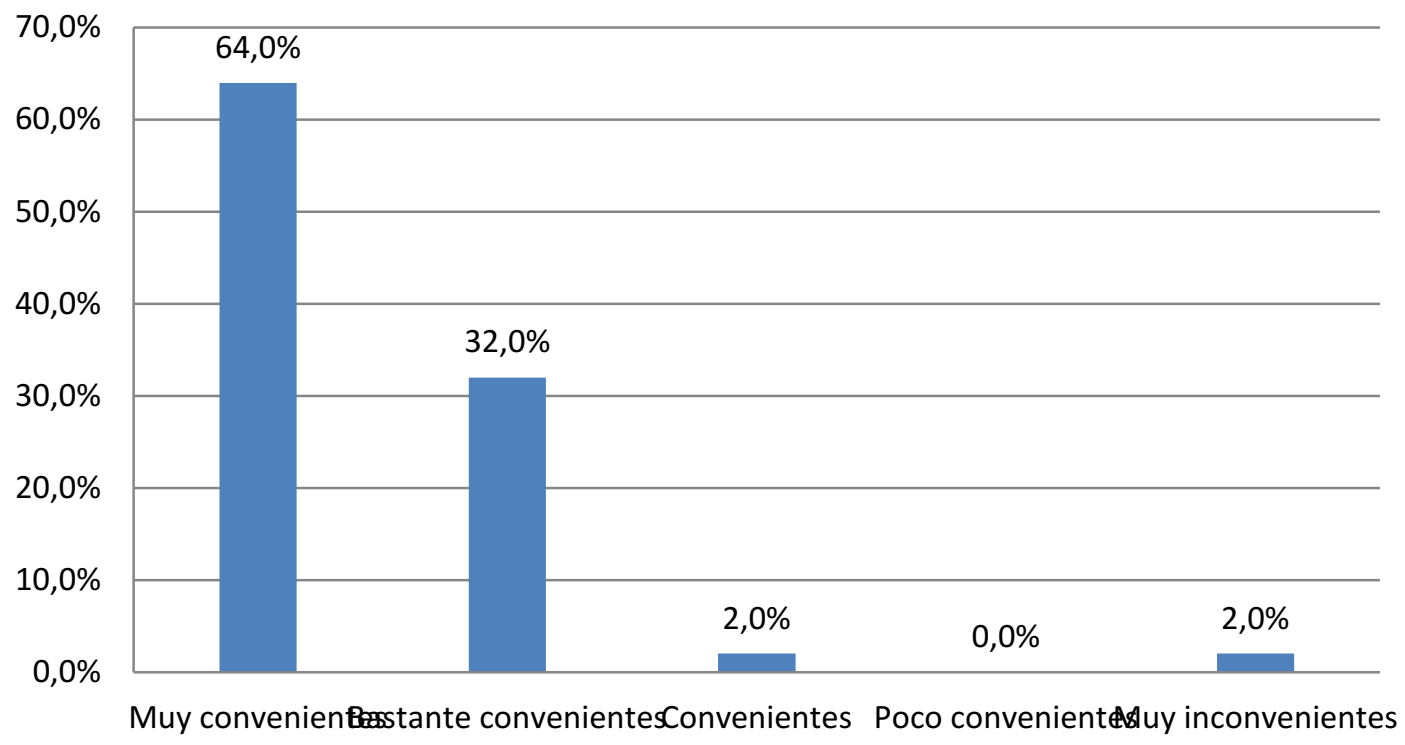

Saldo de Respuesta: 1,44 "Muy convenientes" con tendencia a "Bastante convenientes". 


\subsubsection{Percepción}

\section{Conveniencia de los horarios de trabajo del servicio}

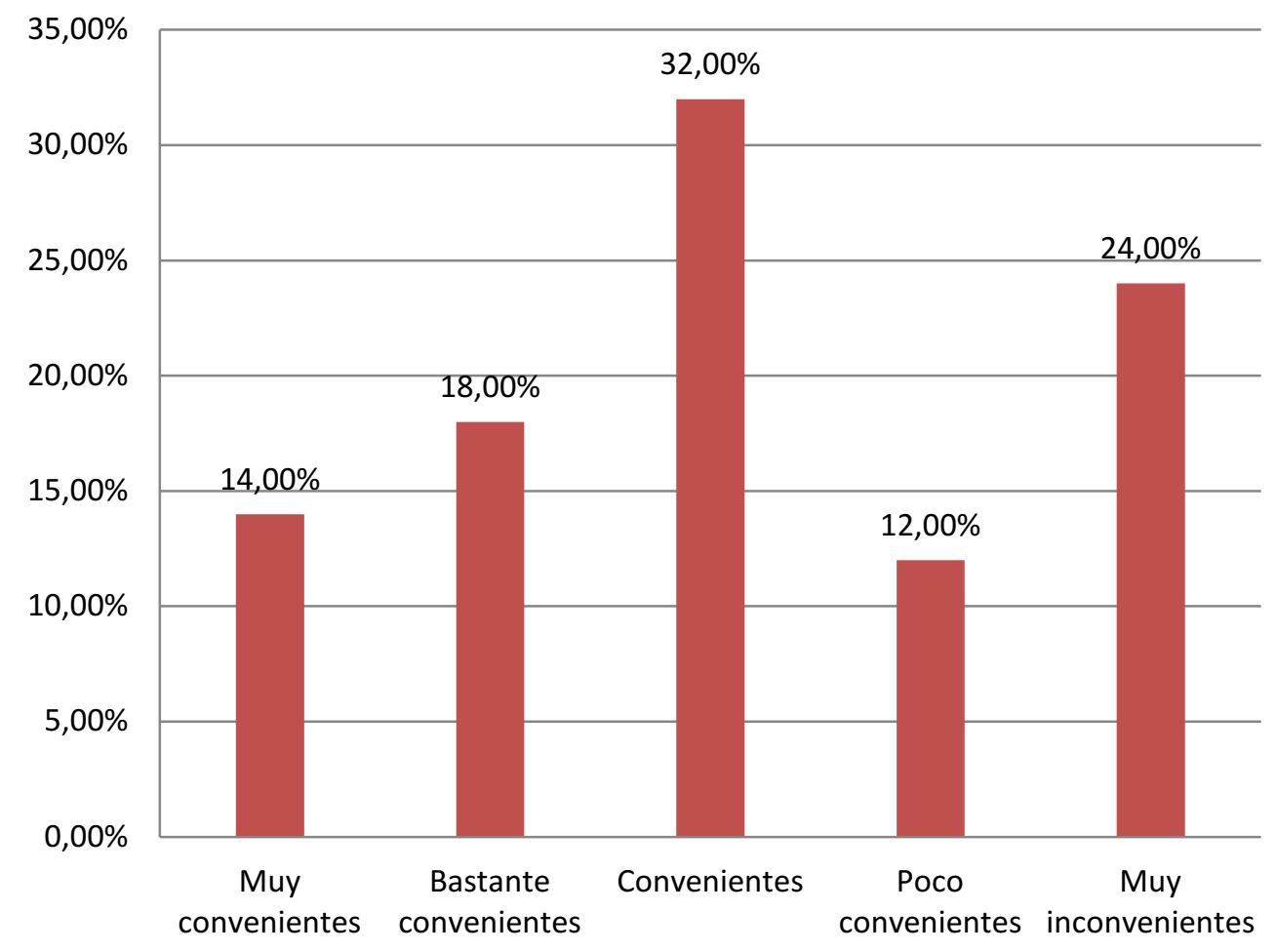

El Saldo de Respuesta de la conveniencia percibida en los horarios de trabajo del servicio es de 3,14 . Los usuarios puntuaban de 1 a 5 , de muy convenientes a muy inconvenientes.

\subsubsection{Brecha}


Conveniencia de los horarios de trabajo del servicio

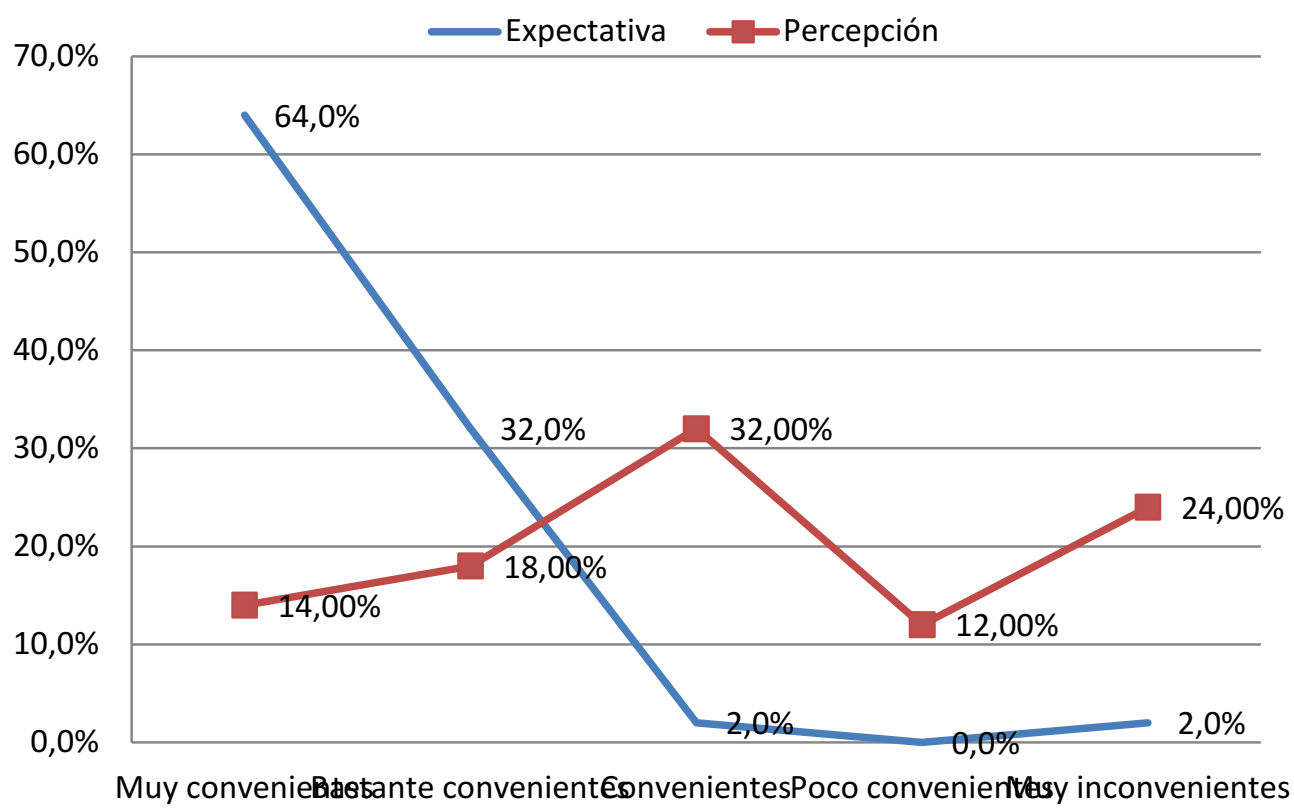

\section{Brecha horarios}

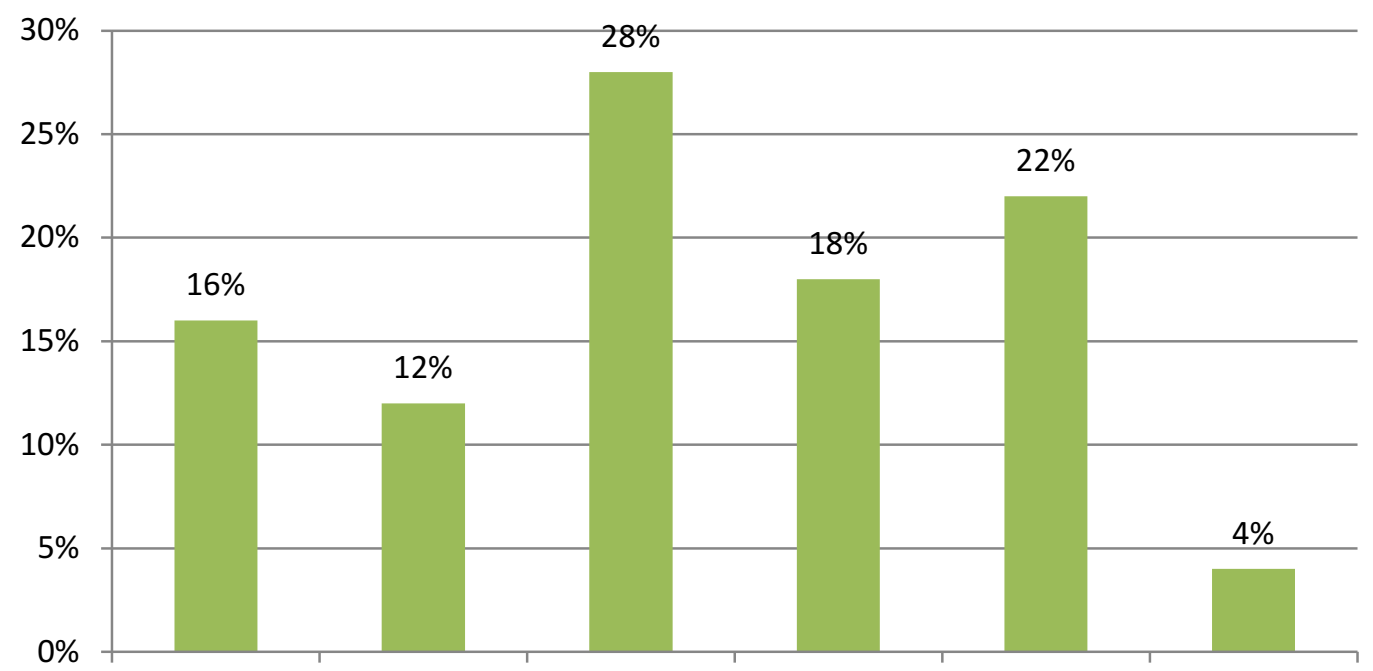

Insatisfacción tołłally insatisf@edscbante insatisfedlgo insatisfecho SatisfecAdgo más que satisfecho

Saldo de Respuesta: -1,70 "Bastante insatisfecho" con tendencia a "Algo insatisfecho" 


\subsubsection{Nivel de personalización en la atención del servicio}

\subsubsection{Expectativa}

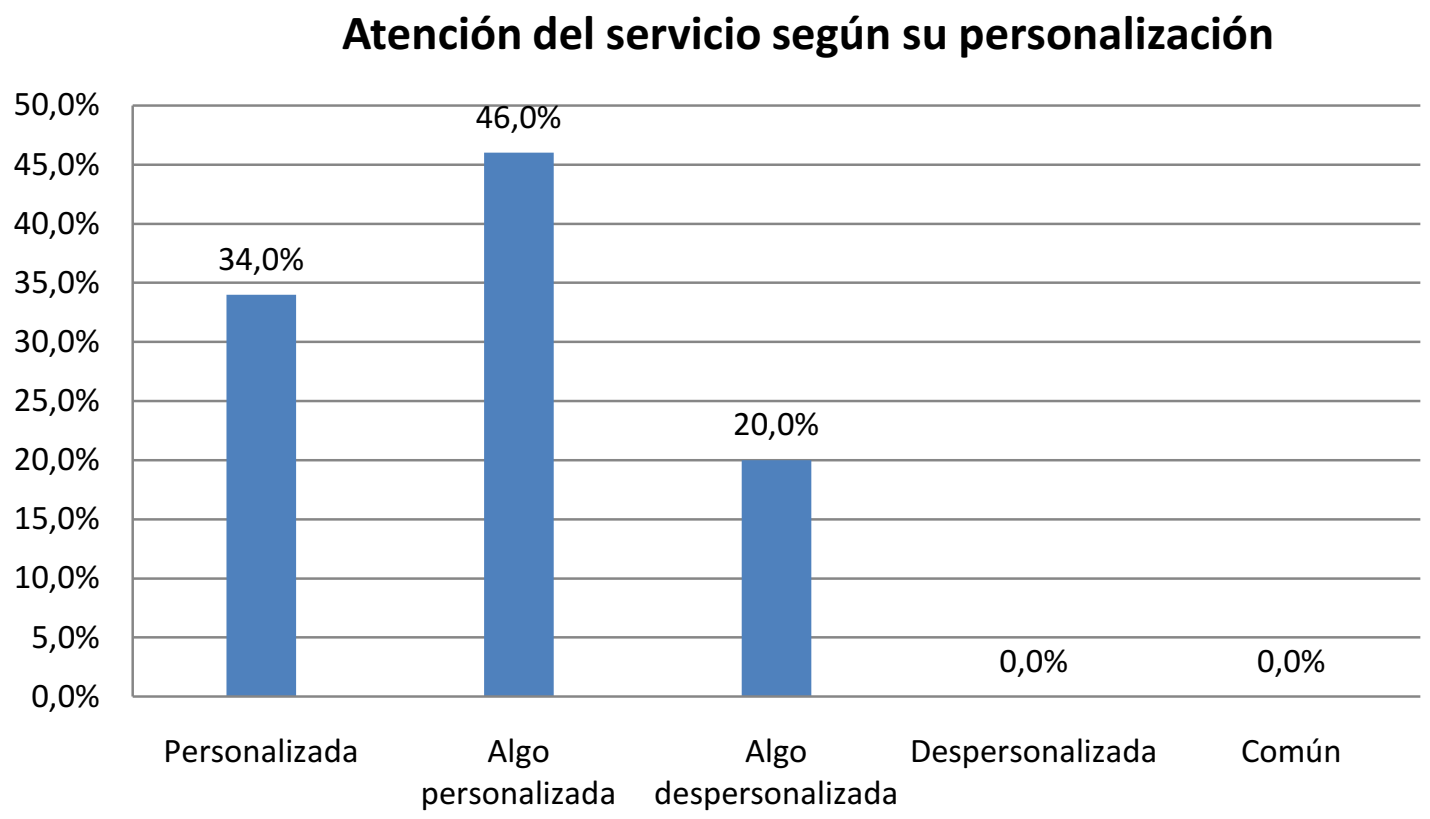

Saldo de Respuesta: 1,86 "Algo personalizada" a "Personalizada".

\subsubsection{Percepción}


Atención del servicio según su personalización

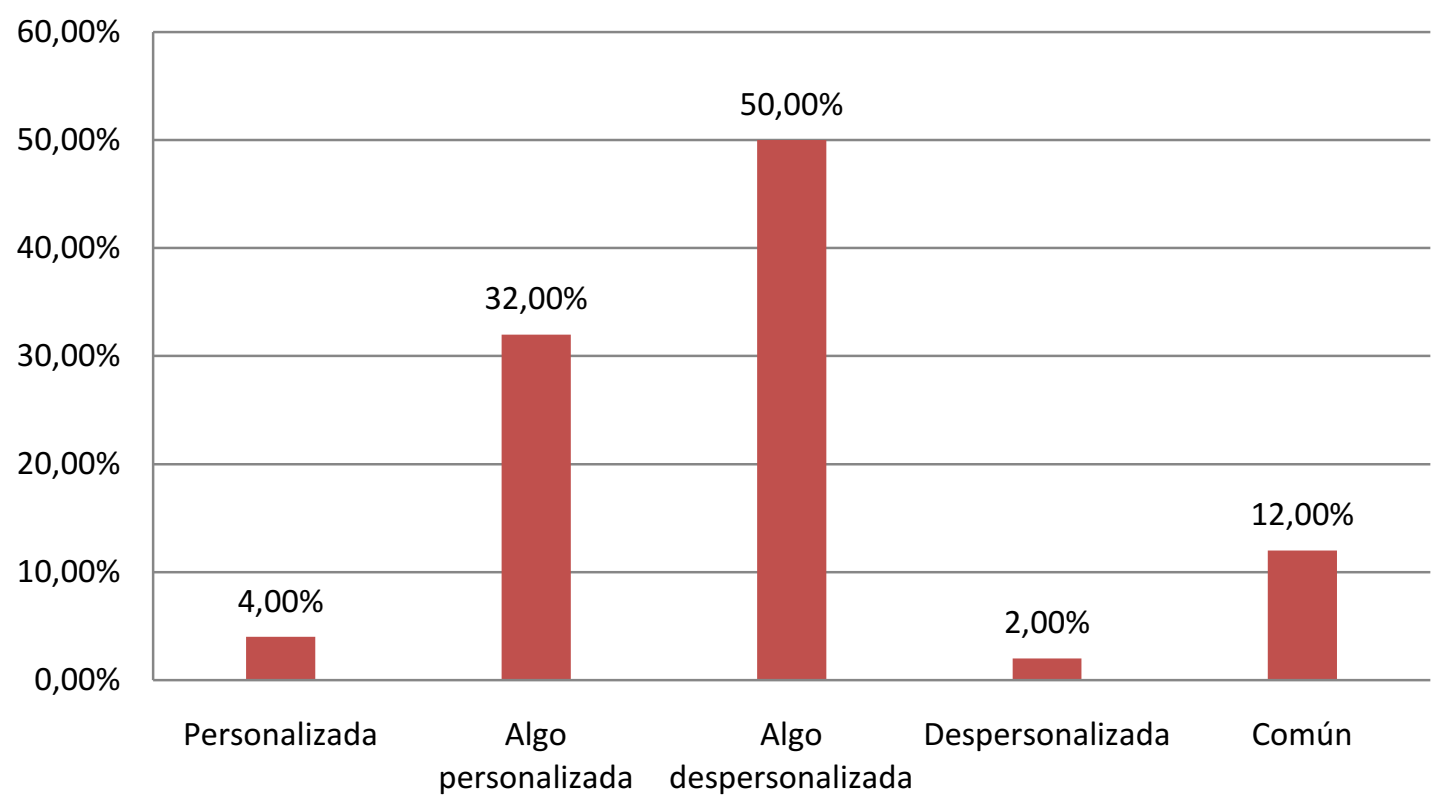

La calificación de la atención personalizada se percibió cercana a algo despersonalizada, con un Saldo de Respuesta de 2,86. 


\subsubsection{Brecha}

\section{Atención del servicio según su personalización}

Expectativa $\rightarrow-P e r c e p c i o ́ n$

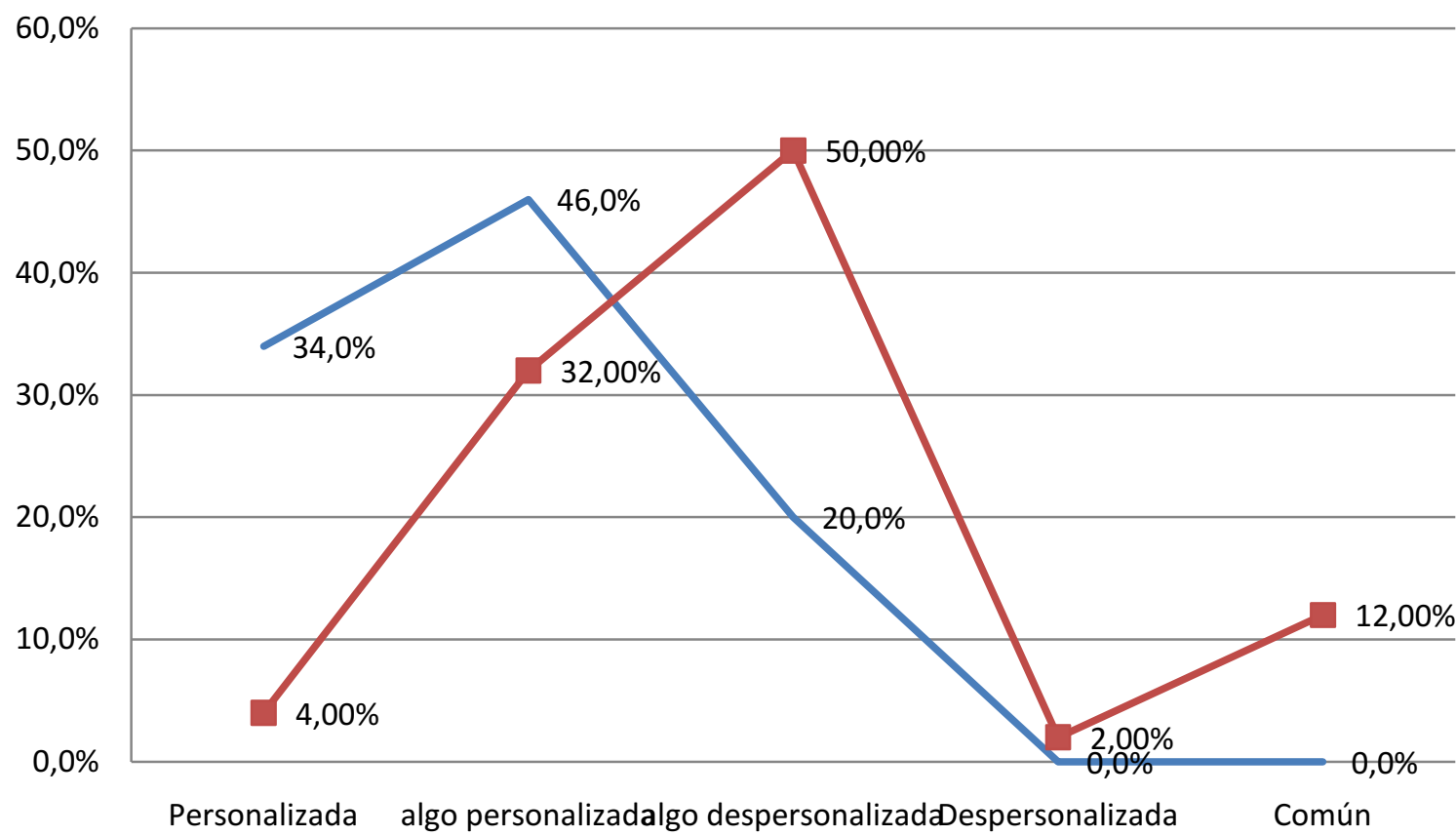

\section{Brecha personalización}

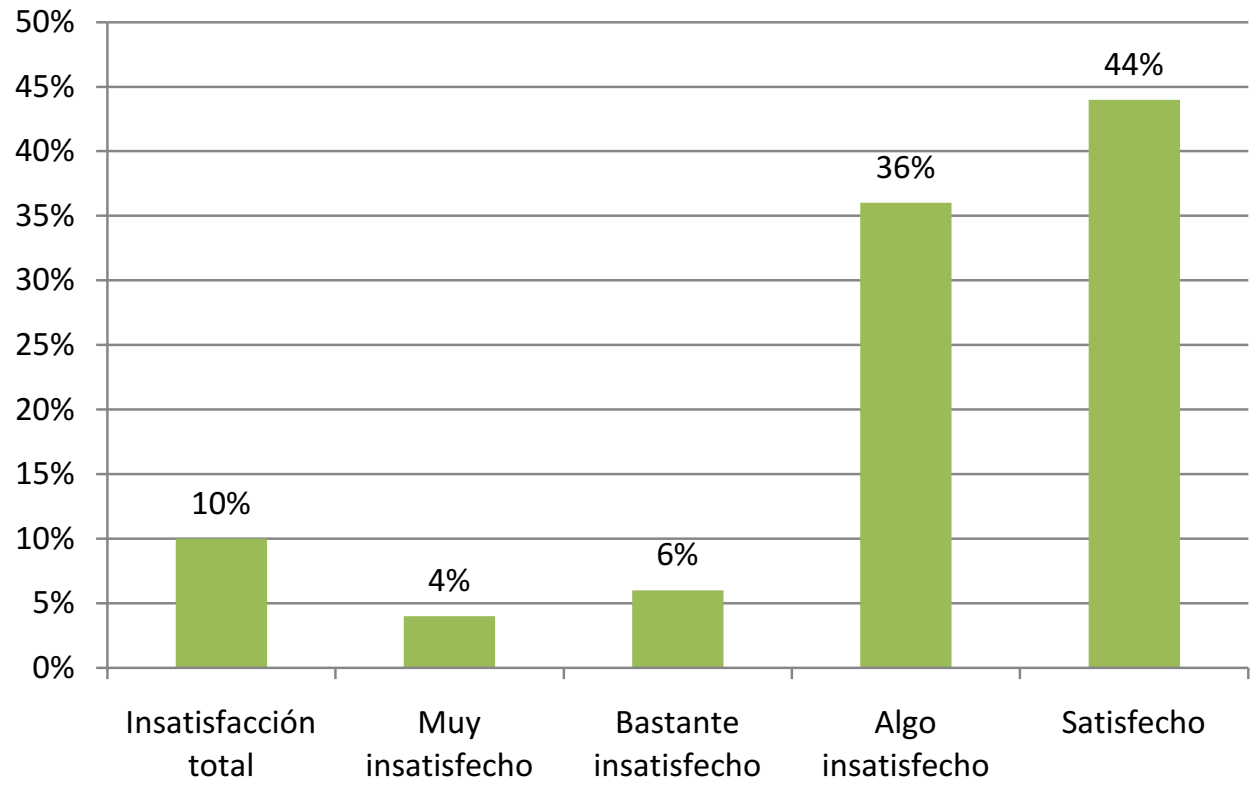

Saldo de Respuesta: -1,00 "Algo insatisfecho". 
7.6.4 Grado de preocupación que tienen los empleados por los intereses del cliente

\subsubsection{Expectativa}

Preocupación de los empleados con sus intereses

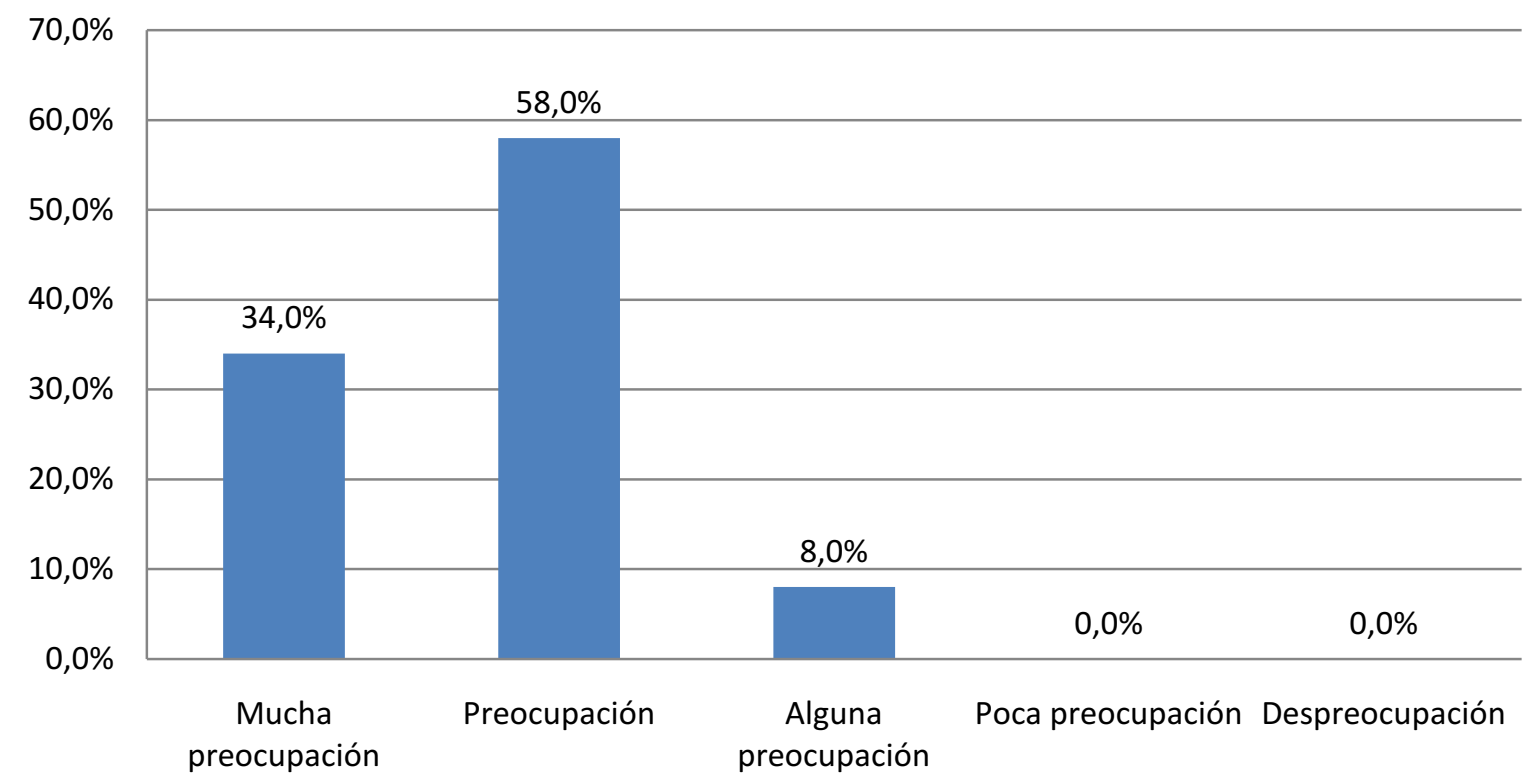

Saldo de Respuesta: 1,74 "Preocupación" "Mucha preocupación”. 


\subsubsection{Percepción}

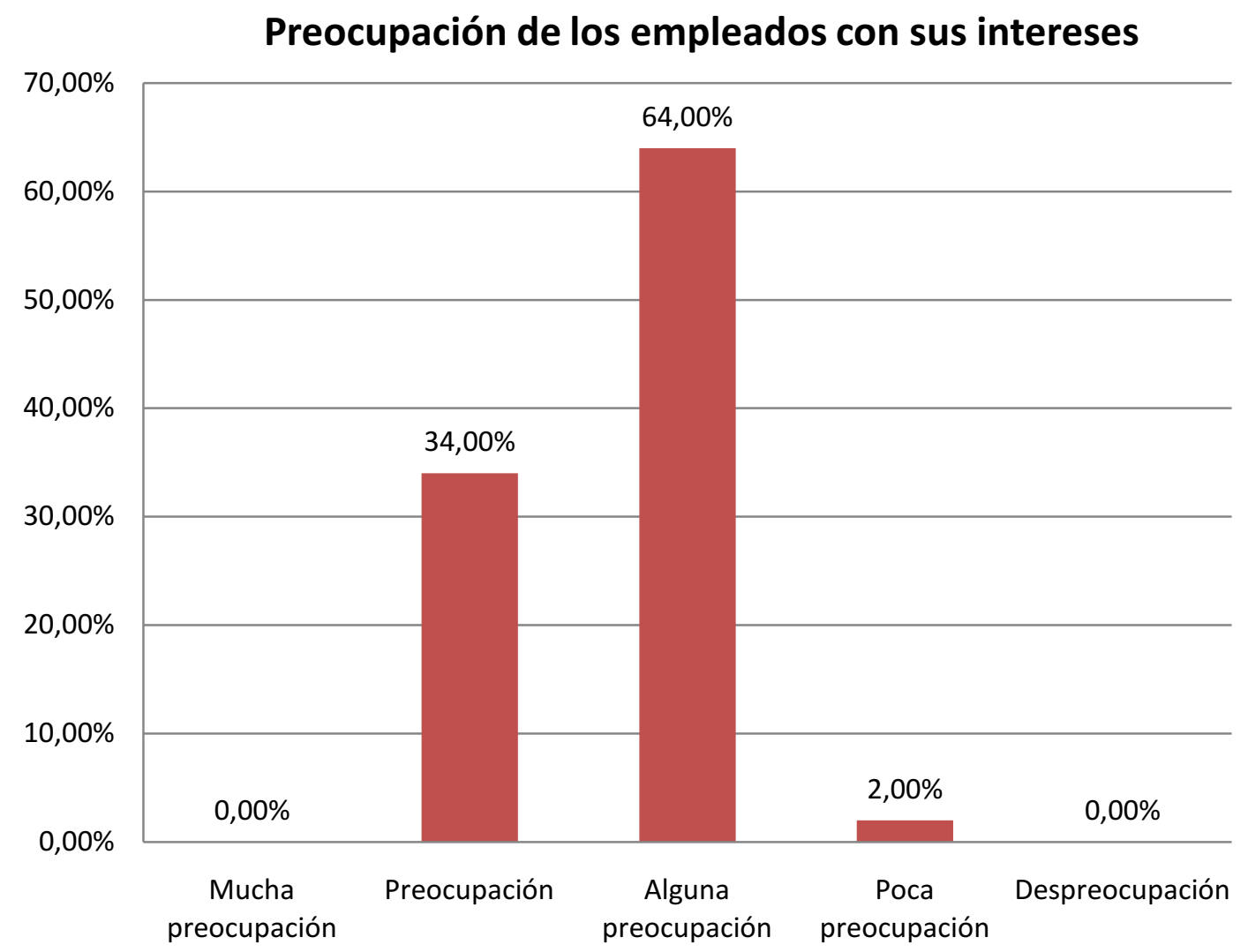

Con un Saldo de Respuesta de 2,68 los clientes estiman que los empleados presentan sólo un poco más que "alguna" preocupación respecto de sus intereses. 


\subsubsection{Brecha}

\section{Preocupación de los empleados con sus intereses}

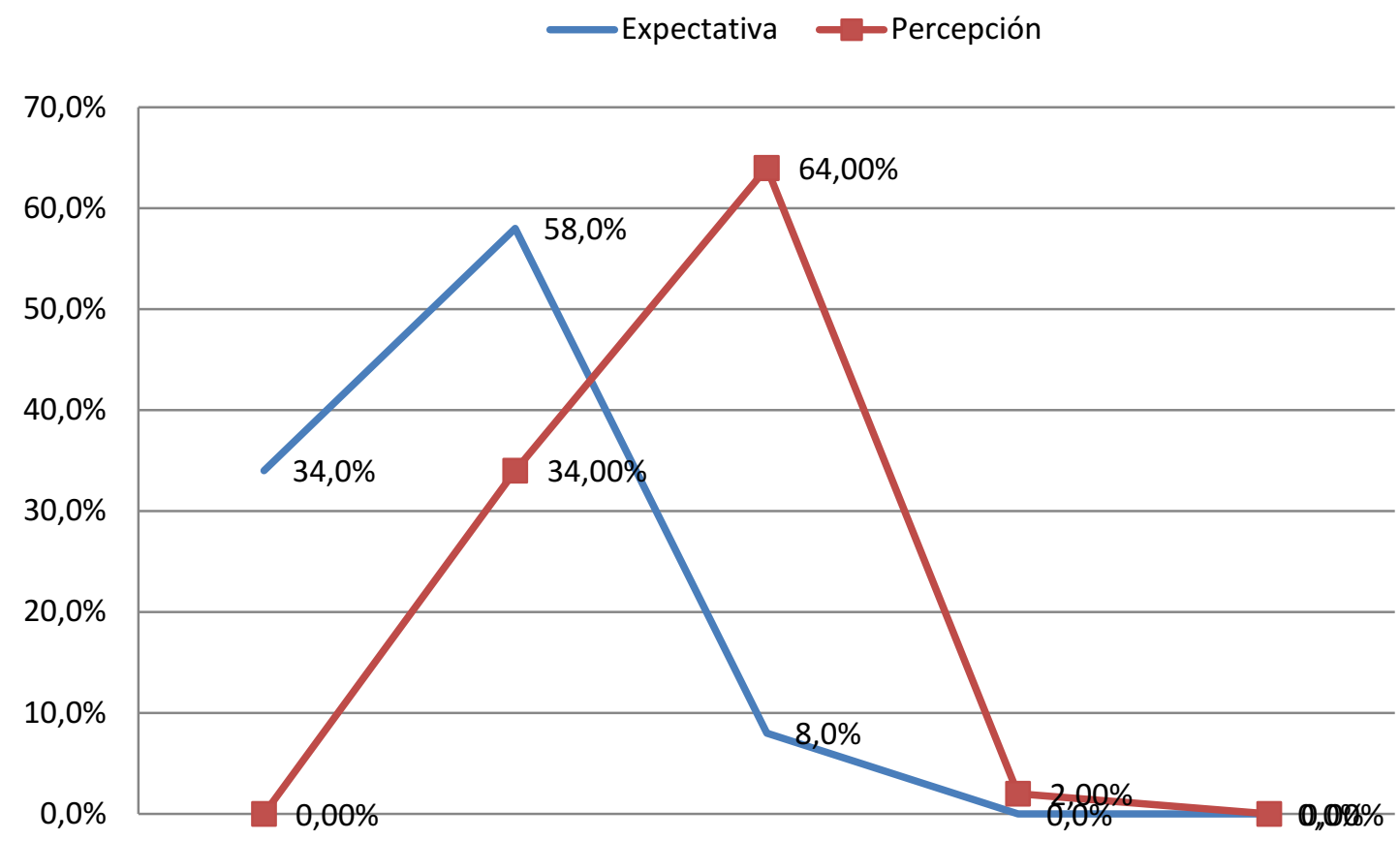

Mucha preocupación Preocupación Alguna preocupacióploca preocupación Despreocupación

\section{Brecha preocupación}

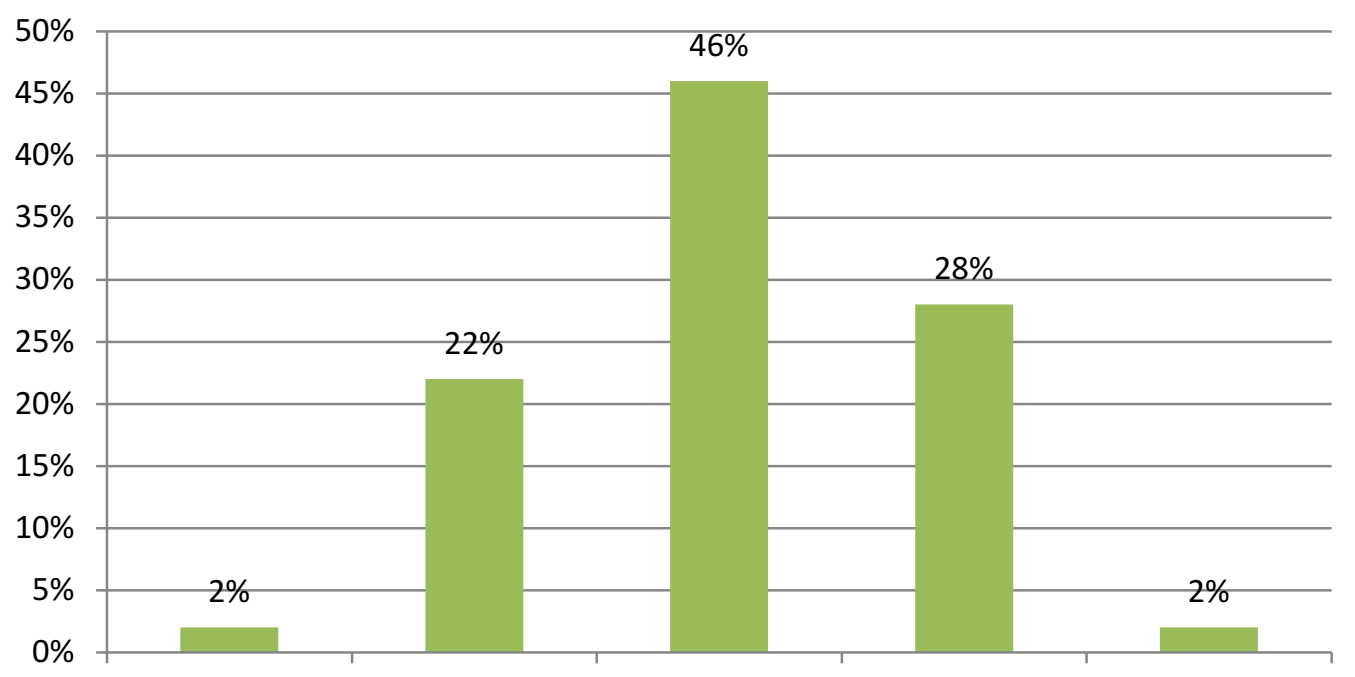

Muy insatisfechastante insatisfech@lgo insatisfecho Satisfecho Algo más que satisfecho

Saldo de Respuesta: -0,94 "Algo insatisfecho". 
Como se observa en el gráfico anterior, en la gran mayoría de los casos no se logra la expectativa con la que los usuarios llegaron al servicio con respecto a la Preocupación de los empleados con sus intereses.

\subsubsection{Grado en que el servicio comprende las necesidades específicas del} cliente

\subsubsection{Expectativa}

Grado en que el servicios comprende las necesidades del cliente

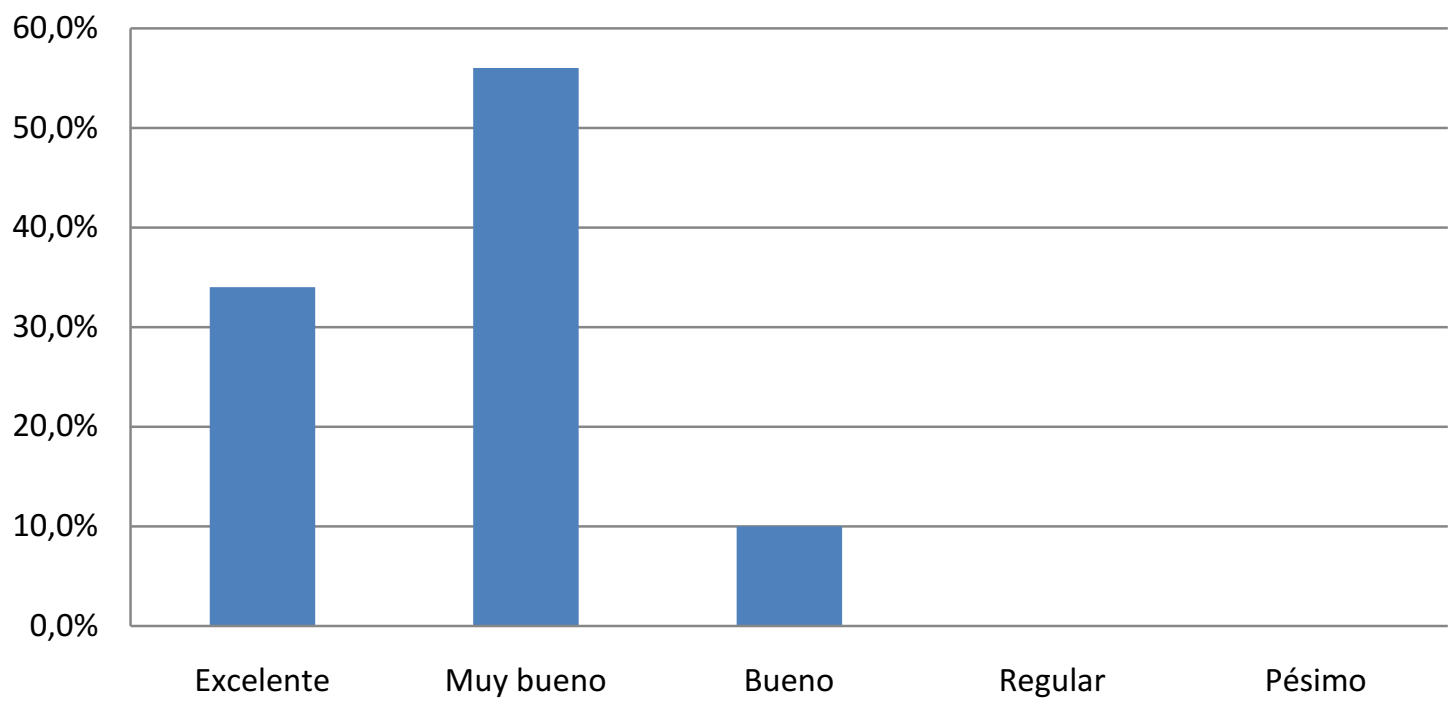

Saldo de Respuesta: 1,76 "Muy Bueno" con tendencia a "Excelente".

\subsubsection{Percepción}


Grado en que el servicios comprende las necesidades del cliente

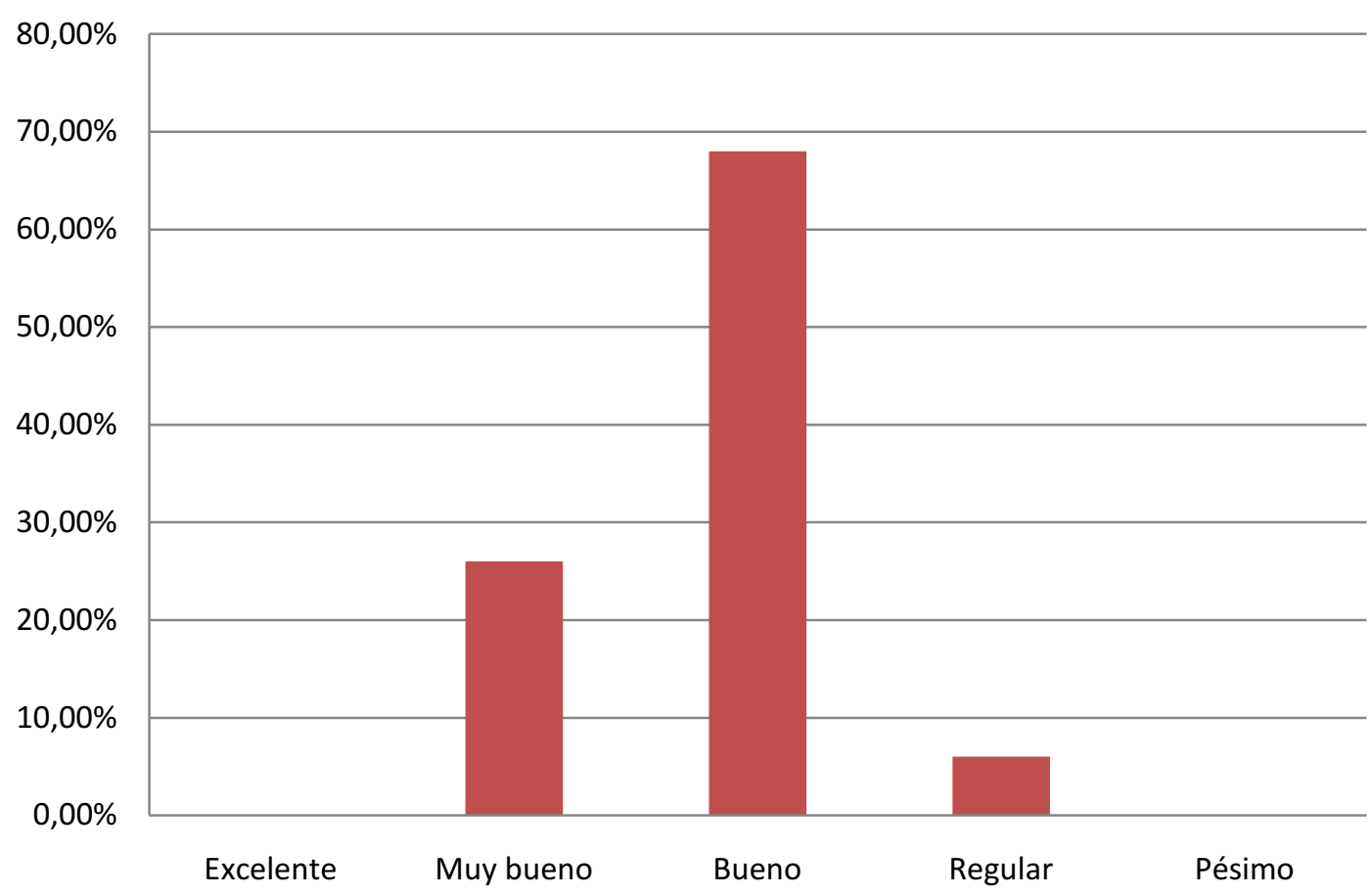

La calificación obtenida por el grado de comprensión de las necesidades del cliente con un Saldo de Respuesta de 2,80 fue bueno a muy bueno. 


\subsubsection{Brecha}

Grado en que el servicios comprende las necesidades del cliente

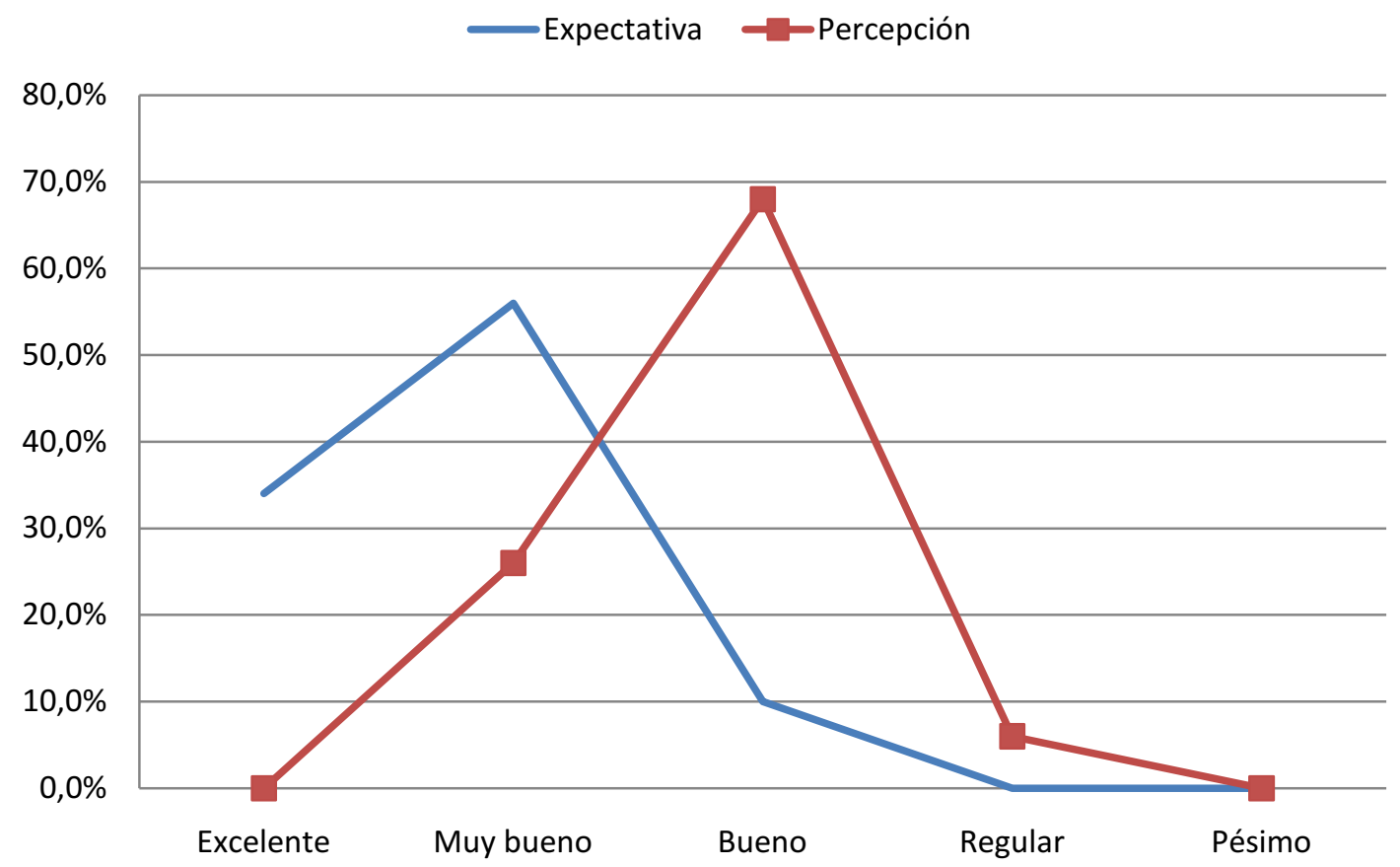

Brecha comprende necesidades

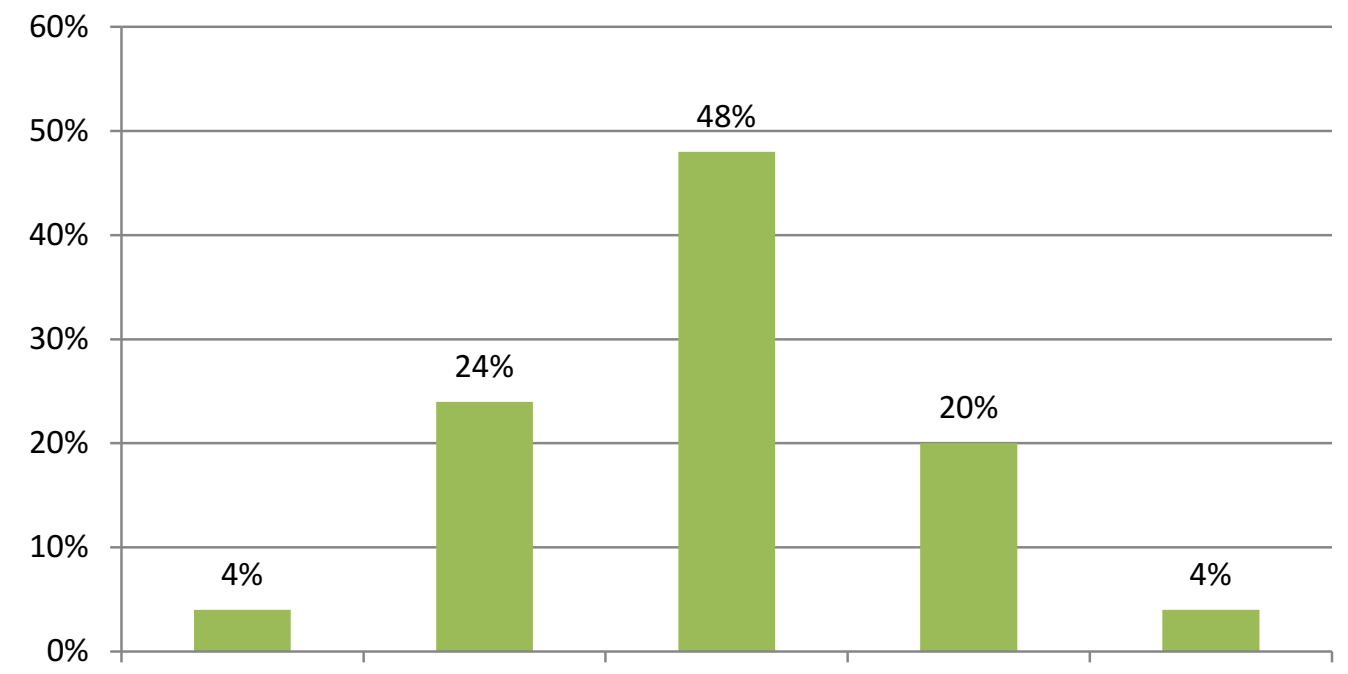

Muy insatisfechrastante insatisfechadgo insatisfecho SatisfechoAlgo más que satisfecho

Saldo de Respuesta: -1,04 "Algo insatisfecho". 
7.7 ¿Cuál es la dimensión más importante para el cliente de la Dirección de Defensa del Consumidor?

Se les pidió a los usuarios del servicio de Defensa del Consumidor que ordenasen en función a sus prioridades de importancia las distintas dimensiones. La dimensión más importante para los usuarios del servicio de Defensa del Consumidor es la Capacidad de respuesta junto con la Seguridad. La tercera en importancia es la Confiabilidad, y la cuarta es la Empatía. Quedando en último lugar la Dimensión Elementos tangibles.

\begin{tabular}{|lcc|}
\multicolumn{1}{c}{ Dimensión } & Valor & Importancia \\
\hline Capacidad de respuesta & 2,06 & $1^{\circ}$ \\
\hline Seguridad & 2,08 & $2^{\circ}$ \\
\hline Confiabilidad & 2,88 & $3^{\circ}$ \\
\hline Empatía & 3,46 & $4^{\circ}$ \\
\hline Elementos tangibles & 4,52 & $5^{\circ}$ \\
\hline
\end{tabular}

7.8 Calificación global de la percepcion de los usuarios de la Dirección Operativa de Licencias de Conducir.

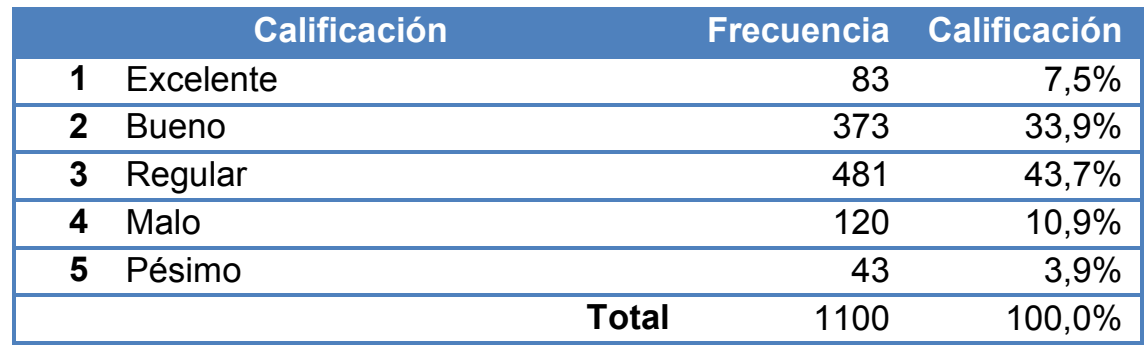

Con un Saldo de respuesta de 2,70 la calificación global es Regular (con tendencia a Bueno).

7.9 Calificación global de la percepcion de los usuarios de la Dirección Operativa de Licencias de Conducir.

\begin{tabular}{|rlrr|}
\hline \multicolumn{1}{|c}{ Calificación } & Frecuencia & Calificación \\
\hline $\mathbf{1}$ & Excelente & 549 & $49,9 \%$ \\
\hline $\mathbf{2}$ & Bueno & 462 & $42,0 \%$ \\
\hline $\mathbf{3}$ & Regular & 83 & $7,5 \%$ \\
\hline $\mathbf{4}$ & Malo & 5 & $0,5 \%$ \\
\hline $\mathbf{5}$ & Pésimo & 1 & $0,1 \%$ \\
\hline & & 1100 & $100,0 \%$ \\
\hline
\end{tabular}




\subsection{Calificación global de la percepcion de los usuarios de la Dirección Operativa de Licencias de Conducir.}

\begin{tabular}{|rlrr|}
\hline \multicolumn{1}{|c}{ Calificación } & Frecuencia & Calificación \\
\hline $\mathbf{- 4}$ & Insatisfacción total & 33 & $3,0 \%$ \\
\hline $\mathbf{- 3}$ & Muy insatisfecho & 82 & $7,5 \%$ \\
\hline $\mathbf{- 2}$ & Bastante insatisfecho & 260 & $23,6 \%$ \\
\hline $\mathbf{- 1}$ & Algo insatisfecho & 361 & $32,8 \%$ \\
\hline $\mathbf{0}$ & Satisfecho & 325 & $29,5 \%$ \\
\hline $\mathbf{1}$ & Algo más que satisfecho & 39 & $3,5 \%$ \\
\hline $\mathbf{2}$ & Bastante más que satisfecho & 0 & $0,0 \%$ \\
\hline $\mathbf{3}$ & Mucho más que satisfecho & 0 & $0,0 \%$ \\
\hline $\mathbf{4}$ & Satisfacción absoluta & 0 & $0,0 \%$ \\
\hline & & 1100 & $100,0 \%$ \\
\hline
\end{tabular}

Con un Saldo de respuesta de -1,11 la calificación global es Algo insatisfecho (con leve tendencia a Bastante insatisfecho).

\section{Conclusiones}

En una primera instancia la mayoría de los usuarios califican a la organización del servicio en general como buena tendiendo a regular. Pero cuando ahondamos en todas y cada una de las dimensiones del servicio podemos observar lo siguiente:

Respecto a la dimensión I, los elementos tangibles, la apariencia física de los empleados fue la que tuvo el mayor grado de satisfacción. Por otro lado la apariencia visual de los elementos de comunicación tuvo un nivel de insatisfacción muy elevado. Mientras que el resto de los aspectos consultados (los equipos, las instalaciones físicas) las percepciones obtenidas por los encuestados han sido bastante inferiores a las expectativas que tenían.

En lo referente a la confiabilidad, la segunda de las dimensiones, los resultados han sido parejos en los cinco aspectos consultados, la gran mayoría se sintió algo insatisfecho. 
En lo que respecta a la capacidad de respuesta, las percepciones globales no alcanzan a las expectativas. La insatisfacción está más que nada explicada por la pobre velocidad del servicio. A pesar de ello, por otro lado cabe mencionar que una gran cantidad de usuarios sintió cumplidas sus expectativas, siendo el nivel de comunicación el aspecto consultado con mayor calificación de la dimensión.

En lo relativo a la dimensión IV, seguridad, el público se muestra solo algo insatisfecho con tendencia a satisfecho, siendo la amabilidad con que fue atendido el aspecto a destacar con un gran porcentaje de satisfacción. Con respecto a esta dimensión, resta mencionar que en el aspecto seguridad se obtuvieron los peores resultados.

Finalmente, la dimensión V empatía, los usuarios se manifestaron muy insatisfechos con los horarios del servicio. Sin embargo, en el resto de los aspectos consultados, la mayoría se ha sentido solo algo insatisfecho.

Es de destacar que los usuarios consultados definieron a las dimensiones capacidad de respuesta y seguridad como las más importantes, la primera con una leve diferencia a favor. Luego le siguen en valoración, confiabilidad y, empatía. Menor importancia se le ha dado a los elementos tangibles.

Se concluye que el cliente del servicio de Defensa del Consumidor de la Municipalidad de La Plata se muestra en líneas generales algo insatisfecho. En las dimensiones que menor importancia les dieron los consumidores, empatía y elementos tangibles, están los aspectos consultados que mayor grado de insatisfacción se observó sobretodo en elementos tangibles. En el resto de las dimensiones los resultados fueron parejos sin alcanzar las expectativas, solo cabe mencionar el buen nivel de satisfacción que tuvo el aspecto amabilidad por el lado de la dimensión seguridad y la apariencia física de los empleados por el lado de los elementos tangibles. 


\section{Bibliografía}

- Álvarez, M. (1998): El liderazgo de la calidad total. Madrid: Editorial Escuela Española.

- Asensio, P. (2008). Marketing municipal. Madrid: Díaz de Santos.

- Badía A. (1999): Técnicas para la gestión de Calidad. Ed. Técnoc.

- Bernillón, A.; Cerutti, O. (1989): Implantar y gestionar la calidad total. Barcelona: Gestión 2.000.

- Control total de la calidad / Armand V. Feigenbaum; tr. Ma. Ascención G. de la Campa Pérez -- Editorial CECSA, c1994 Título original: Total Quality Control.

- Deming WE. (1989): Calidad, productividad y competitividad. La salida de la crisis. Madrid: Díaz de Santos.

- Desarrollo de una cultura de calidad / Humberto Cantú Delgado; rev. téc. Jesús Cantú Rodríguez-- Editorial McGraw-Hill, c2001.

- Dona Bedián, a. (1991): "La calidad de la atención médica. Definición y métodos de evaluación", Méjico: La Prensa Médica Mexicana.

- Donnelly, M. \& Shiu, E. (1999). Assessing Service Quality and its Link with value for Money in a UK Local Authority's Housing Repairs Service Using the SERVQUAL Approach. Total Quality Management, 10(4/5), 498-506.

- Donnelly, M., Wisniewski, M., Dalrymple, J. F. \& Curry, A. C. (1995). Measuring Service Quality in Local Government: the Servqual Approach. International Journal of Public Sector Management, 8(7), 15-20

- Drummond, H. (1995): Qué es hoy la calidad total: el movimiento de la calidad. Bilbao: Deusto D.L.

- Fernández Barcalá, M. (2000). Validación de Servqual como instrumento de medida de la calidad de servicio bancario. Revista Europea de Dirección y Economía de la Empresa, 9(1), 57-70.

- Galgano, A. (1995): Los siete instrumentos de la calidad total: manual operativo. Madrid: Díaz de Santos.

- Gaster, L. (1996). Quality Services in Local Government: a Bottom-Up Approach. Journal of Management Development, 15(2), 80-96. 
- Gil, I. (1996). La evaluación de la calidad de servicio percibida y las limitaciones de la herramienta Servqual. Revista Europea de Dirección y Economía de la empresa, 5(2), 19-32.

- Grima Cintas, P; Tort-Martorell, J (1995): Técnicas para la gestión de la calidad. Madrid: Díaz de Santos. Ishikawa K.

- Gutiérrez, Mario (1989) Administrar para la calidad: conceptos administrativos del control total de calidad / -- Editorial Limusa.

- Gutiérrez, P. \& Jorge, M. (2008). El desarrollo de políticas públicas locales como garantes de la satisfacción de los ciudadanos. Madrid: Fundación Alternativas.

- Kotler, P. \& Lee, N. (2007). Marketing en el sector público. Madrid: Prentice Hall. (Original en inglés, 2006).

- Manual de control de calidad / J.M. Juran editor jefe, Frank M. Gryna editor asociado, tr. Josep María Vallhonrat Bou.-- Editorial McGraw-Hill, c1993.

- Méndez, J. M. (1996). Servicios municipales: análisis de situación y líneas de mejora sugeridas. Barcelona: Diputación de Barcelona, Papers de Formación Municipal, 25.

- Sancho Royo, D. (1999). Gestión de servicios públicos: estrategias de marketing y calidad. Madrid: Ed. Tecnos.

- Santesmases Mestre, M. (2007). Marketing: conceptos y estrategias. Madrid: Ediciones Pirámide.

- Scott, D. \& Shieff, D. (1993). Service Quality Components and Group Criteria in Local Government. International Journal of Service Industry Management, 4(4), 42-53.

- Senllé, A. (1996). Calidad total en los servicios y en la administración pública. Barcelona: Ed. Gestión 2000. 


\title{
10. Referencias y Anexos
}

\section{Anexo 1 ENCUESTA}
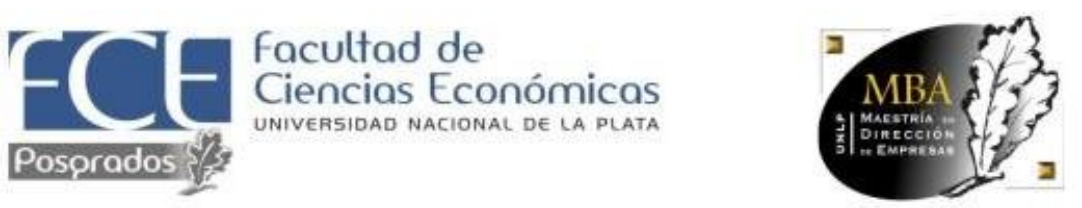

\author{
MAESTRIA EN \\ DIRECCIÓN DE EMPRESAS
}

Encuesta №

Encuesta dirigida a clientes del servicio de Defensa del Consumidor de la Municipalidad de La Plata.

\section{OBJETIVO}

Medir la satisfacción de los clientes del servicio de Defensa del Consumidor de la Municipalidad de La

Plata.

1.- ¿Con que frecuencia utiliza el servicio de Defensa del Consumidor?

\begin{tabular}{|l|l|}
\hline 1) A diario & \\
\hline 2) Varias veces a la semana & \\
\hline 3) Una vez al mes & \\
\hline 4) Una vez cada seis meses & \\
\hline 5) Una vez al año & \\
\hline 6) Cada varios años & \\
\hline
\end{tabular}

\section{2.- ¿Cómo calificaría la organización del servicio de Defensa del Consumidor?}

\begin{tabular}{|l|l|}
\hline 1) Excelente & \\
\hline 2) Bueno & \\
\hline 3) Regular & \\
\hline 4) Malo & \\
\hline 5) Pésimo & \\
\hline
\end{tabular}

3.- En las siguientes preguntas, califique de 1 a 5 según corresponda

Dimensión 1: Elementos Tanqibles

\begin{tabular}{|l|l|l|}
\hline \multicolumn{1}{|c|}{$\begin{array}{c}\text { Apariencia de las instalaciones físicas, equipos, personal y materiales de } \\
\text { comunicación }\end{array}$} & Expectativa & Percepción \\
\hline Los equipos con que cuenta el servicio son... [1 = Modernos a 5 = Obsoletos] & & \\
\hline Las instalaciones físicas del servicio son [1 = Atractivas a 5 = Desagradables] & & \\
\hline La apariencia física de los empleados es... [1 = Pulcra a 5 = Desaseada] & & \\
\hline $\begin{array}{l}\text { La apariencia visual de los elementos materiales de comunicación es... [1 = } \\
\text { Atractivos a 5 = Desagradables] }\end{array}$ & & \\
\hline
\end{tabular}

\section{Dimensión 2: Confiabilidad}

\begin{tabular}{|l|c|c|}
\hline Habilidad para ejecutar el servicio prometido de forma confiable y cuidadosa & Expectativa & Percepción \\
\hline Los empleados del servicio municipal cumplen lo que prometen... [1 = Siempre & & \\
\hline
\end{tabular}


Satisfacción del Cliente del Servicio de Defensa del Consumidor - Municipalidad de La Plata

\begin{tabular}{|l|l|l|}
\hline Cumplen a 5 = Nunca Cumplen] & & \\
\hline $\begin{array}{l}\text { El interés que tienen los empleados del servicio en solucionar los problemas } \\
\text { de los clientes es... [1 = Total Interés a } 5=\text { Completo Desinterés }]\end{array}$ & & \\
\hline $\begin{array}{l}\text { La eficacia del servicio municipal es... [1 = Realiza el trabajo bien a la primera } \\
\text { vez a } 5=\text { nunca lo hace bien] }\end{array}$ & & \\
\hline $\begin{array}{l}\text { El tiempo del cumplimiento del trabajo es... [1 = Siempre a tiempo a 5 Nunca a } \\
\text { tiempo] }\end{array}$ & & \\
\hline $\begin{array}{l}\text { El trabajo que el servicio mantiene según su eficiencia es... [1 = Exento de } \\
\text { errores a } 5=\text { Con serias deficiencias] }\end{array}$ & & \\
\hline
\end{tabular}

\section{Dimensión 3: Capacidad de Respuesta}

\begin{tabular}{|l|l|l|}
\hline \multicolumn{1}{|c|}{$\begin{array}{c}\text { Disposición y voluntad de los empleados para ayudar al cliente y } \\
\text { proporcionar el servicio }\end{array}$} & Expectativa & Percepción \\
\hline $\begin{array}{l}\text { El nivel de comunicación que tiene con los empleados es... [1 = Excelente a } 5= \\
\text { Pésimo] }\end{array}$ & & \\
\hline $\begin{array}{l}\text { La velocidad del servicio es... [1 = Muy Rápido a } 5=\text { Muy Lento] } \\
\text { Disponible] }\end{array}$ & & \\
\hline $\begin{array}{l}\text { El grado de disponibilidad para atención inmediata frente a otras actividades } \\
\text { es... [1 = Siempre disponible a } 5 \text { = Nunca Disponible] }\end{array}$ & & \\
\hline
\end{tabular}

\section{Dimensión 4: Sequridad}

\begin{tabular}{|l|l|l|}
\hline \multicolumn{1}{|c|}{$\begin{array}{c}\text { Conocimiento y atención mostrados por los empleados y sus habilidades } \\
\text { para inspirar credibilidad y confianza }\end{array}$} & Expectativa & Percepción \\
\hline $\begin{array}{l}\text { La confianza que brinda el comportamiento de los empleados es... [1 = } \\
\text { Completa Confianza a } 5=\text { Absoluta Desconfianza] }\end{array}$ & & \\
\hline $\begin{array}{l}\text { El nivel de seguridad que usted siente en sus transacciones con el servicio es... } \\
{[1=\text { Muy seguro a } 5=\text { Muy Inseguro] }}\end{array}$ & & \\
\hline $\begin{array}{l}\text { El nivel de amabilidad que muestran los empleados del servicio es... [1 = Muy } \\
\text { Amable a } 5 \text { = Muy descortés] }\end{array}$ & & \\
\hline $\begin{array}{l}\text { El grado de conocimiento que tienen los empleados para resolver sus } \\
\text { inquietudes es... [1 = Totalmente Conocedor a } 5=\text { Absolutamente Ignorante] }\end{array}$ & & \\
\hline
\end{tabular}

\section{Dimensión 5: Empatía}

\begin{tabular}{|l|l|l|}
\hline \multicolumn{1}{|c|}{ Atención individualizada que ofrece la organización a los clientes } & Expectativa & Percepción \\
\hline $\begin{array}{l}\text { La atención del servicio según su individualización es... [1 = Individualizada a } 5 \\
\text { = Colectiva] }\end{array}$ & & \\
\hline $\begin{array}{l}\text { Los horarios de trabajo -por conveniencia- son... }[1=\text { Muy convenientes o } 5= \\
\text { Muy Inconvenientes] }\end{array}$ & & \\
\hline $\begin{array}{l}\text { La atención del servicio según su personalización es... [1 = Personalizada a } 5= \\
\text { Común }]\end{array}$ & & \\
\hline $\begin{array}{l}\text { El grado de preocupación que tienen los empleados con sus intereses es... [1 } \\
\text { Mucha Preocupación a 5 = Despreocupación] }\end{array}$ & & \\
\hline $\begin{array}{l}\text { El grado en que el servicio comprende sus necesidades específicas es... [1 }= \\
\text { Excelente a 5 = Pésima] }\end{array}$ & & \\
\hline
\end{tabular}


4.- Distribuya del 1 al 5 según el grado de importancia que las siguientes dimensiones ocupan para usted en este servicio

\begin{tabular}{|l|l|}
\hline Elementos tangibles & \\
\hline Confiabilidad & \\
\hline Capacidad de respuesta & \\
\hline Seguridad & \\
\hline Empatía & \\
\hline
\end{tabular}

\section{5.- Perfil del encuestado}

Sexo $\quad 1 \square$ Hombre $2 \square$ Mujer

Edad $\begin{aligned} & 1 \square \text { Hasta } 20 \text { años } \\ & 2 \square \text { Más de } 20 \text { y hasta } 30 \text { años } \\ & 3 \square \text { Más de } 30 \text { y hasta } 40 \text { años } \\ & 4 \square \text { Más de } 40 \text { y hasta } 50 \text { años } \\ & 5 \square \text { Más de } 50 \text { y hasta } 60 \text { años } \\ & 6 \square \text { Más de } 60 \text { años }\end{aligned}$

Ocupación $\quad 1 \square$ Independiente $2 \square$ Empleado $3 \square$ Jubilado $4 \square$ Desempleado $5 \square$ Otros (especifique): 


\section{Anexo 2 MATRIZ DE RESULTADOS}

\section{Matriz de Resultados}

A continuacion se expone las matrices de expectativa, percepción y brecha entre ambas con los resultados obtenidos de cada pregunta de las encuestas realizadas a los usuarios del servicio. También se expone el resumen de brechas entre expectativa y percepción por cada dimensión junto con el resultado de la brecha del servicio en su totalidad.

\section{Expectativa de los consumidores en la calidad del servicio}

\begin{tabular}{|c|c|c|c|c|c|c|c|c|c|c|c|c|c|c|c|c|c|c|c|c|c|c|}
\hline \multirow{3}{*}{$\frac{0}{\pi}$} & \multicolumn{4}{|c|}{$\begin{array}{c}\text { Elementos } \\
\text { Tangibles }\end{array}$} & \multicolumn{5}{|c|}{ Confiabilidad } & \multicolumn{4}{|c|}{$\begin{array}{c}\text { Capacidad de } \\
\text { Respuesta }\end{array}$} & \multicolumn{4}{|c|}{ Seguridad } & \multicolumn{5}{|c|}{ Empatía } \\
\hline & $\begin{array}{l}\text { o } \\
\frac{0}{3} \\
\overline{\tilde{J}}\end{array}$ & 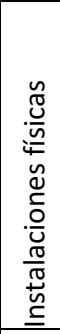 & 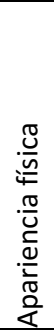 & 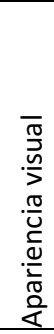 & 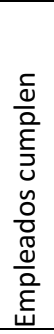 & 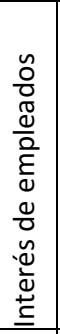 & 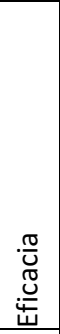 & 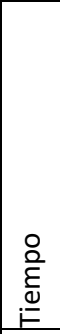 & 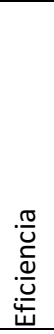 & 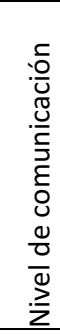 & $\begin{array}{l}\frac{0}{\pi} \\
\frac{\pi}{0} \\
\frac{0}{0} \\
\frac{0}{2}\end{array}$ & 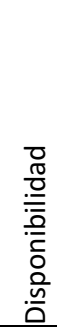 & 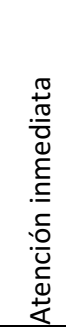 & 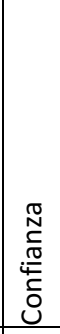 & 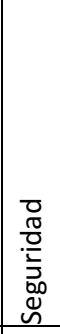 & $\begin{array}{l}\frac{0}{\pi} \\
\frac{\pi}{0} \\
\frac{0}{\overline{0}} \\
\frac{0}{0} \\
\frac{8}{\alpha}\end{array}$ & 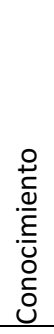 & 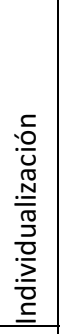 & $\begin{array}{l}\text { 은 } \\
\frac{0}{0} \\
\text { 온 }\end{array}$ & 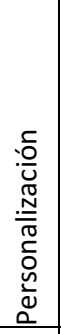 & 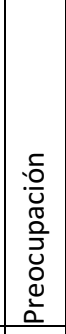 & 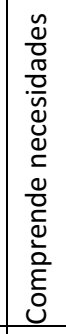 \\
\hline & 1.1 & 1.2 & 1.3 & 1.4 & 2.1 & 2.2 & 2.3 & 2.4 & 2.5 & 3.1 & 3.2 & 3.3 & 3.4 & 4.1 & 4.2 & 4.3 & 4.4 & 5.1 & 5.2 & 5.3 & 5.4 & 5.5 \\
\hline 1 & 33 & 32 & 27 & 39 & 22 & 20 & 25 & 24 & 16 & 29 & 39 & 21 & 17 & 29 & 35 & 19 & 18 & 21 & 32 & 17 & 17 & 17 \\
\hline 2 & 13 & 15 & 23 & 7 & 23 & 26 & 18 & 21 & 32 & 20 & 9 & 23 & 25 & 20 & 14 & 31 & 27 & 19 & 16 & 23 & 29 & 28 \\
\hline & 3 & 2 & 0 & 3 & 4 & 4 & 7 & 5 & 2 & 1 & 2 & 6 & 7 & 1 & 1 & 0 & 5 & 10 & 1 & 10 & 4 & 5 \\
\hline & 1 & 1 & 0 & 1 & 1 & 0 & 0 & 0 & 0 & 0 & 0 & 0 & 1 & 0 & 0 & 0 & 0 & 0 & 0 & 0 & 0 & 0 \\
\hline & 0 & 0 & 0 & 0 & 0 & 0 & 0 & 0 & 0 & 0 & 0 & 0 & 0 & 0 & 0 & 0 & 0 & 0 & 1 & 0 & 0 & 0 \\
\hline & 5 & 50 & 50 & 5 & 50 & 50 & 50 & 50 & 50 & 50 & 50 & 50 & 50 & 50 & 50 & 50 & 50 & 50 & 50 & 50 & 50 & 50 \\
\hline
\end{tabular}

\section{Percepción de los consumidores en la calidad del servicio}

\begin{tabular}{|c|c|c|c|c|c|c|c|c|c|c|c|c|c|c|c|c|c|c|c|c|c|c|}
\hline \multirow{3}{*}{$\frac{\frac{0}{0}}{>}$} & \multicolumn{4}{|c|}{$\begin{array}{l}\text { Elementos } \\
\text { Tangibles }\end{array}$} & \multicolumn{5}{|c|}{ Confiabilidad } & \multicolumn{4}{|c|}{$\begin{array}{c}\text { Capacidad de } \\
\text { Respuesta }\end{array}$} & \multicolumn{4}{|c|}{ Seguridad } & \multicolumn{5}{|c|}{ Empatía } \\
\hline & 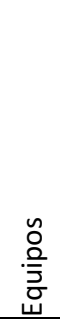 & 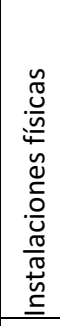 & 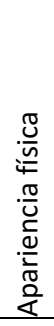 & $\begin{array}{l}\bar{\pi} \\
\frac{\pi}{3} \\
\frac{n}{2} \\
\frac{\pi}{U} \\
\frac{\pi}{0} \\
\frac{0}{2} \\
\frac{\pi}{2} \\
\frac{0}{4}\end{array}$ & 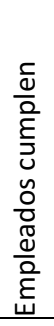 & 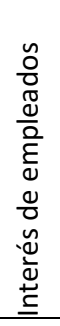 & 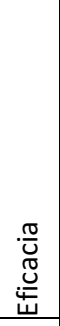 & 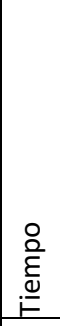 & 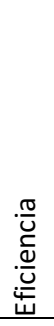 & 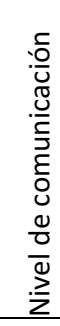 & $\begin{array}{l}\frac{0}{\pi} \\
\frac{\pi}{0} \\
\frac{0}{0} \\
\end{array}$ & 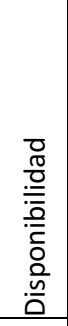 & 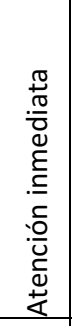 & 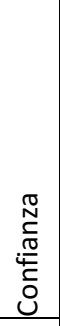 & 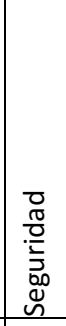 & 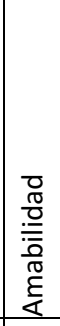 & 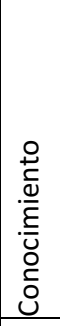 & 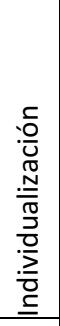 & 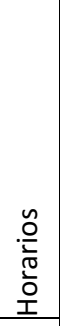 & 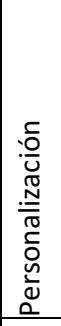 & 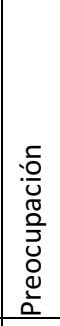 & 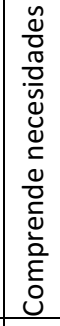 \\
\hline & 1.1 & 1.2 & 1.3 & 1.4 & 2.1 & 2.2 & 2.3 & 2.4 & 2.5 & 3.1 & 3.2 & 3.3 & 3.4 & 4.1 & 4.2 & 4.3 & 4.4 & 5.1 & 5.2 & 5.3 & 5.4 & 5.5 \\
\hline 1 & - & - & 16 & - & 2 & - & 1 & 1 & 0 & 10 & 1 & 1 & 1 & 8 & 8 & 13 & 8 & 4 & 7 & 2 & - & - \\
\hline 2 & 3 & 4 & 23 & - & 15 & 24 & 21 & 18 & 21 & 30 & 16 & 22 & 13 & 30 & 16 & 33 & 13 & 16 & 9 & 16 & 17 & 13 \\
\hline 3 & 31 & 25 & 9 & 13 & 26 & 22 & 26 & 26 & 23 & 9 & 27 & 26 & 24 & 9 & 25 & 3 & 25 & 25 & 16 & 25 & 32 & 34 \\
\hline 4 & 16 & 20 & 2 & 19 & 7 & 3 & 2 & 4 & 1 & 1 & 6 & 1 & 12 & 3 & 1 & 1 & 4 & 2 & 6 & 1 & 1 & 3 \\
\hline 5 & 0 & 1 & 0 & 18 & 0 & 1 & 0 & 1 & 0 & 0 & 0 & 0 & 0 & 0 & 0 & 0 & 0 & 3 & 12 & 6 & 0 & 0 \\
\hline & 50 & 50 & 50 & 50 & 50 & 50 & 50 & 50 & 50 & 50 & 50 & 50 & 50 & 50 & 50 & 50 & 50 & 50 & 50 & 50 & 50 & 50 \\
\hline
\end{tabular}


Brecha generada entre la expectativa y la percepción de los consumidores en la calidad del servicio
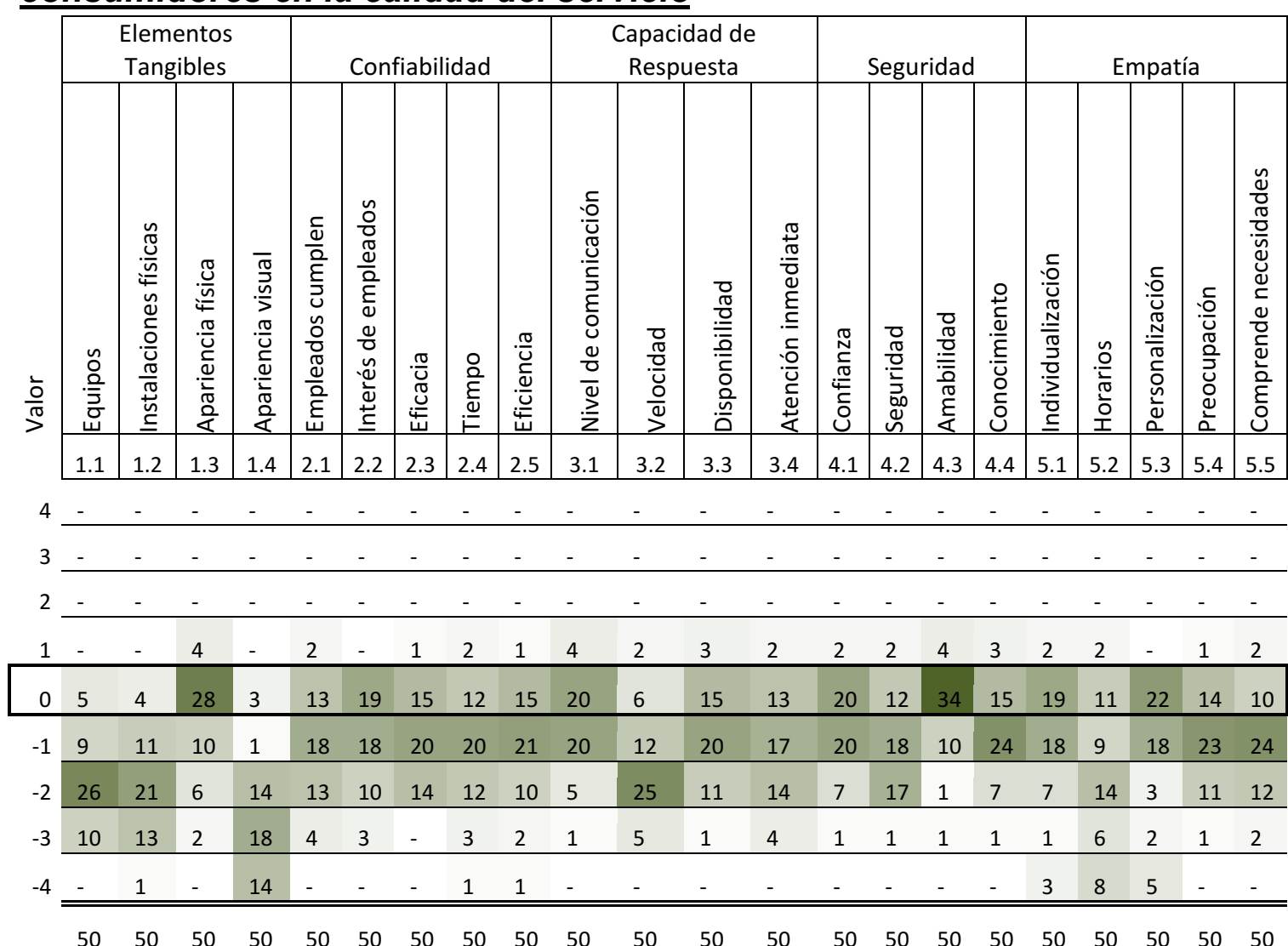

Diferencia entre expectativa y percepción. Arrojando valores negativos consumidores insatisfechos (percepción por debajo de su expectativa). 